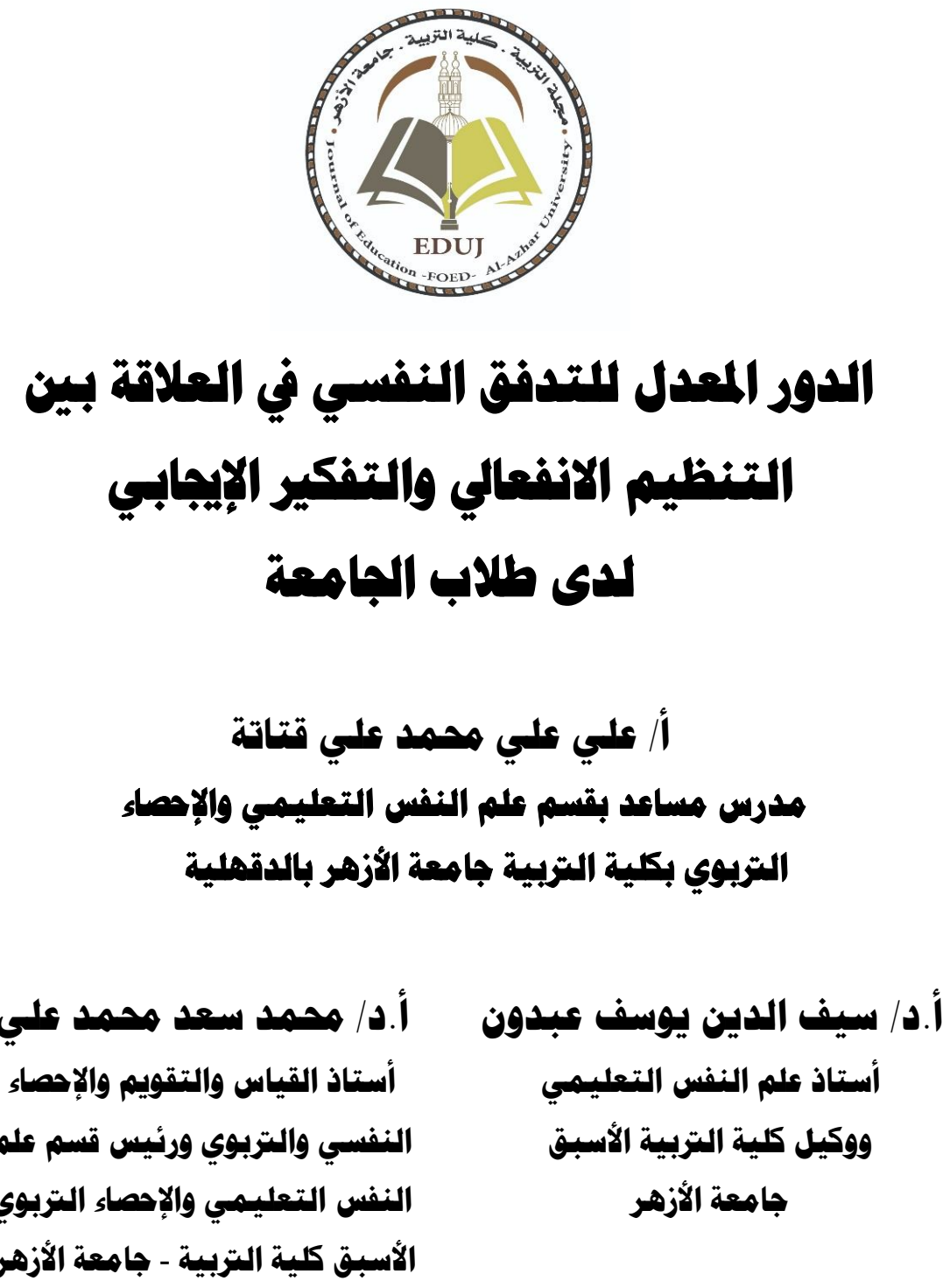


الدور المعدل للتدفق النفسي في العلاقة بين التنظيم الانفعالي والتفكير

\section{الإيجابي لدى طلاب الجامعة}

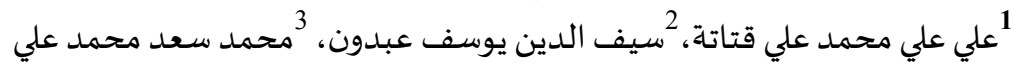
قسم علم النفس التعليمي والاحصاء التربوي - كلية التربية - جامعة الزٔزهر aliali@azhar.edu.eg البريد الإلكتروني: drsaifuddinyousuf@gmail.com ${ }^{2}$

MohamedAli674.el@azhar.edu.eg ${ }^{3}$

يهدف البحث الحالي إلى تفسير العلاقات بين التنظيم الانفعالي كمتغير مستقل والتدفق النفسي

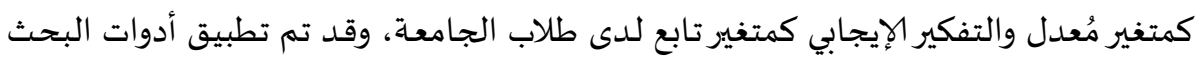

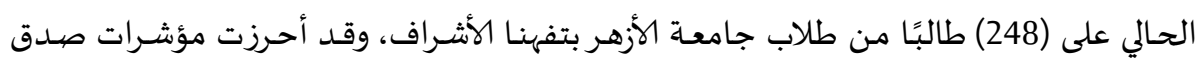

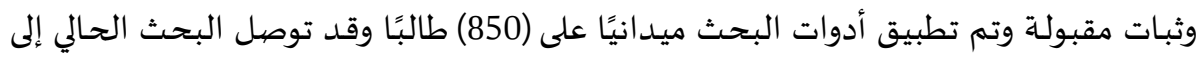

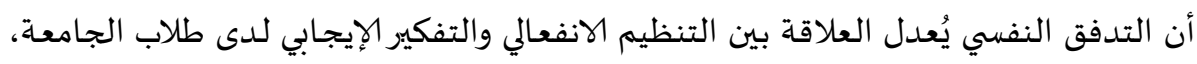
وقد أسفر البحث عن توصيات ومقترحات بحثية للمعنيين من المسؤولين وأولياء الأمور والباحثين. الكلمات الافتتاحية: الدور المُعدل، التدفق النفسي، التنظيم الانفعالي، التفكير الإيجابي. 
The Moderating Role of Psychological Flow in the

\title{
Relationship Between Emotional Regulation and
} Positive Thinking among University Students

\author{
${ }^{1}$ Ali Ali Mohammad Ali Qatata, ${ }^{2}$ Saifuddin Yousuf Abdoun, \\ ${ }^{3}$ Mohamed Saad Mohamed Ali \\ Email: ${ }^{1}$ aliali@azhar.edu.eg \\ 2 drsaifuddinyousuf@gmail.com \\ ${ }^{3}$ MohamedAli674.el@azhar.edu.eg \\ ABSTARCT
}

The present research aimed at explaining the relationships between emotional regulation as an independent variable, psychological flow as a moderating variable, and positive thinking as dependent variable among university students. The current research instruments have been administered to (248) students, and they obtained acceptable indicators of validity and reliability. The field research consisted of (850) students. Findings revealed that psychological flow moderated the relationship between emotional regulation and positive thinking among university students. The study provided recommendations and research suggestions for responsible stakeholders, parents and researchers.

Keywords: Moderating Analysis Psychological Flow, Emotional Regulation, Positive thinking. 


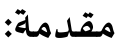

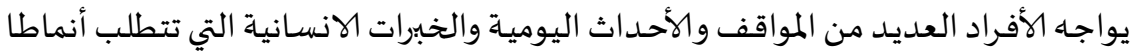

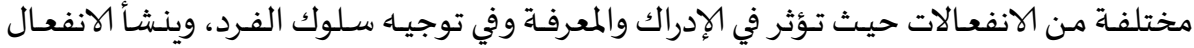

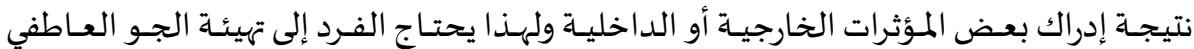

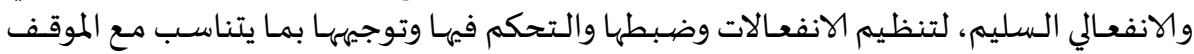
المثير والتعبير عنها بصورة طبيعية.

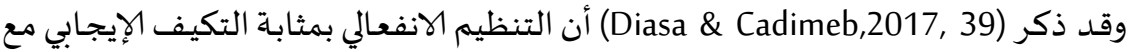

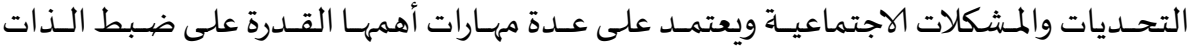

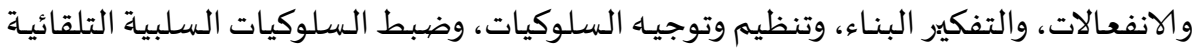

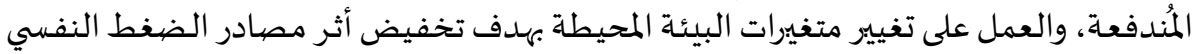

ويرى (Babkirk, Rios \& Dennis,2015,836) أن التنظيم الانفعالي يحتل أهميـة كبيرة في

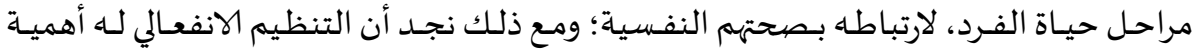

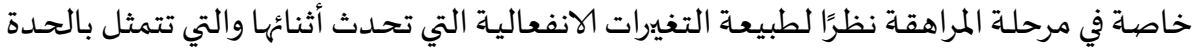

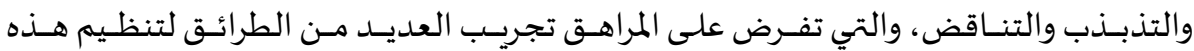

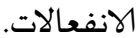

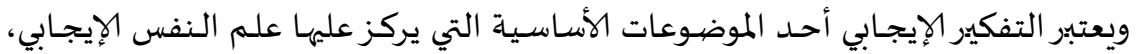

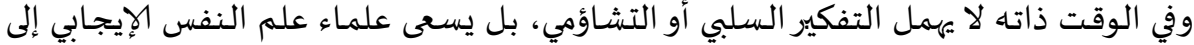

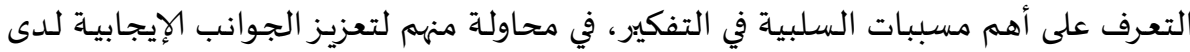
الفرد، والتي تدفع به إلى التخلص من التفكير السلبي (Conoley \& Conoley, 2009, 67).

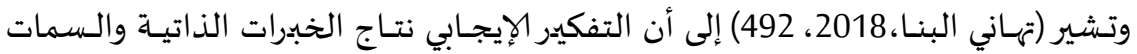

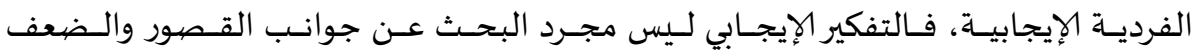

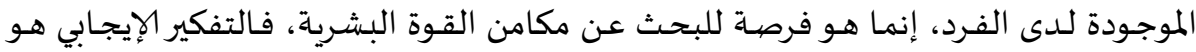

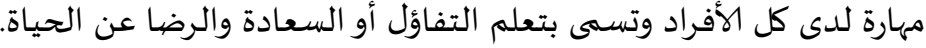

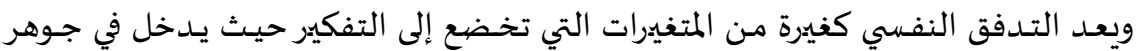

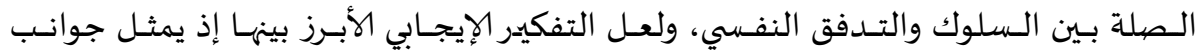

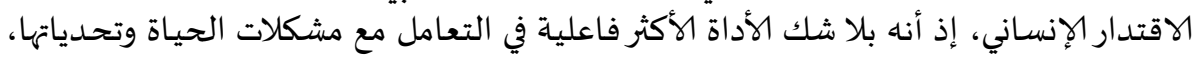

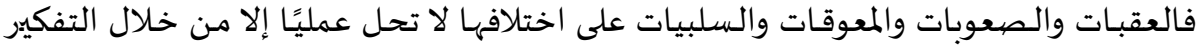

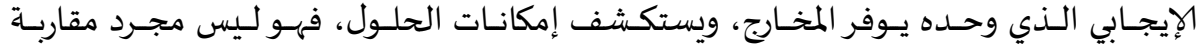

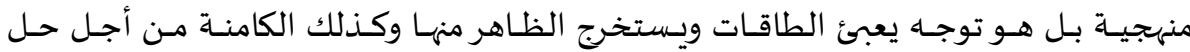
المشكلات ( أنس شطب، عبد العزيز الموسوي، الماتئ 2016، 54).

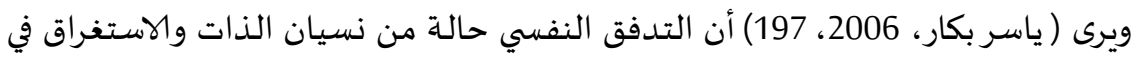

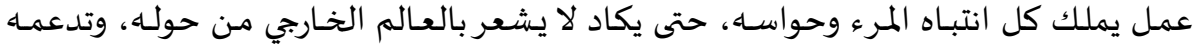

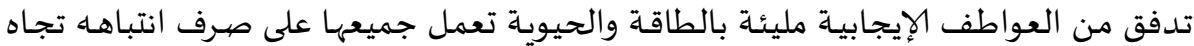

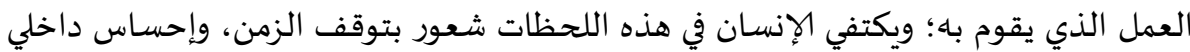




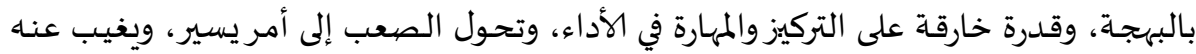

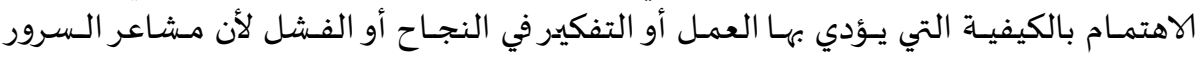

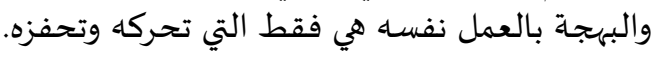

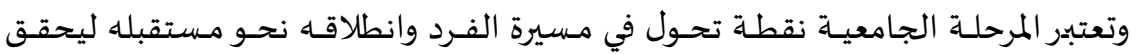

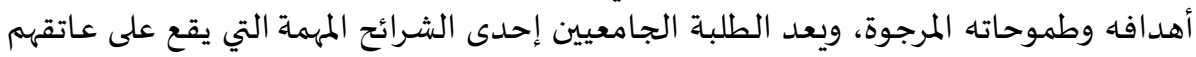

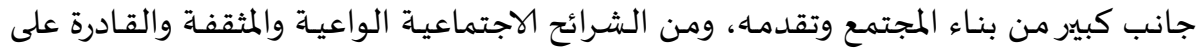

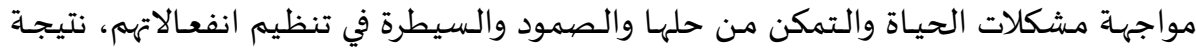

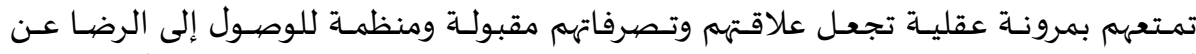

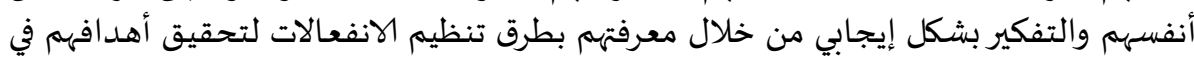

الحياة (محدب رزيقة، 2014، 101).

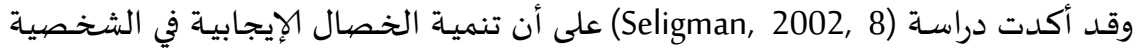

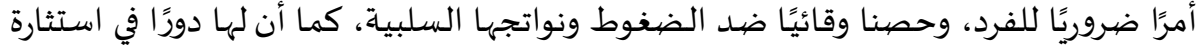

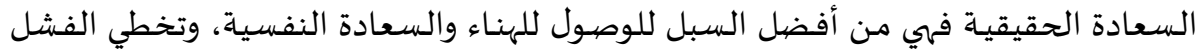
وتحمل الصعاب، وتحرر الفرد من قسوة المبل الماضي.

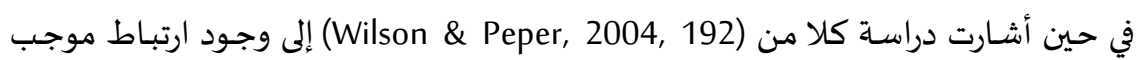

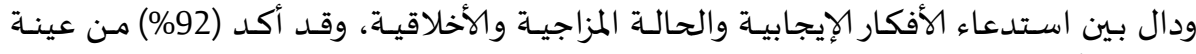

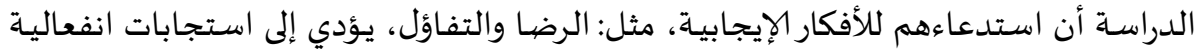

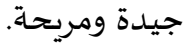

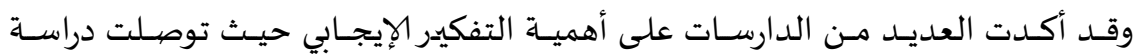
(Scheier, Micheal \& Charles., 2005)

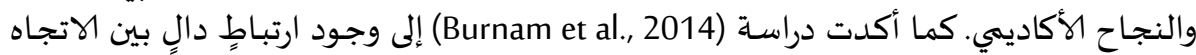

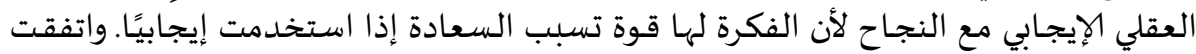

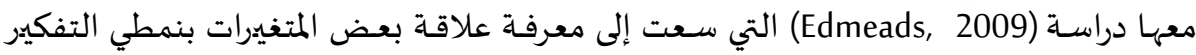

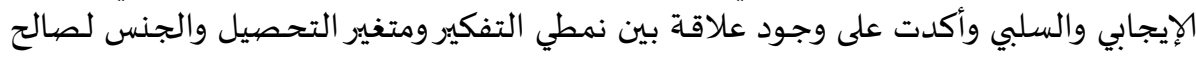
الإناث.

وكشفت دراسة (يوسف اسليم، 2017، 81) عن وجود علاقة طردية بين التفكير الإيجابي

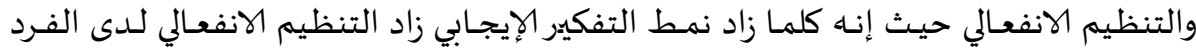

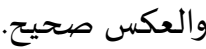

ويدلل على ذلك أيضًا دراسة (Salovey \&Mayer, 2009) والتي توصلت نوائت نتائجها إلى أهمية

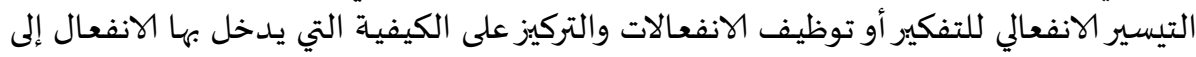

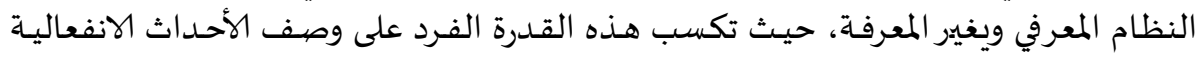

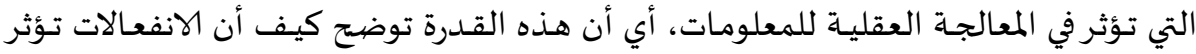

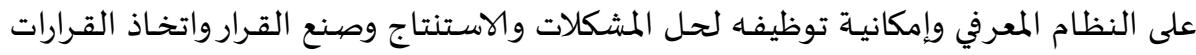




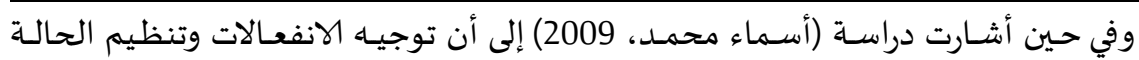

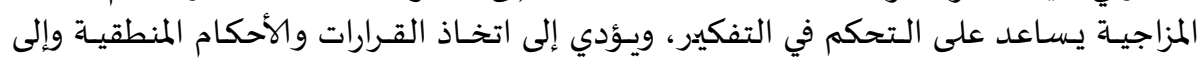

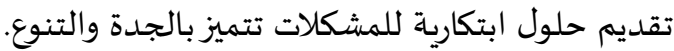

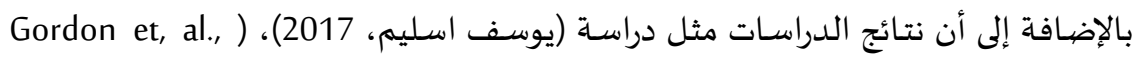

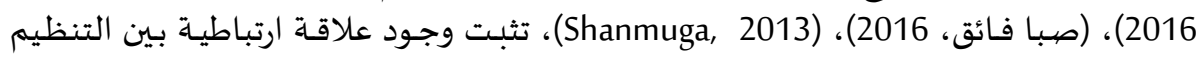

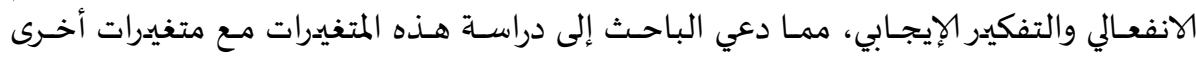
كالتدفق النفسي.

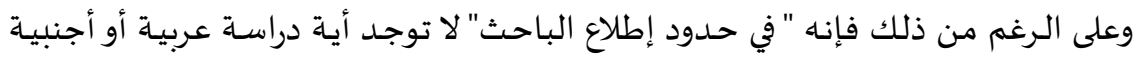

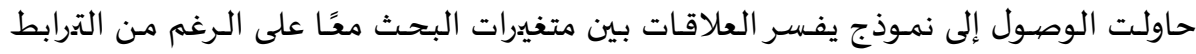

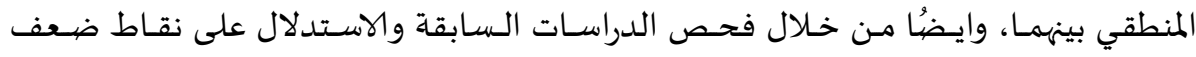

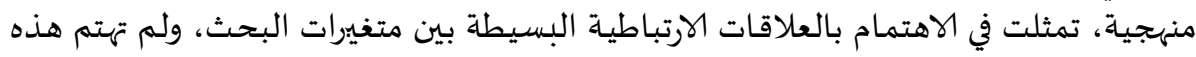

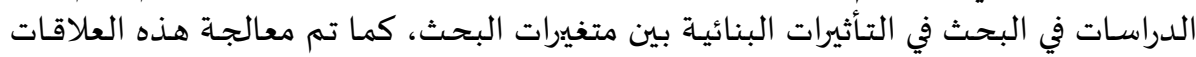

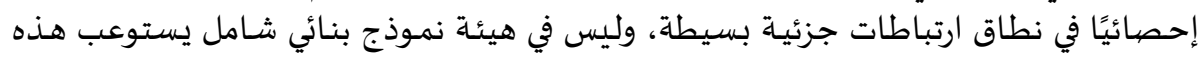

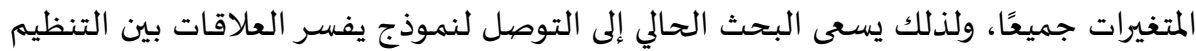

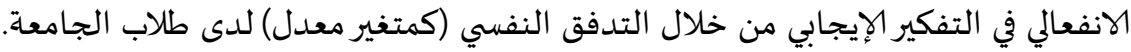

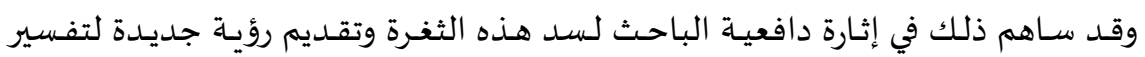

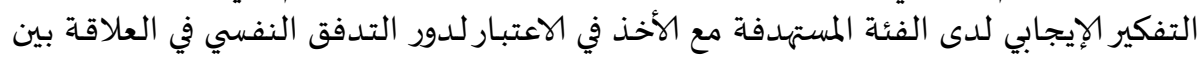
التنظيم الانفعالي والتفكير الإيجابي.

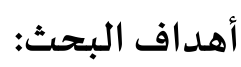

يهدف البحث الحالي إلى التعرف على:

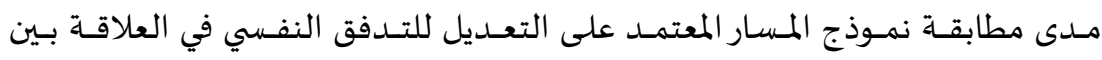
التنظيم الانفعالي والتفكير الإيجابي لبيانات عينة البحث من طلابل المعاب الجامعة.

الدور المُعـل للتدفق النفسي في العلاقـة بين التنظيم الانفعالي والتفكير الإيجابي لدى لـي

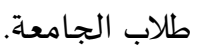

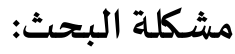

\section{تتحدد مشكلة البحث في التساؤلات الأتياة:}

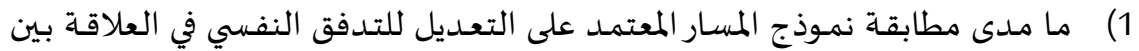

التنظيم الانفعالي والتفكير الإيجابي لبيانات عينة البحث من طلاب المعلئ الجامعة؟

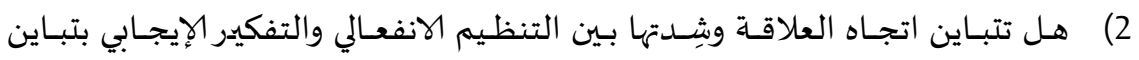

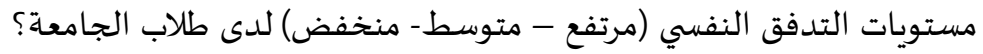


يمكن أن تتضح أهمية البحث الحالي من خلال:

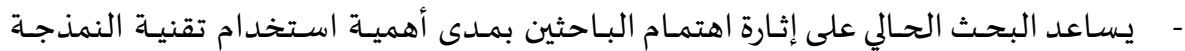

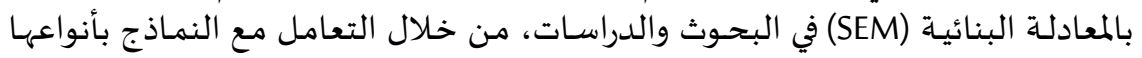
المختلفة من حيث التصميم وآليات الاختبار.

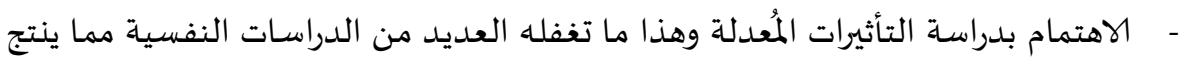

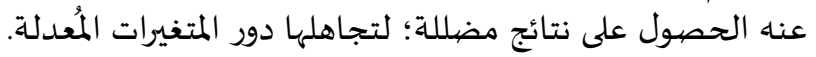

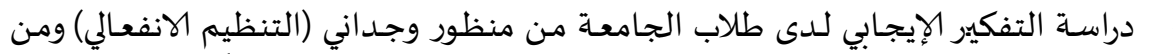

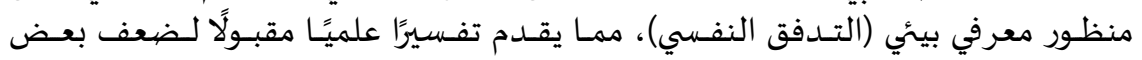
الطلاب في التفكير بطريقة إيجابية.

- الانتقال من التنظيز بالفرضيات إلى التنظير بالنماذج، والابتعاد عن النمطية المعتمدة في

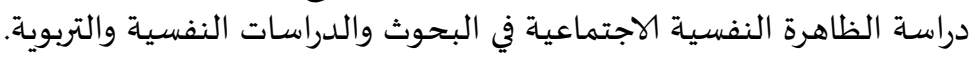

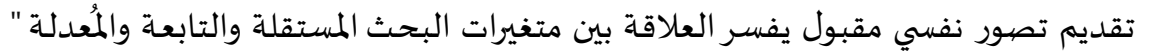

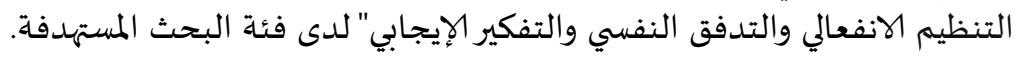

- إعـداد بعض المقاييس الهامـة مثل مقيـاس التـدفق النفسي والتنظيم الانفعالي والتفكير الإيجابي بحيث يمكن الاستفادة منها في الدراسات والمأبحاث المات المستقبلية. بنـاء البرامج والهـتراتيجيات في ضهوء النمـوذج (المُعـدل) لتحسين وتطوير قـدرات الطالب

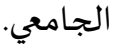
تقديم توصيات مهمة تفيد في التعامل الأمثل - في ضوء نتائج المسارات المؤثرة في تفكيرهم

$$
\text { التعريف الإجرائي لمصطلحابي مع طلاب الجامعة. }
$$

الدور المُعدل: Moderating Role

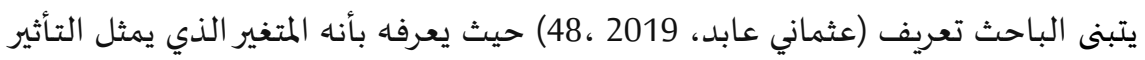

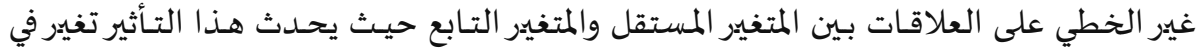

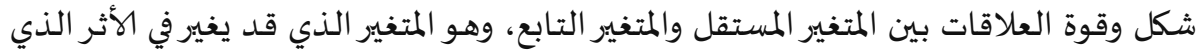

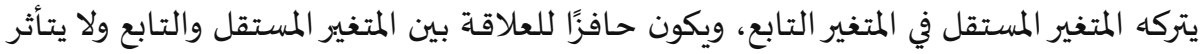

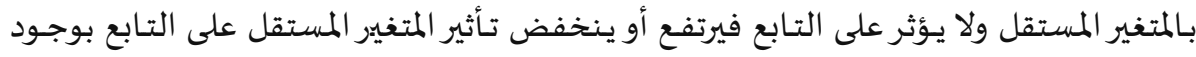


التدفق النفسي: Psychological Flow

يعرفه الباحث بأنه حالة وجدانية تتضمن اندماج الفرد مع ما يقوم بـه من عمل، والتركيز

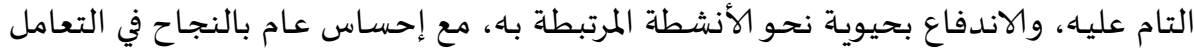

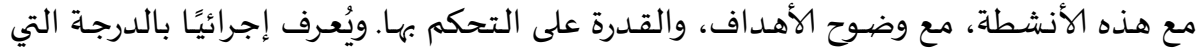

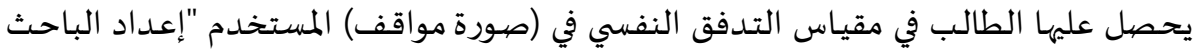
الحالي".

التنظيم الانفعالي: Emotional Regulation

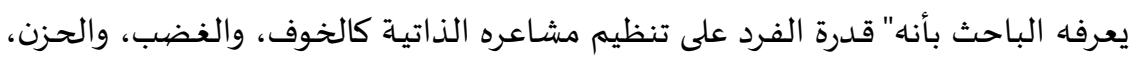

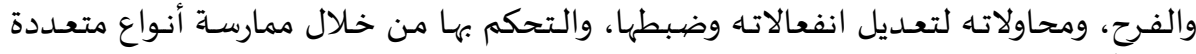

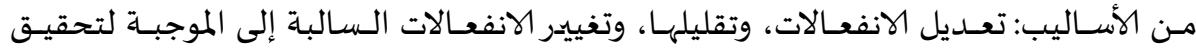

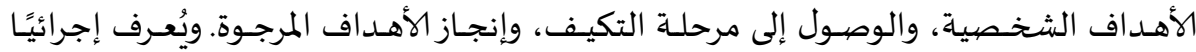

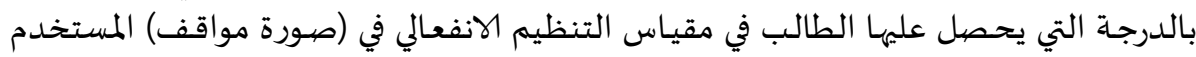
"إعداد الباحث الحالي".

positive thinking التفكير الإيججابي:

يعرفه الباحث بأنه:" عملية وجدانية ومعرفية يستطيع الفرد من خلالها التحكم في أفكاره

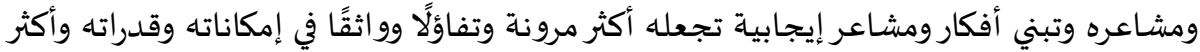

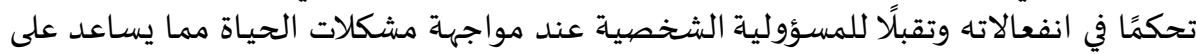

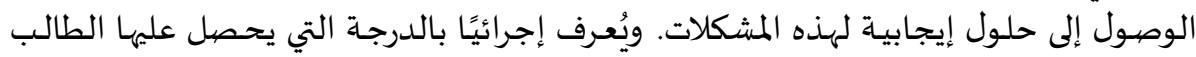

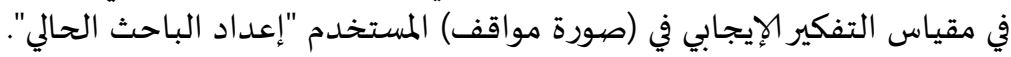
إإطار النظري:

Emotion Regulation أولاً: التنظيم الإنفعارئي النظري تعددت وجهات النظر المختلفة للباحثين السابقين الذين تناولوا مفهوم التنظيم الانفعالي، حيث صينف البـاحثون تلك الآراء تبعًا للخلفيـات النظريـة التي انطلقت منها، في ضيوء عـدة

محاور هي: (أ) التنظيم الانفعالي كعملية. (ب) التنظيم الانفعالي كقدرة. (ج) التنظيم الانفعالي كمكون من مكونات العمليات المعرفية. وسوف يعرض الباحث التصنيفات السابقة بالتفصيل كما يلي:

(أ) التنظيم الانفعالي كعملية

يعرف (Wolters, 2011, 275) التنظيم الانفعـالي بأنـه عمليـة مراقبـة وتقييم وتغيييرووقوع شدة أو حدة التجارب الانفعالية وردود الأفعال. 


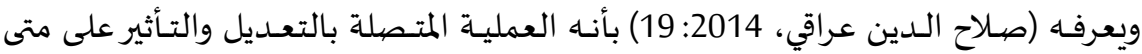

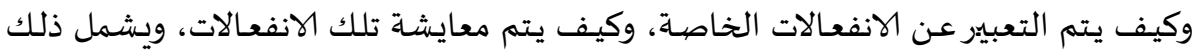

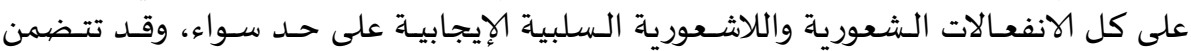
الانفعالات المتولدة والمختزلة وكذلك الحفات الماظ على الانفعالات

ويذكر كل من (Cashwell, Giordano, King, Lankford \& Henson, 2017, 19) أن تنظيم

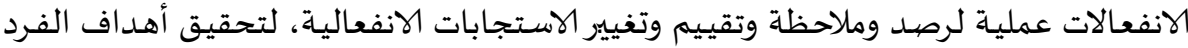

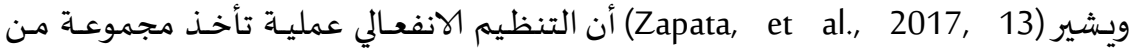

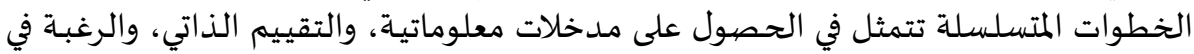

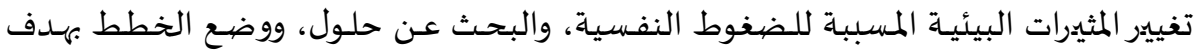
التغيير وتنفيذ هذه الحلول على الواقع ثم العمل على تقويمها.

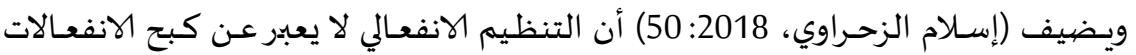

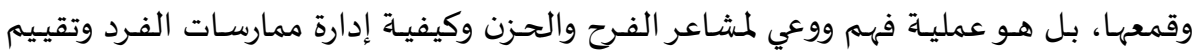

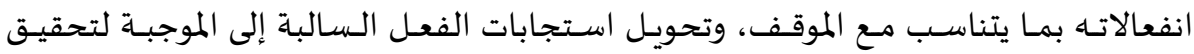

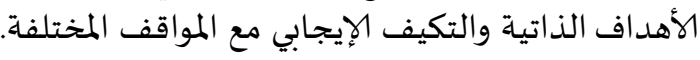
(ب) التنظيم الانفعالي كقدرة يذكر (Babkirk, Rios, \& Dennis, 2015, 832) أن مفهوم تنظيم الانفعالات يعني القدرة

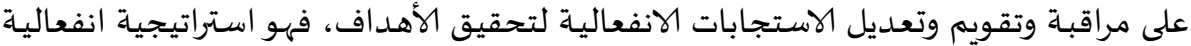

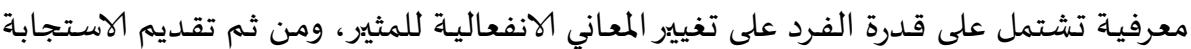
المناسبة في السياق الاجتماعي. وقد أشار (Kuzucu, 2016, 850) أن التنظيم الانفعالي قدرة الفرد على تعديل وتكييف انفعالاته ضمن السياقات الاجتماعية.

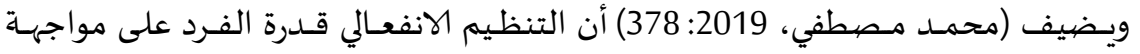
انفعالاته السلبية وتقبلها وإدارتها وتعديل سلوكياته عند مروره بها. ويُعرف (ماجد عيسى، 2019: 15) التنظيم الانفعالي المعرفي بأنها قدرة المتعلم على المراقبة الماتها

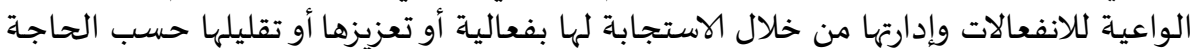

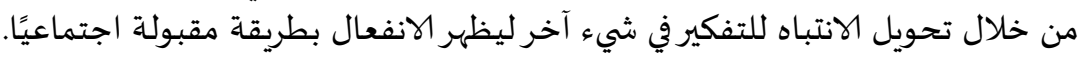

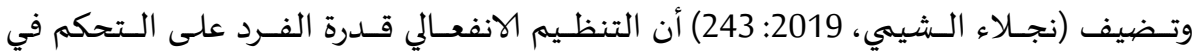

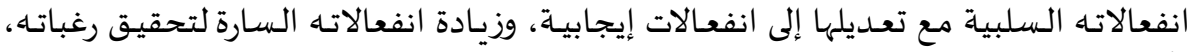


(ج) التنظيم الانفعالي كمكون من مكونات العمليات المعرفية (الوي، والاستراتيجيات،

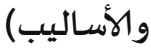

يذكر كل من (Brans, Koval, Verduyn, Lim, Kuppens, 2013, 9) أن التنظيم الانفعالي

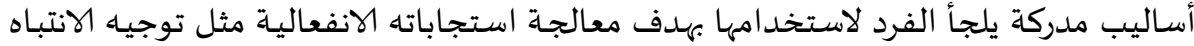

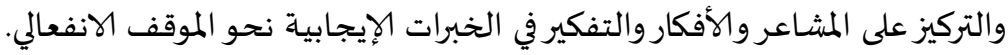

وبينما يعرف كل من (Brenning, soenens, Petegem \& Vansteenkiste, 2015, 561)

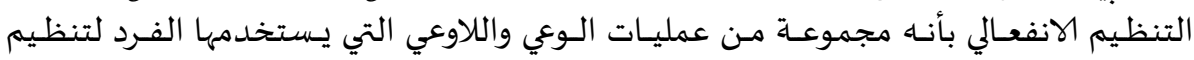

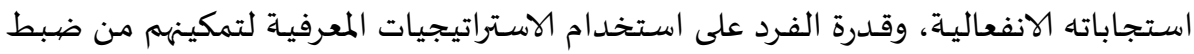
انفعالاتهم نحو المثيرات في البيئة المحيطة.

وقد أشـارت (حنـان محمود، 2016: 73) أن التنظيم الانفعالي هو مجموعـة الاستراتيجيات

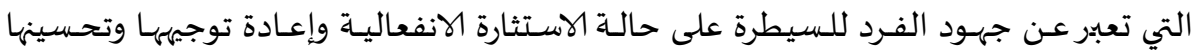

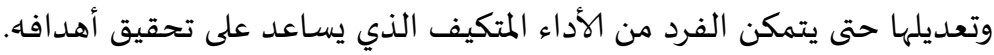

ويضيف كل من (Kuo, Fitzpatrick, Mmetcalfe, Mcmain, 2016, 54) أن تنظيم الانفعال

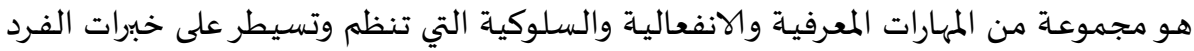
وتعبيراته الناشئة من تفاعله مع بيئته.

وكما وصف (Park \& Yoo, 2016, 327) إلى أن التنظيم الانفعالي نوع من التنظيم الذاتي

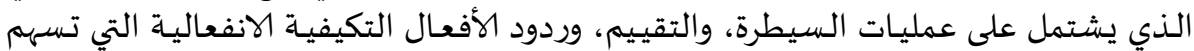
في تحقيق الأهداف الشخصية.

وكما ذهب كل من (Cashwell, Giordano, King, Lankford \& Henson, 2017, 18) إلى أن الن

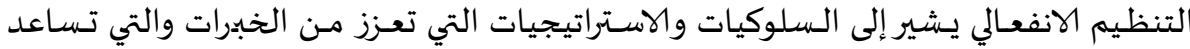

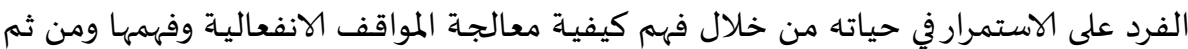
القدرة على التعبير عن الانفعالات.

يتضح من التعريفات السابقة في تناولها لمفهوم التنظيم الانفعالي أنها تتضمن إنتاج

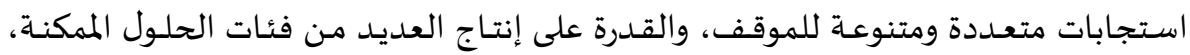

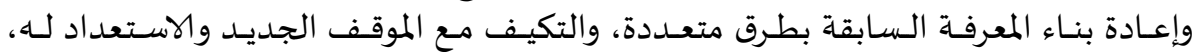

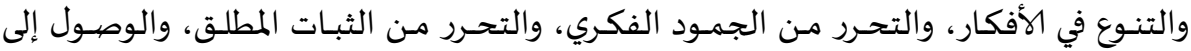

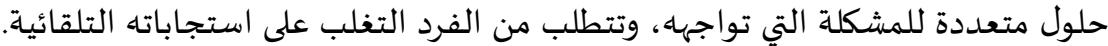

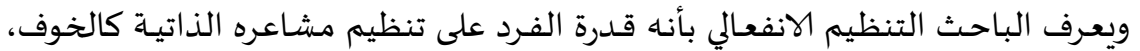

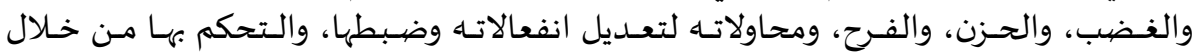

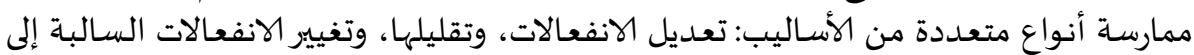
الموجبة لتحقيق الأهداف الشخصية، والوصول إلى مرحلة التكيف، وإنجاز الأهداف المرجوة.

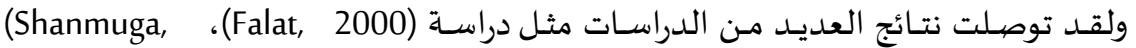
(2013، (Nei\& Rostami, 2014)، (صبا فائق، 2016)، (Gordon et, al., 2016)، (ليث عياش (2016) (2016)

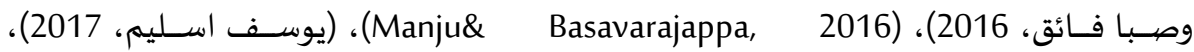


(Nikmanesh, shirazi\& Farazinezhad, 2017)، (إسـلام الزحراوي،2018)، (هالة مصطفي،

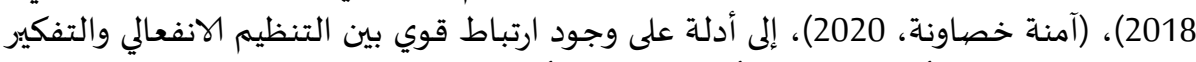

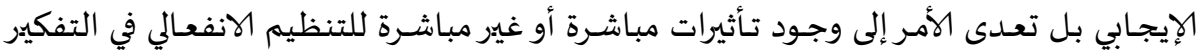
الإيجابي على اختلاف وجهات نظات نظر الباحثين.

Positive Thinking ثانيًا: التفكير الإيجابي إنباب

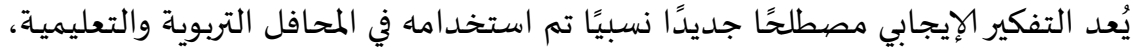

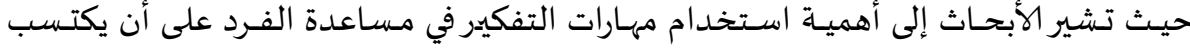

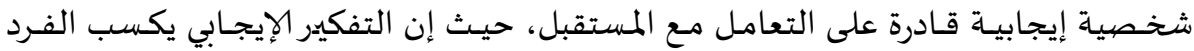

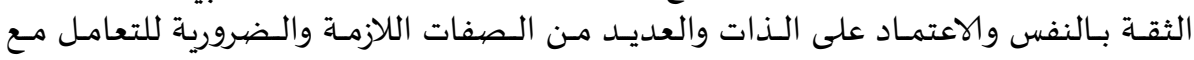

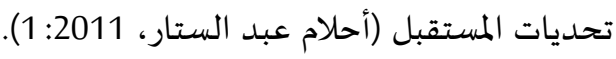

فقد تعددت تعريفات ذلك المفهوم وفقًا لاختلاف آراء الباحثين وتباين وجهات النظر بينهم

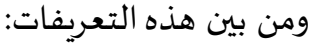

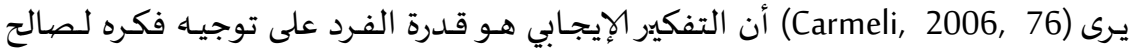

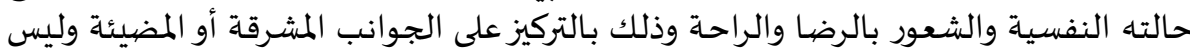

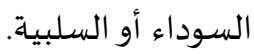

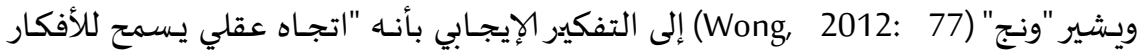

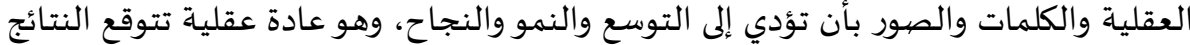

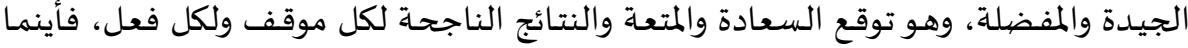

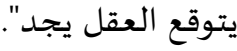
كما يعرف بأنه نمط من أنماط التفكير يرتقي بالفرد ويساعده على استثمار عقله والهاه ومشاعره

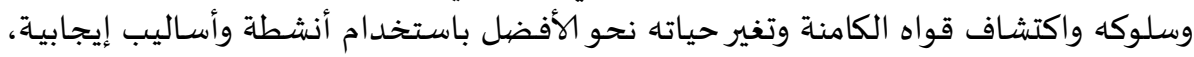

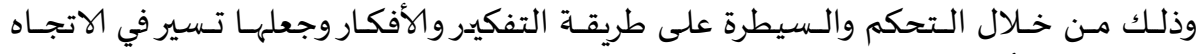

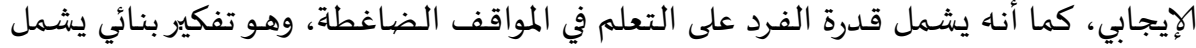

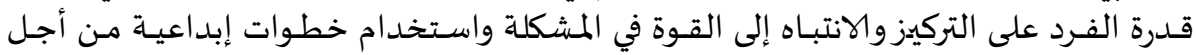
الوصول إلى حلول مرضية (سامية الأنصاري، 2012: 74 ).

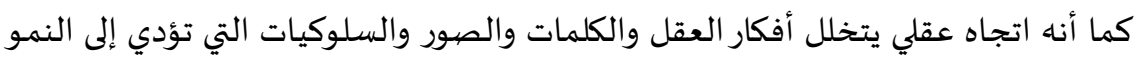

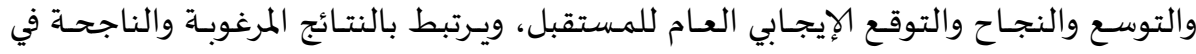
المواقف المتعددة. (Hong \& Lin, 2012:275)

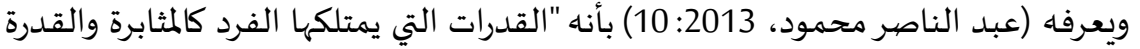

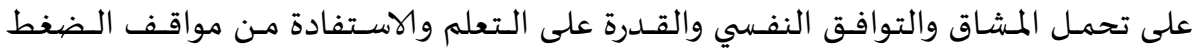

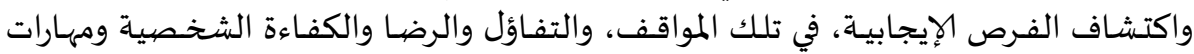
التفاعل الاجتماعي والإحساس بالجمال والمثابرة والتطلع نحو المبال والمستقبل". 


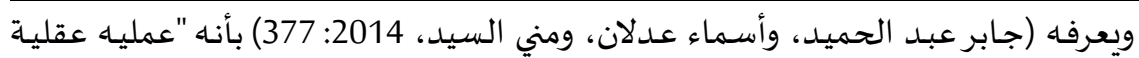

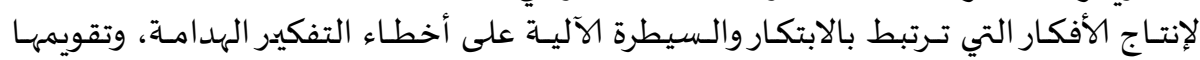

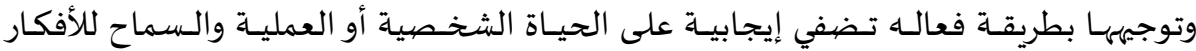

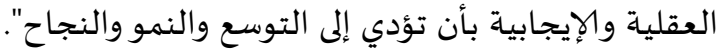

وتعرفـه (سـناء عثمـان، 2015: 7) بأنـه "نمـط مـن أنماط التفكيير يمكن الفـرد مـن القيـادة

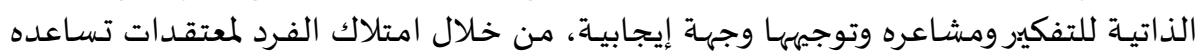

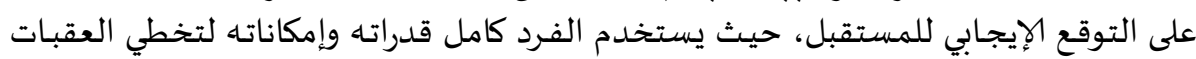

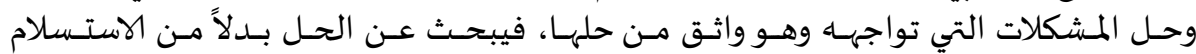
للمشكلات".

كما يـرى (Ghodsbin, et al.2015:342) أن التفكير الإيجـابي هـو امتلاك الفـرد لقناعـات

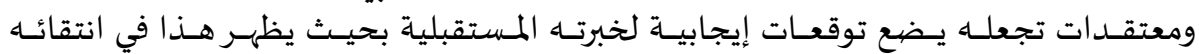
وتفضيله لسلوك محدد.

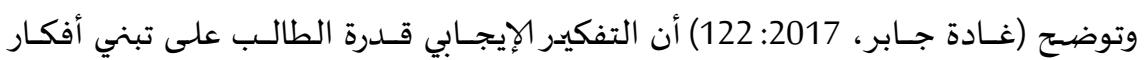

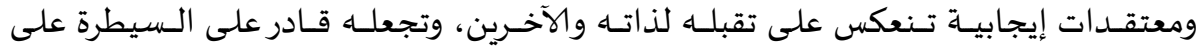

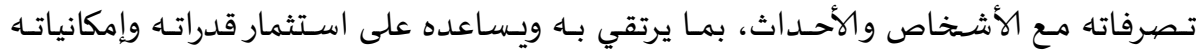

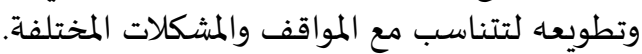

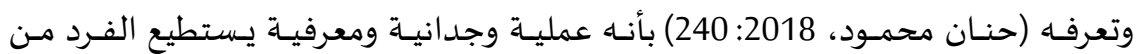

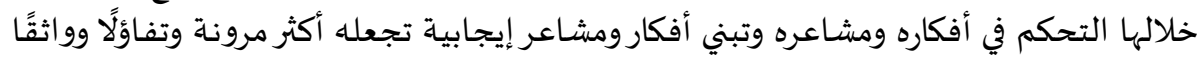

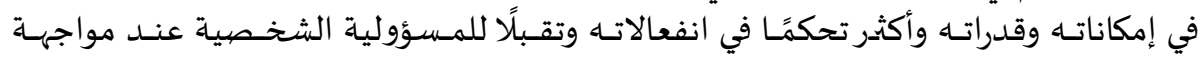
مشكلات الحياة مما يساعد على الوصيول إلى حلول إيجابية لهذه المشكلات.

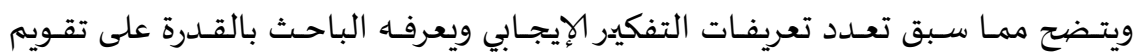

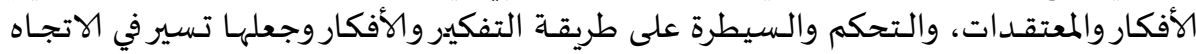

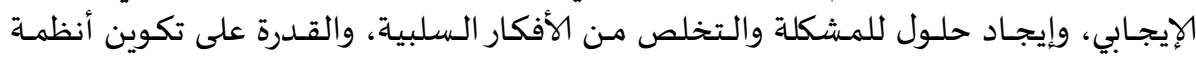

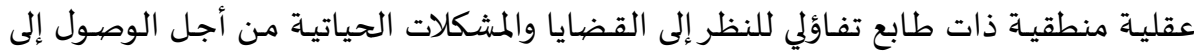

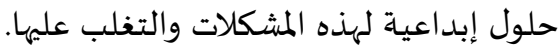

ثالثًا: التدفق النفسي Psychological Flow

وتعددت وجهات النظر المختلفة للباحثين السابقين الذين تناولوا مفهوم التدفق النفسي، النساء

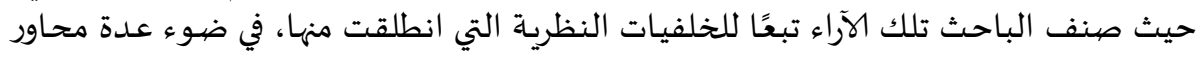

$$
\text { (أ) التدفق النفسي كحالة. }
$$

وسوف يعرض الباحث التصنيفات السابقة بالتفصيل كما يلي: 


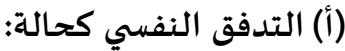

وأشار (Moran, 2012, 87) إلى أن التدفق النفسي حالة شبه تلقائية من الجهـد، ولكنها

مركزة من الوعي.

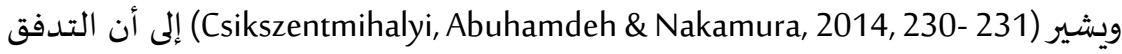

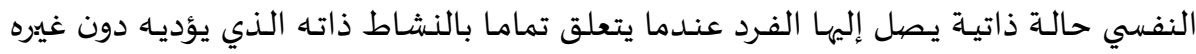

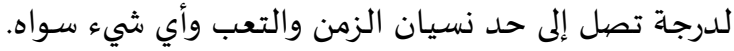

وتعرف (ربيعة الشيخ، 2015: 42- 43) التدفق النفسي باعتباره حالة وجدانية آنية يخبرها

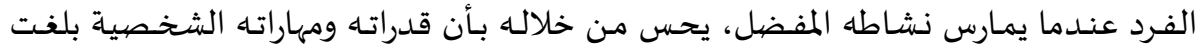

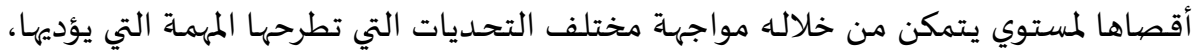

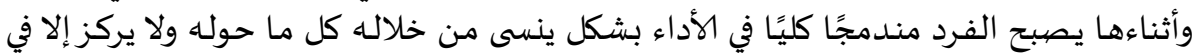

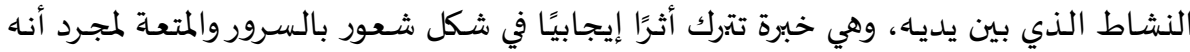
يؤدي هذا النشاط.

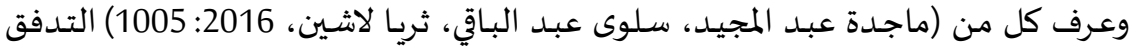

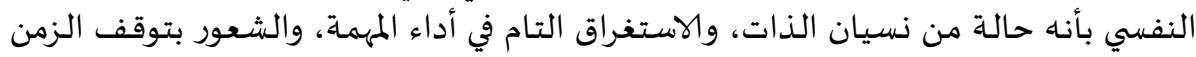

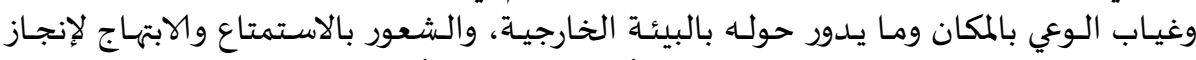

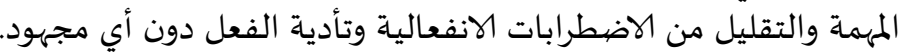

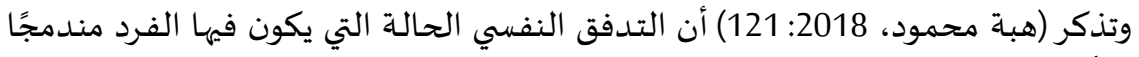

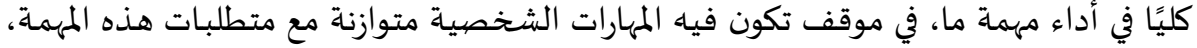

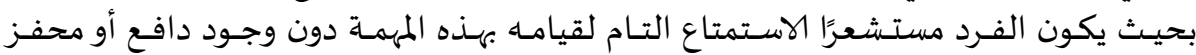

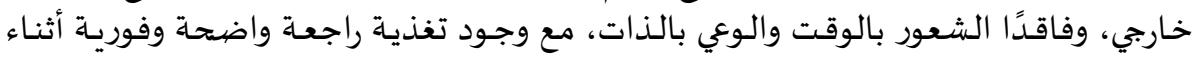

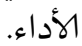

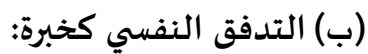

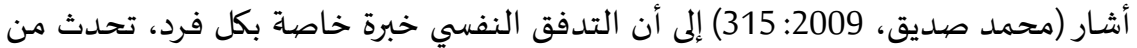

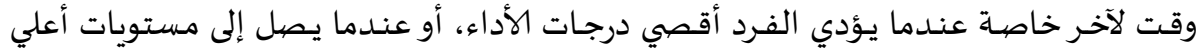

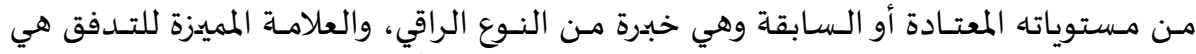

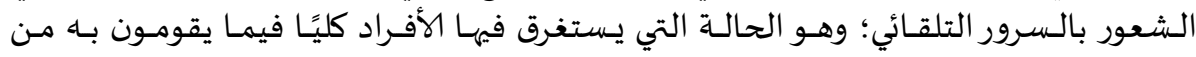

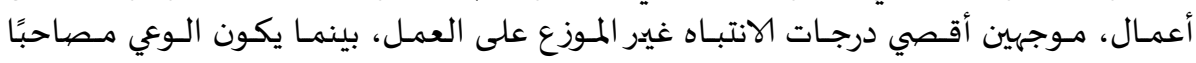

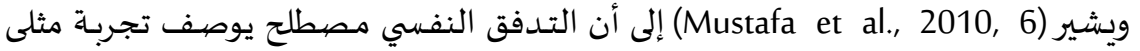
تستحوذ على نشاط ممتع بحيث يصبح القيام باه لذاته دون وجود النداف دافع خارجي.

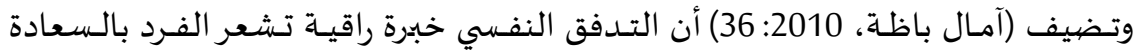

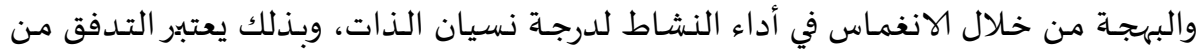




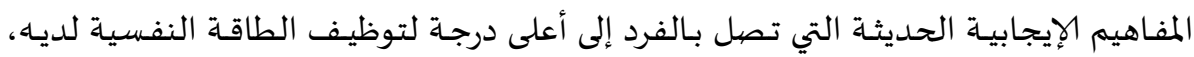

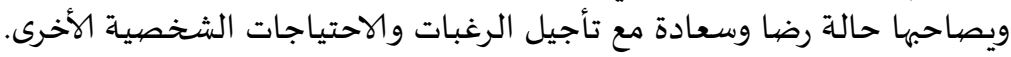

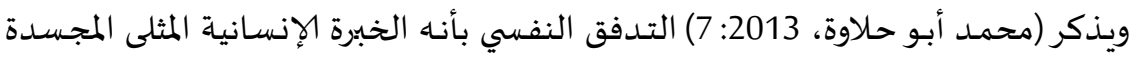

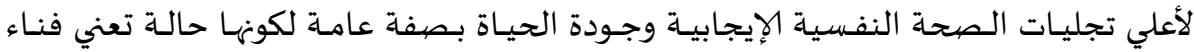

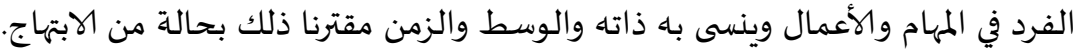

وكما يعرف (Jackson, 2014, 2305-2306 التدفق النفسي بأنه تجربة نفسية إيجابية،

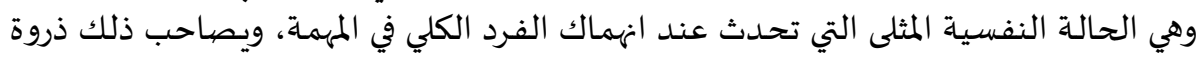
النشاط وتحقيق مستويات متقدمة من الأداء.

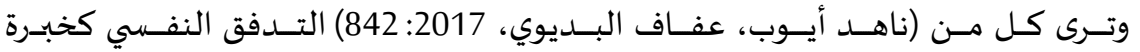

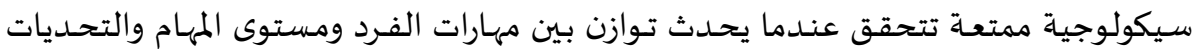

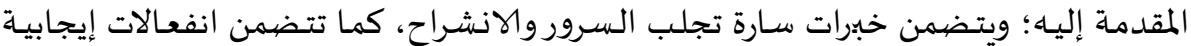

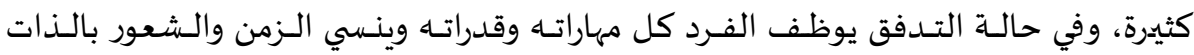

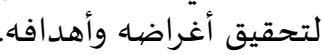

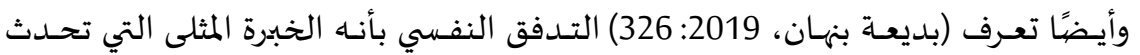

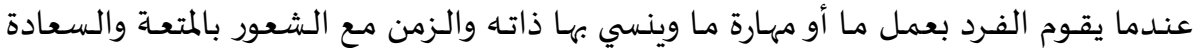

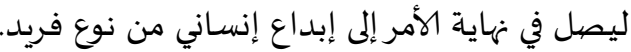

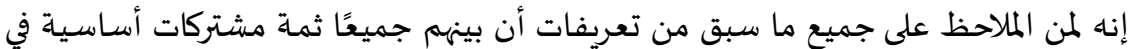

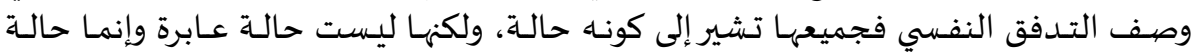

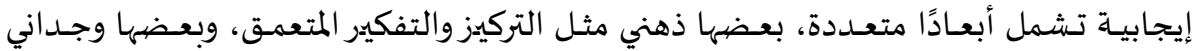

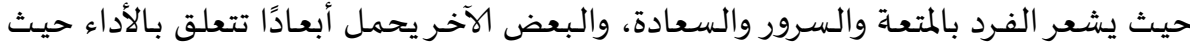

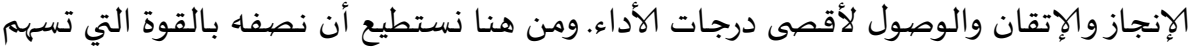

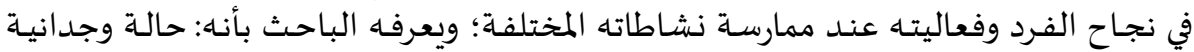

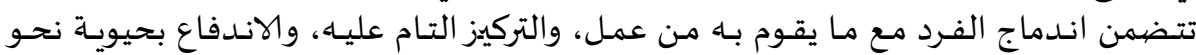

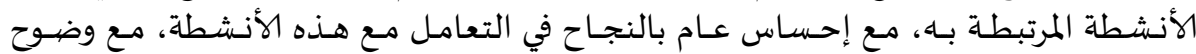
الأهداف، والقدرة على التحكم بها.

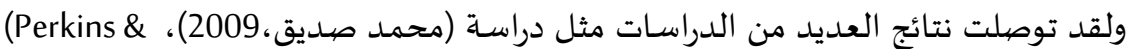

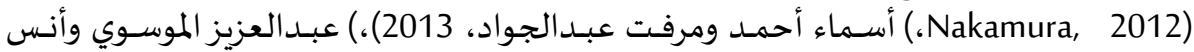

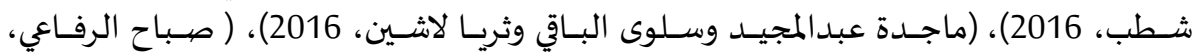

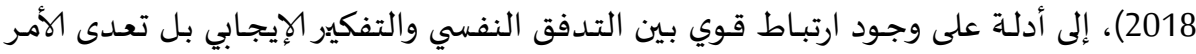

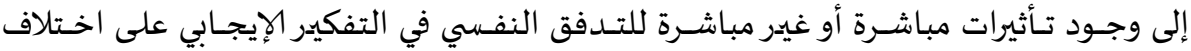

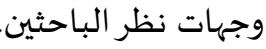

$$
\text { فروض البحث: }
$$

الفرض الأول: لا يتمتع نموذج المسار المعتمد على التعديل للتدفق النفسي في التمالي العلاقة بين

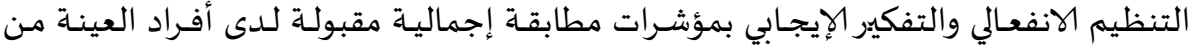

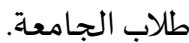


الفـرض الثـاني: لا يتبـاين اتجـاه العلاقـة وشِـــتها بين التنظيم الانفعـالي والتفكير الإيجـابي

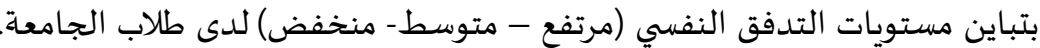

$$
\text { أولًا: منهراء البحث البحث: }
$$

اعتمد البحث الحالي على المنهج الوصفي باعتباره أحد مناهج البحث التربوي المبري النفسي التي

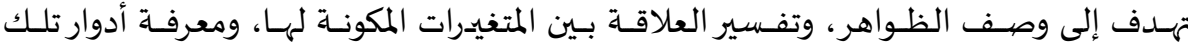

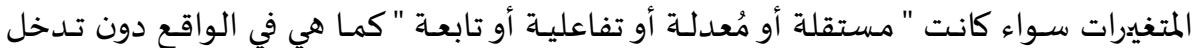

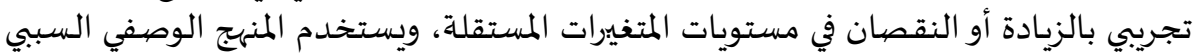

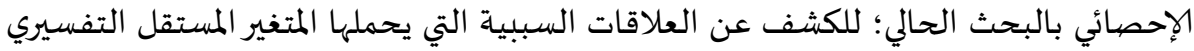

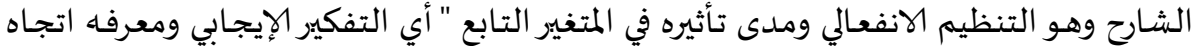

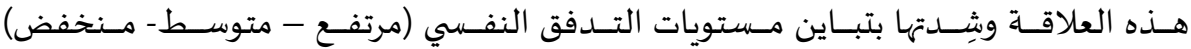

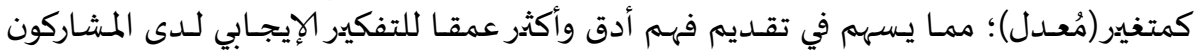

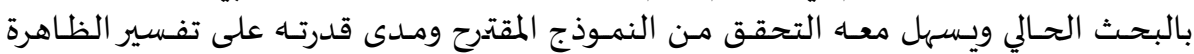
المدروسة استنادًا إلى بيانات المشاركين.

ثانيًا: المشـاركون بالبحث

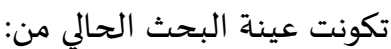

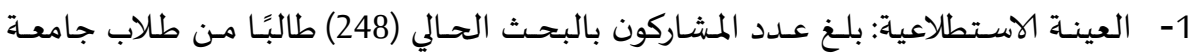

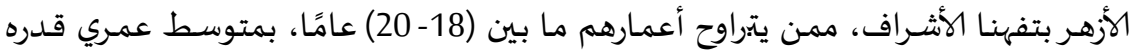

(19.37) عامًا، ووسيط (19) عامًا، وانحراف معياري (0.690).

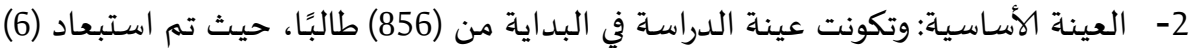

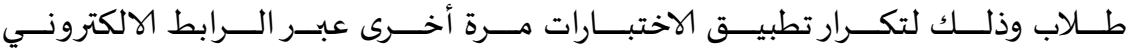

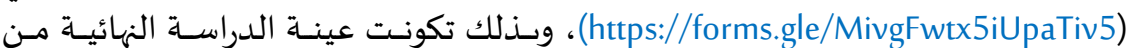

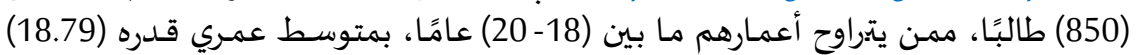

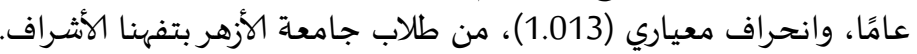

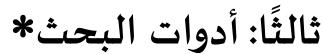

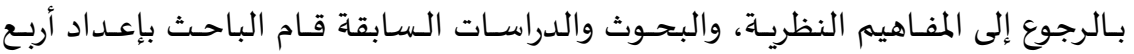

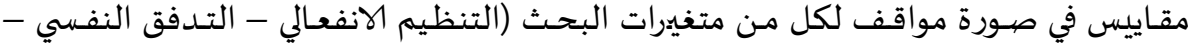

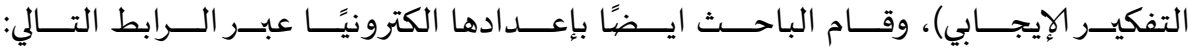

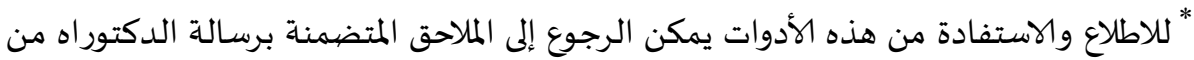

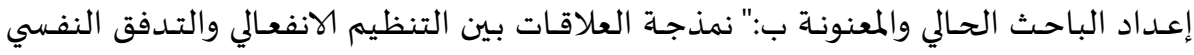
والتوافق الأكاديمي والتفكير الإيجابي لدى طلاب المعند لمدجة العامعات 
(https://forms.gle/MivgFwtx5iUpaTiv5) العاملي الاستكشافي والتوكيدي من الدرجة الثانية قبل استخدامها ميدانيًا: أولًا: مقياس التنظيم الانفعالي (مواقف) (إعداد الباحث): الخصائص السيكومترية للمقياس:

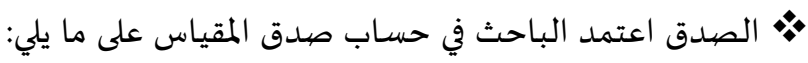

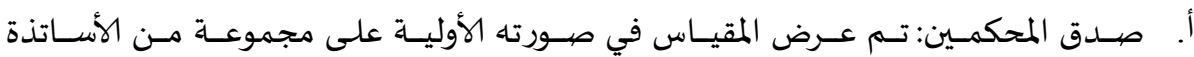

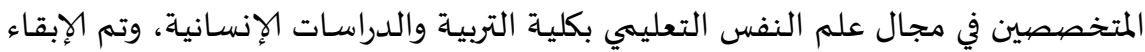

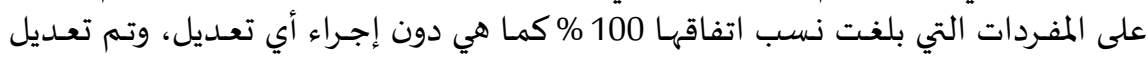
صياغة باقي المفردات بناءً على آراء السادة المحكمين.

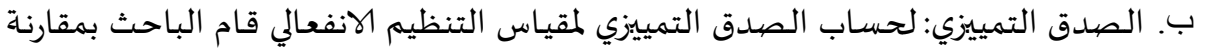

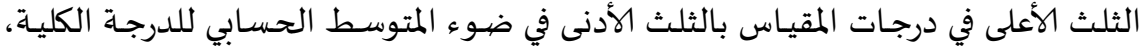

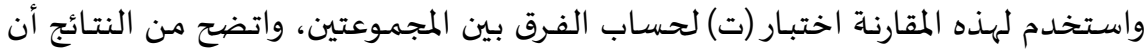

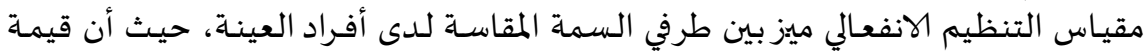
(ت) دالة إحصائيًا عند مستوي 0.01 ولذلك يتصف التئ المقياس بالصدئ المقاد التمييزي.

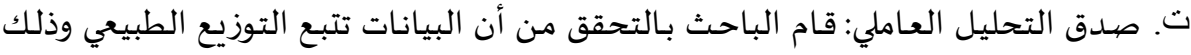

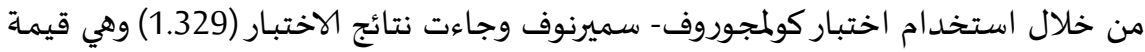

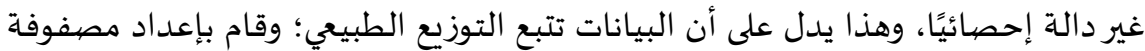

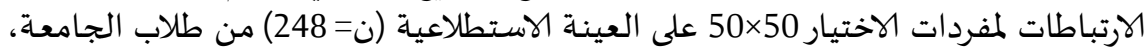

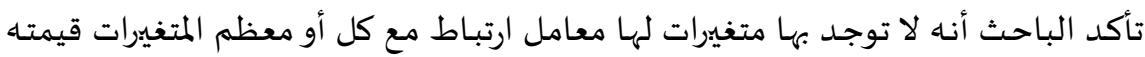

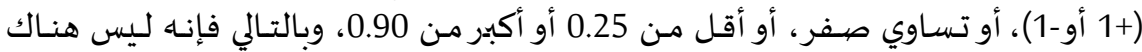

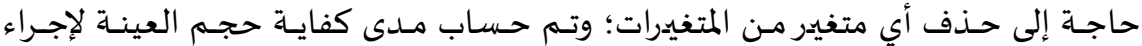

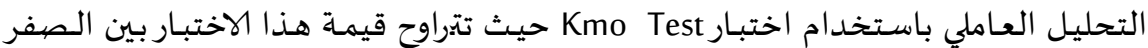

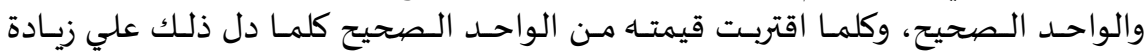

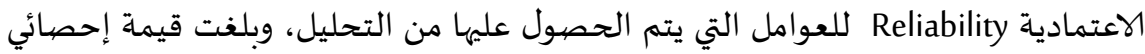

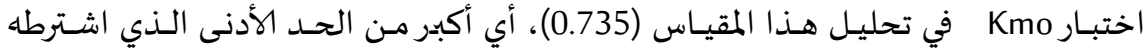

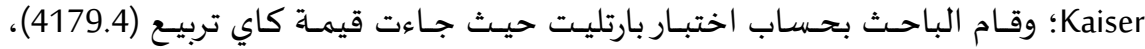

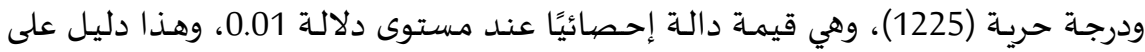

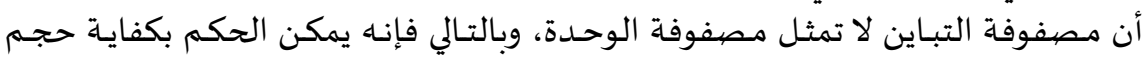

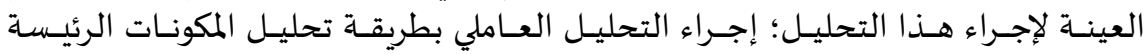

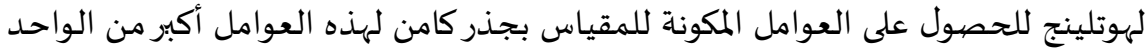

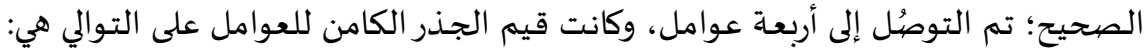

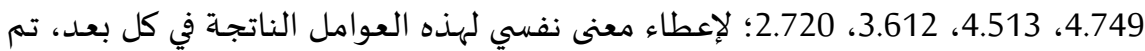

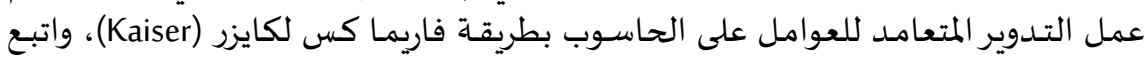

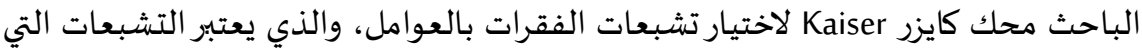
تصل إلى 0.3 أو أكثر تشبعات دالئ. 


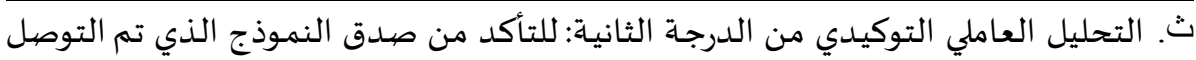

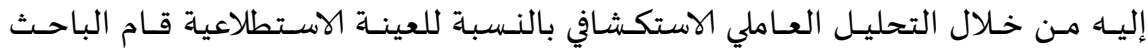

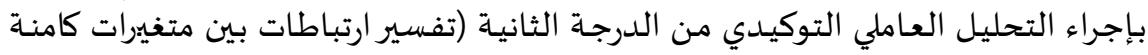

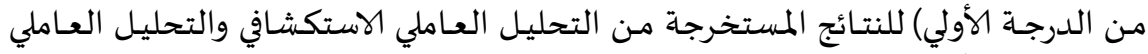

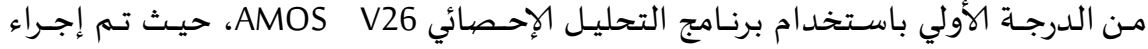

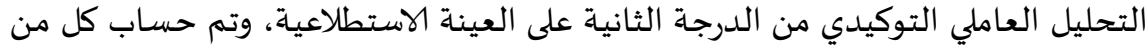

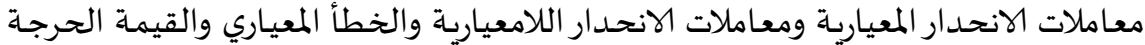

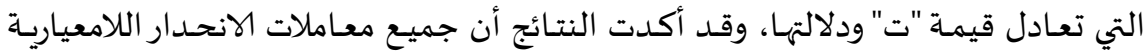

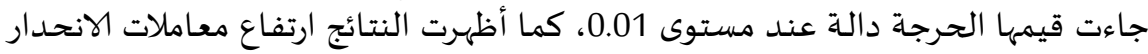

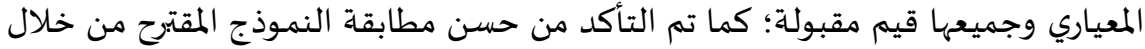
حساب مؤشرات المطابقة والتي أظهرت جميعها حسن مطابعة التاكن النموذج المقترح.

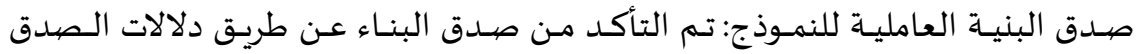

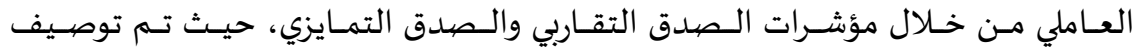

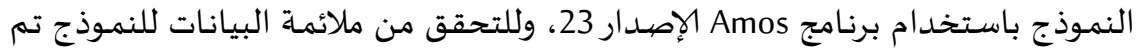

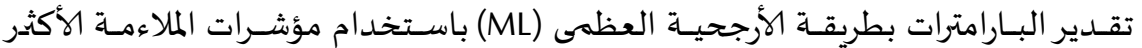

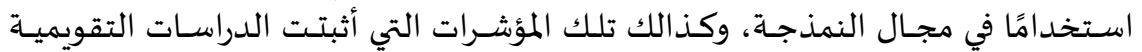

$$
\text { جدارتها. }
$$

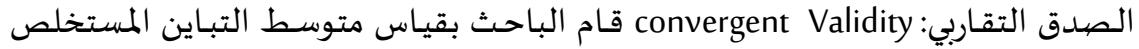

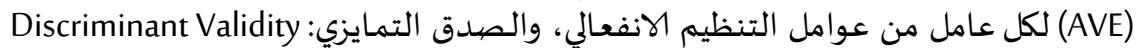

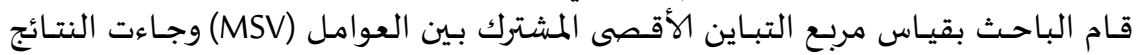

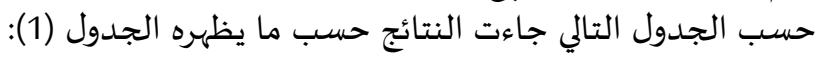

جدول (1)

\begin{tabular}{|c|c|c|c|c|}
\hline \multirow[b]{2}{*}{ CR } & \multicolumn{4}{|c|}{ مؤشرات الصلدق التقاربي والتمايزي لأبعاد التنظيم الانفعالي } \\
\hline & AVE & MSV & 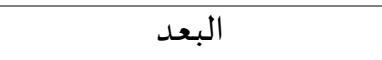 & م \\
\hline .809 & .511 & .494 & التحكم الانفعالي & 1 \\
\hline .803 & .502 & .440 & الوعي والوضوح الانفعالي & 2 \\
\hline .748 & .491 & .383 & تقبل الاستجابات الانفعالية & 3 \\
\hline .640 & .511 & .494 & الاندماج الانفعالي & 4 \\
\hline .838 & .568 & & الدرجة الكلية للمقياس & \\
\hline
\end{tabular}

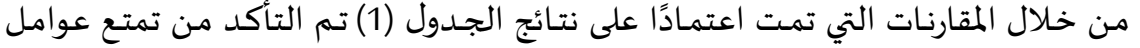

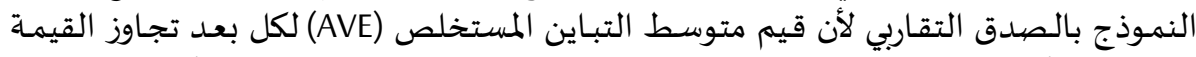

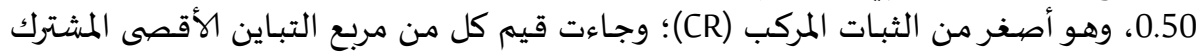


بين العوامل (MSV) أصغر من قيم متوسط التباين المستخلص (AVE)، لكل عوامل النموذج. وهذا المؤشر يدل على تمتع النموذج بالصندق التمايزي.

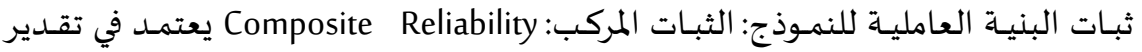

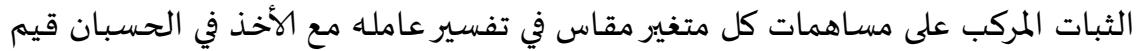

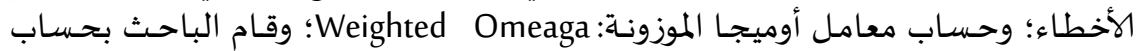

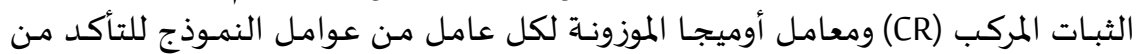

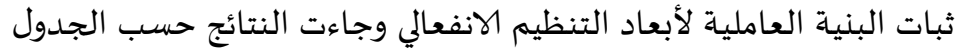

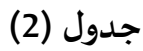
معامل الثبات المركب ومعامل أوميجا الموزون لأبعاد التنظيم الانفعالي

\begin{tabular}{|c|c|c|c|}
\hline$\Omega W$ & CR & البعد & م \\
\hline .803 & .809 & التحكم الانفعالي & 1 \\
\hline .796 & .803 & الوعي والوضيوح الانفعالي & 2 \\
\hline .737 & .748 & تقبل الاستجابات الانفعالية & 3 \\
\hline .629 & .640 & الاندماج الانفعالي & 4 \\
\hline .866 & .838 & ل بدرجة الكلية & \\
\hline
\end{tabular}

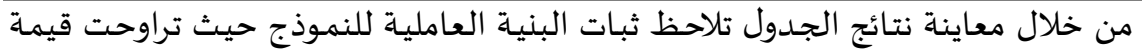

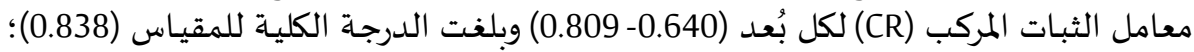

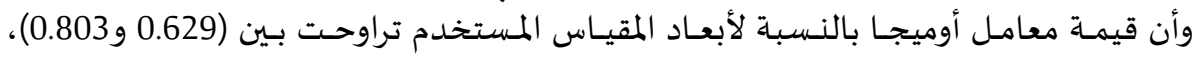

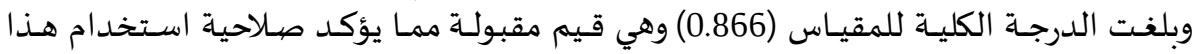
المقياس، وهذا مؤشر دال على ثبات البنية العاملية للنموذج.

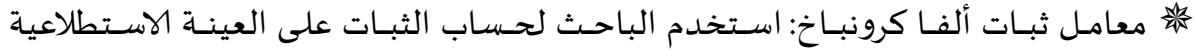

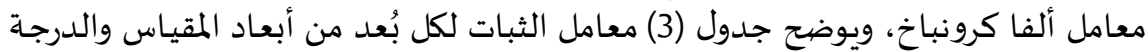

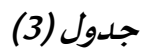

معاملات الثبات للأبعاد والدرجة الكلية لمقياس التنظيم الانفعالي

\begin{tabular}{|c|c|c|}
\hline 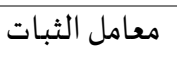 & 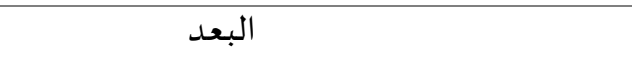 & م \\
\hline .806 & التحكم الانفعالي & 1 \\
\hline .798 & الوعي والوضوح الانفعالي & 2 \\
\hline .743 & تقبل الاستجابات الانفعالية & 3 \\
\hline .637 & الاندماج الانفعالي & 4 \\
\hline .874 & الدرجة الكلية & \\
\hline .893 & معامل ألفا الطبقي Stratified Coefficient Alpha & \\
\hline
\end{tabular}


باستقراء الجدول السابق (3) يتضح ما يلي: أن قيمة معامل ألفا لكرونباك بالنسبة لأبعاد

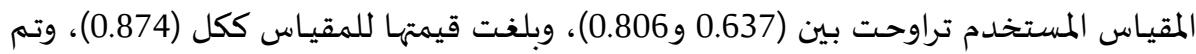

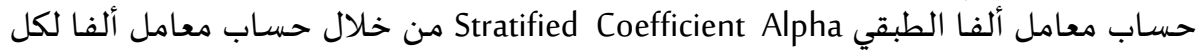

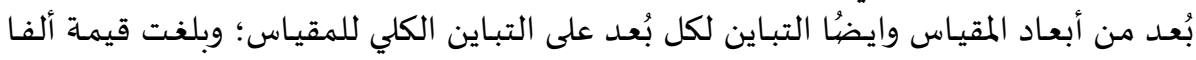

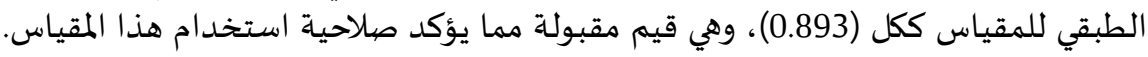

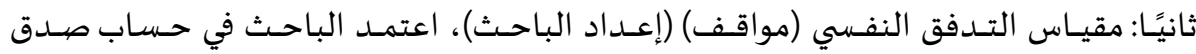

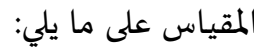

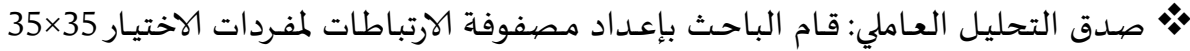

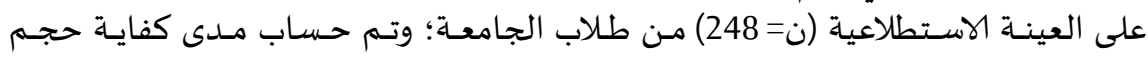

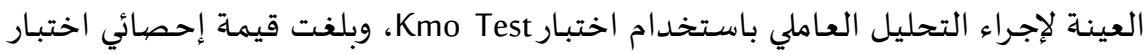

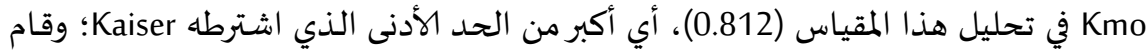

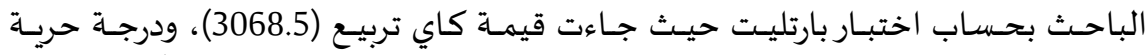

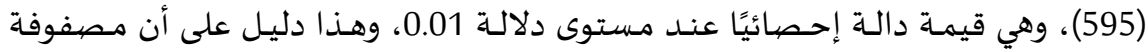

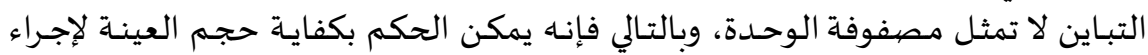

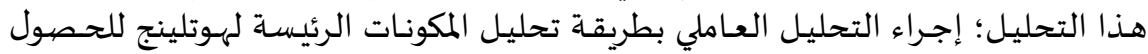

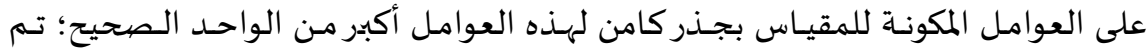

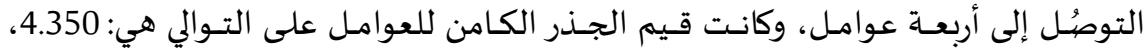

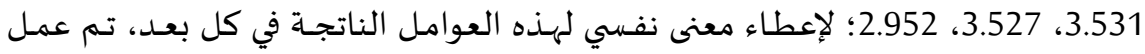

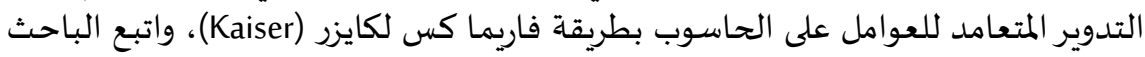

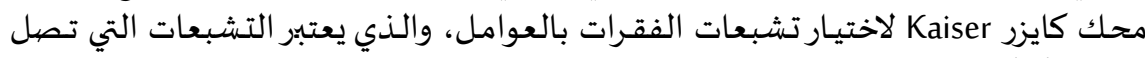

$$
\text { إلى } 0.3 \text { أو أكثر تشبعات دالة. }
$$

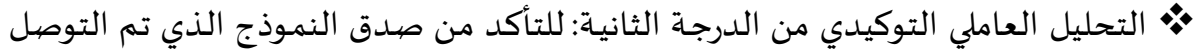

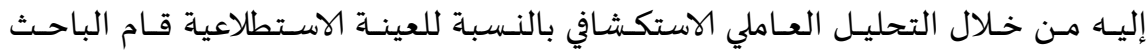

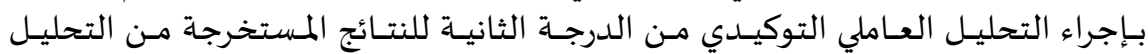

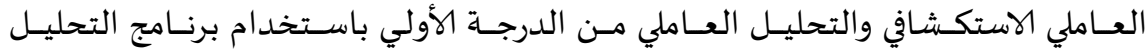

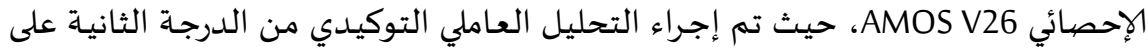

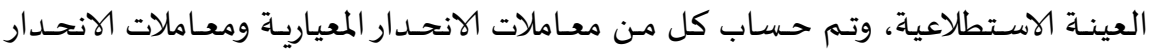

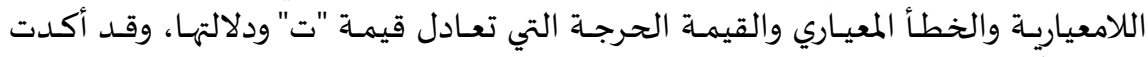

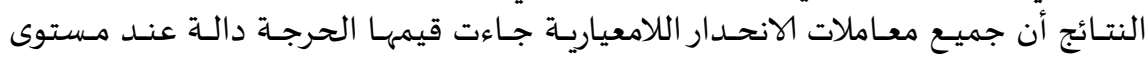

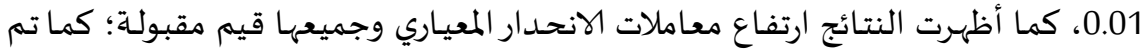

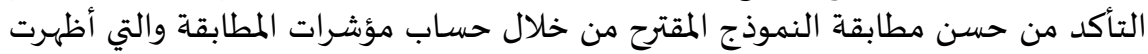
جميعها حسن مطابقة النموذج المقترح.

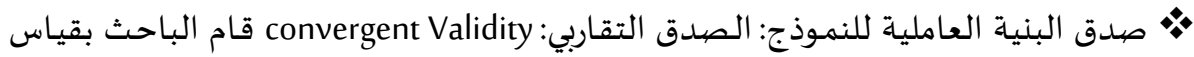

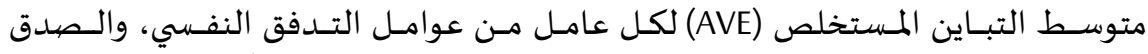

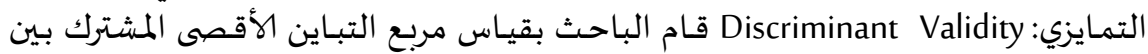


العواهـل (MSV) وجـاءت النتـائج حسب الجــدول التـالي جـاءت النتـائج حسب مـا يظهـره

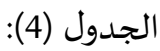

جدول (4) - (4)

\begin{tabular}{|c|c|c|c|c|}
\hline CR & AVE & MSV & 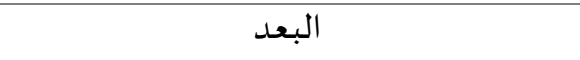 & م \\
\hline 818 & .500 & .482 & الاندماج الكامل أثناء ممارسـة العمل والنشـاط & 1 \\
\hline .756 & .502 & .485 & التخطيط والاستعداد لإدارة الوقت بإيجابية & 2 \\
\hline .791 & .501 & .485 & تحديد الأهد اف ونسيان الذات أثناء الانشغال & 3 \\
\hline .656 & .472 & .505 & الشعور بالمسئولية وتركيز الانتباه & 4 \\
\hline .911 & .719 & & الدرجـة الكلية للمقياس & \\
\hline
\end{tabular}

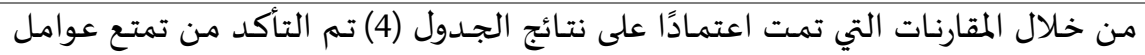

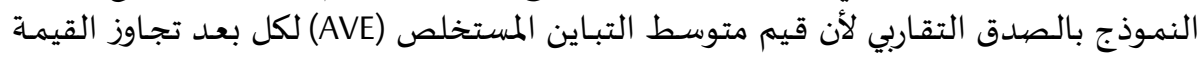

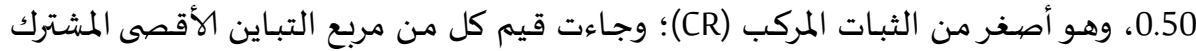

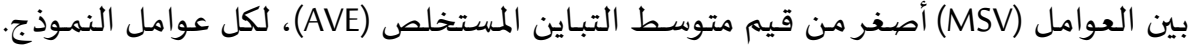
وهذا المؤشر يدل على تمتع النموذج بالصيدق التمايزي.

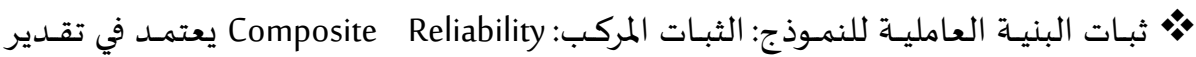

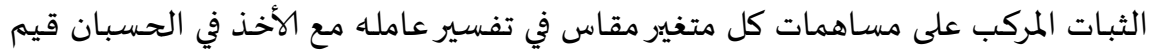

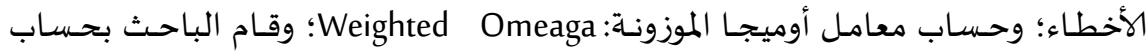

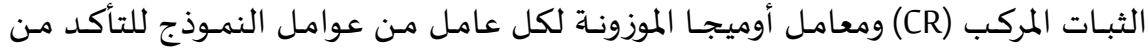
ثبات البنية العاملية لأبعاد التدفق النفسي.

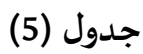

\begin{tabular}{|c|c|c|c|}
\hline$\Omega w$ & CR & 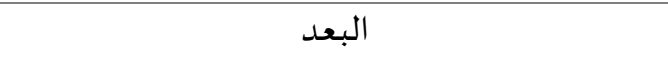 & م \\
\hline .814 & .818 & الاندماج الكامل أثناء ممارسة العمل والنشاط & 1 \\
\hline .754 & .756 & التخطيط والاستعد اد لإدارة الوقت بإيجابية & 2 \\
\hline .782 & .791 & تحديد الأهد اف ونسيان الذات أثناء الانشغال بالمهام & 3 \\
\hline .651 & .656 & الشعور بالمسئولية وتركيز الانتباه & 4 \\
\hline .902 & 911 & الدرجة الكلية & \\
\hline
\end{tabular}


من خلال معاينة نتائج الجدول تلاحظ ثلبات المبات البنية العاملية للنموذج حيث تراوحت قيمة

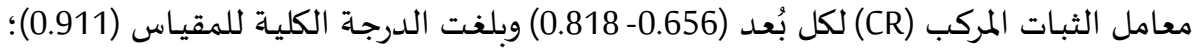

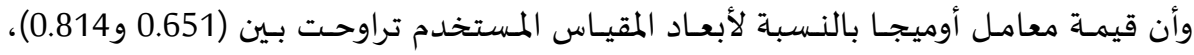

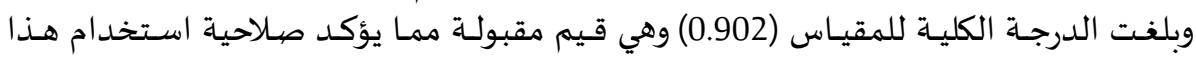
المقياس، وهذا مؤشر دال على ثبات البنية العاملية للنموذج.

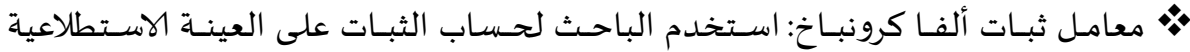

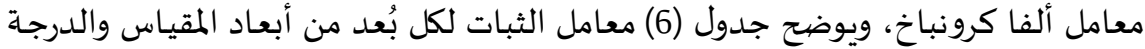

الكلية:

جدول (6)

معاملات الثبات للأبعاد والدرجة الكلية لمقياس التدفق النفسي

\begin{tabular}{|c|c|c|}
\hline 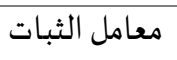 & 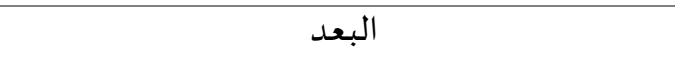 & م \\
\hline .815 & الاندماج الكامل أثناء ممارسة العمل والنشاط & 1 \\
\hline .753 & التخطيط والاستعداد لإدارة الوقت بإيجابية & 2 \\
\hline .788 & تحديد الأهداف ونسيان الذات أثناء الانشغال بالمهام & 3 \\
\hline 651 & الشعور بالمسئولية وتركيز الانتباه & 4 \\
\hline .904 & 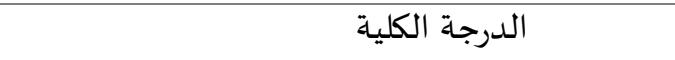 & \\
\hline .912 & ألفا الطبقي Stratified Coefficient Alpha & \\
\hline
\end{tabular}

باستقراء الجدول السابق (6) يتضح ما يلي: أن قيمة معامل ألفا لكرونباك بالمبالنسبة لأبعاد

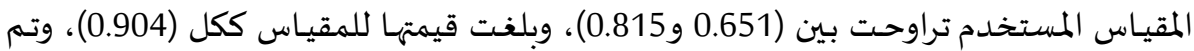

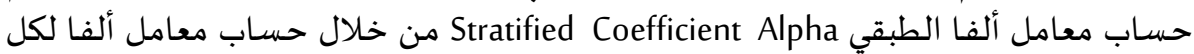

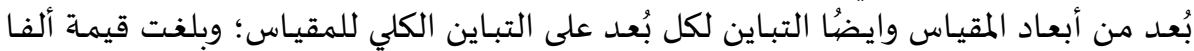

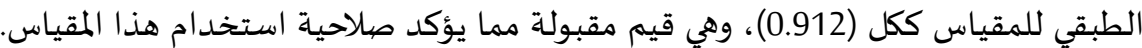

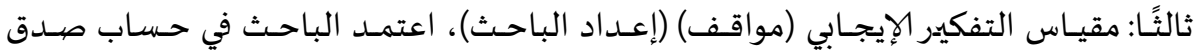

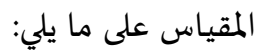

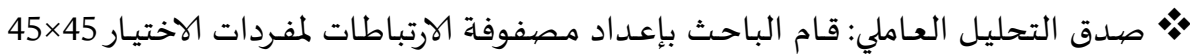

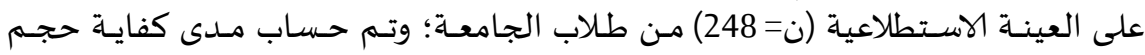

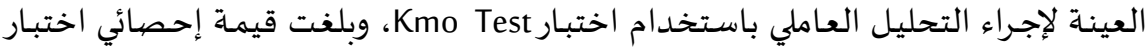

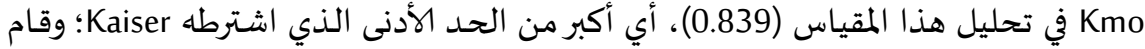

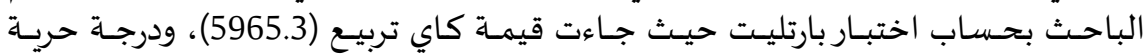

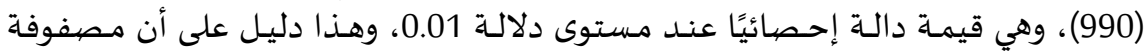

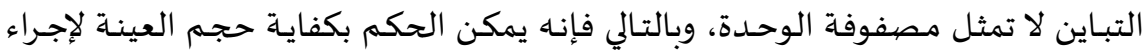




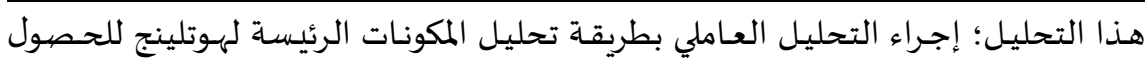

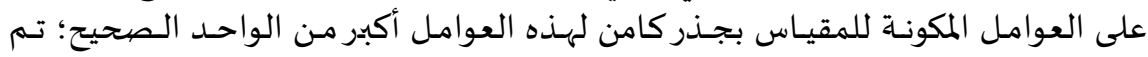

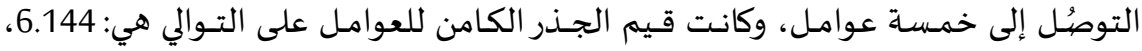

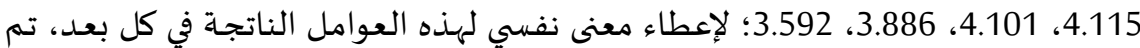

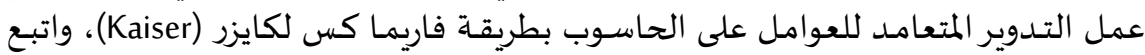

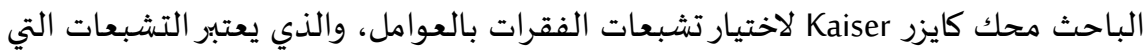

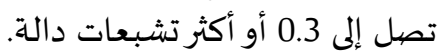

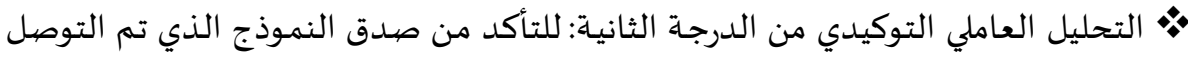

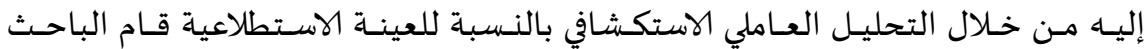

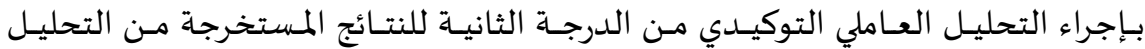

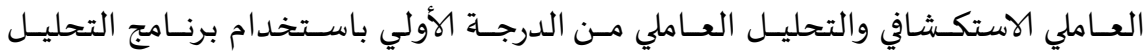

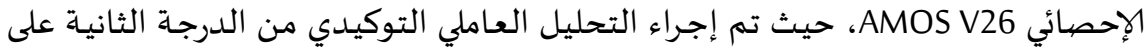

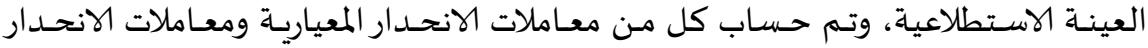

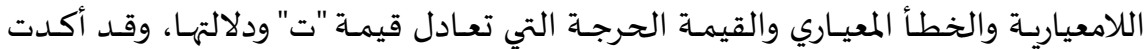

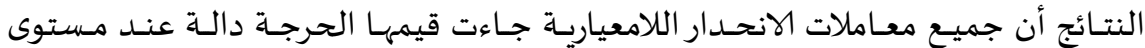

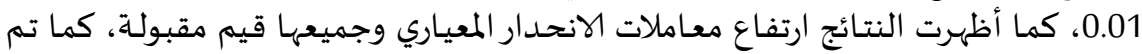

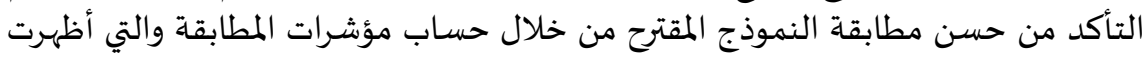
جميعها حُسن مطابقة النموذج المقترح.

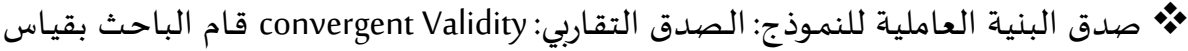

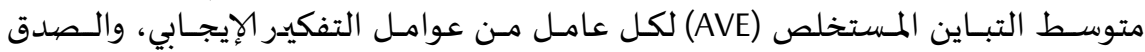

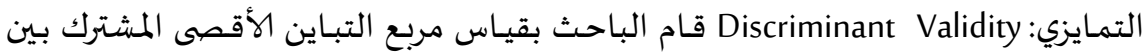

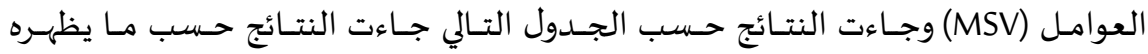

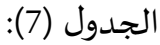

\section{جدول (7) - (7)}

\begin{tabular}{|c|c|c|c|c|}
\hline CR & AVE & MSV & 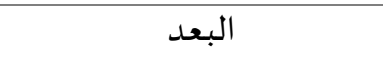 & م \\
\hline .901 & 690 & .629 & التوقعات الإيجابية والتفاؤل & 1 \\
\hline .788 & .649 & .623 & التحكم في العمليات العقلية & 2 \\
\hline .797 & .676 & .629 & المرونة في التفكير & 3 \\
\hline .810 & .489 & .571 & المجازفة الإيجابية & 4 \\
\hline .750 & .448 & .489 & السماحة والأريحية & 5 \\
\hline .922 & .704 & & الدرجة الكلية للمقياس & \\
\hline
\end{tabular}




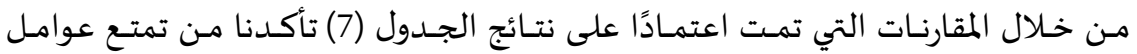

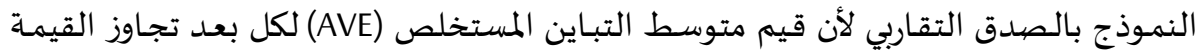

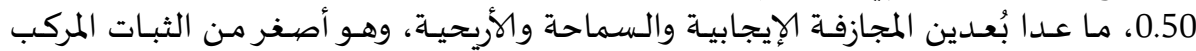

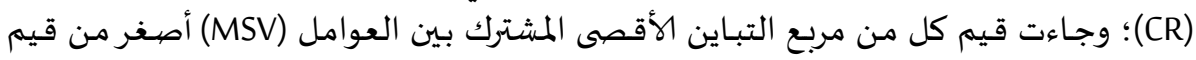

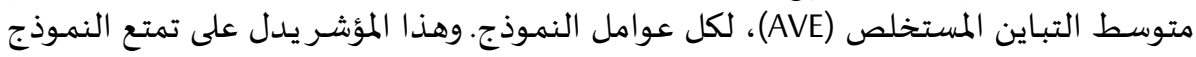
بالصدق التمايزي.

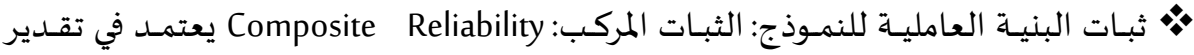

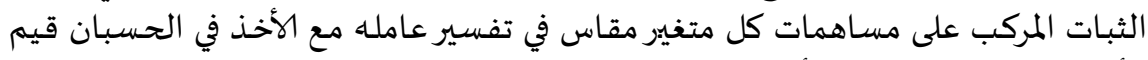

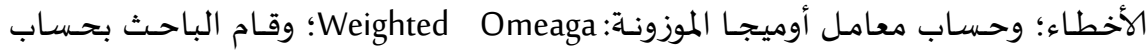

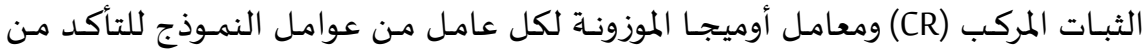

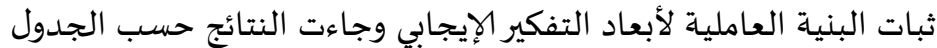

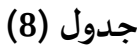
معامل الثبات المركب ومعامل أوميجا الموزون لأبعاد التفكير الإيجابي

\begin{tabular}{|c|c|c|c|}
\hline$\Omega W$ & CR & 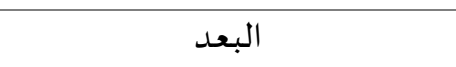 & r \\
\hline .900 & .901 & التوقعات الإيجابية والتفاؤل & 1 \\
\hline .784 & .788 & التحكم في العمليات العقلية العليا & 2 \\
\hline .793 & .797 & المرونة في التفكير & 3 \\
\hline .806 & .810 & المجازفة الإيجابية & 4 \\
\hline .745 & .750 & السماحة والأريحية & 5 \\
\hline .940 & .922 & الدرجة الكلية & \\
\hline
\end{tabular}

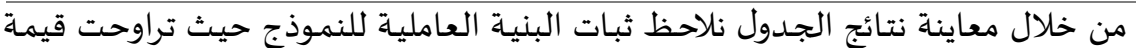

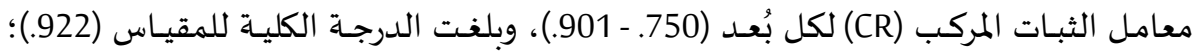

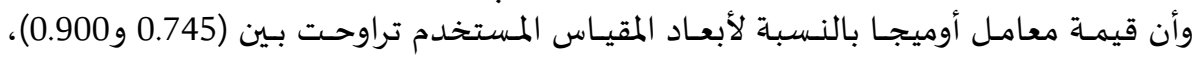

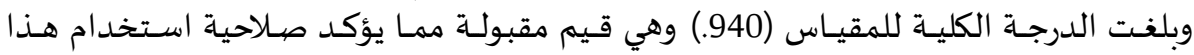
المقياس، وهذا مؤشر دال على ثبات البنية العاملية للنموذج.

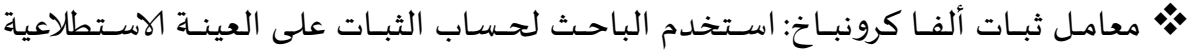

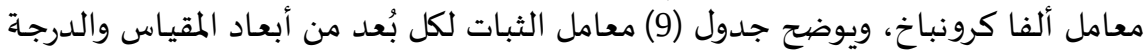




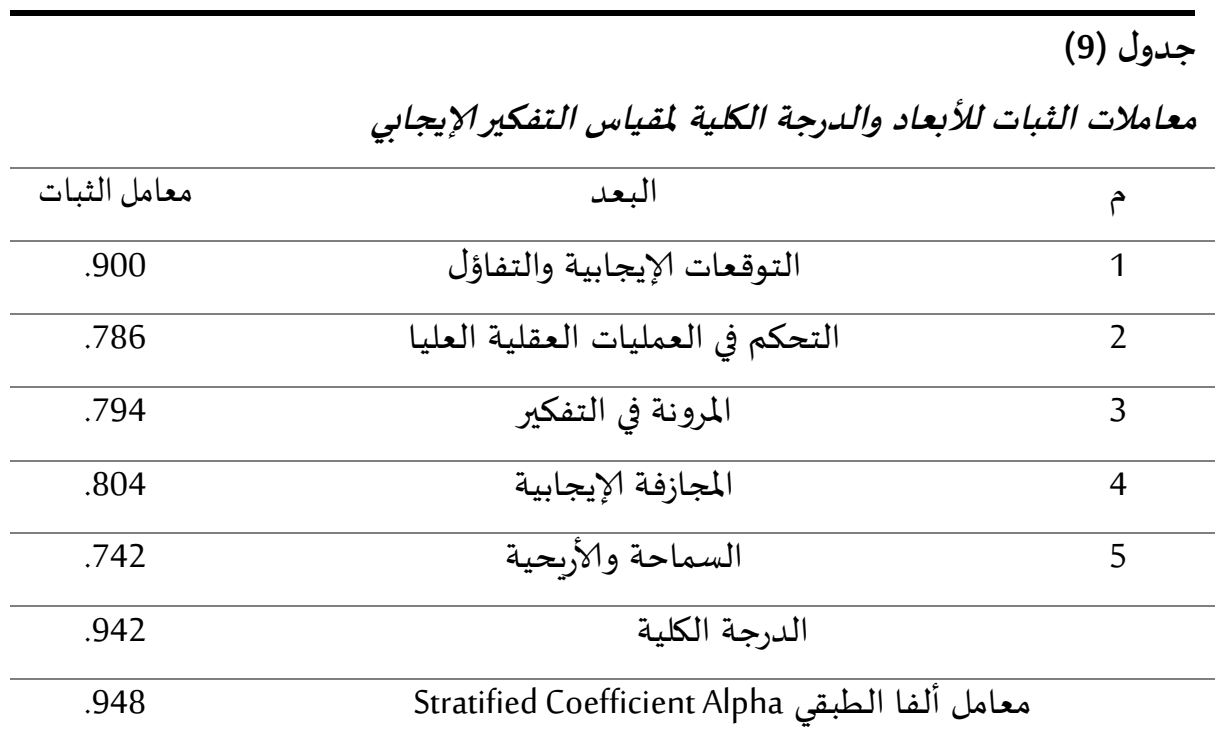

باستقراء الجدول السابق (9) يتضح ما يلي: أن قيمة معامل ألفا لكرونباك بالنسبة لأبعاد

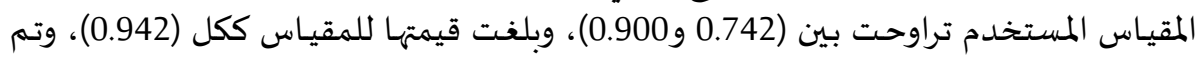

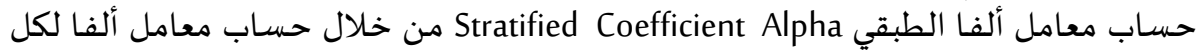

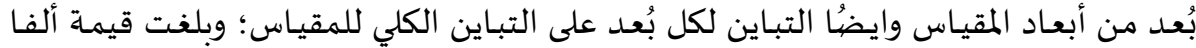

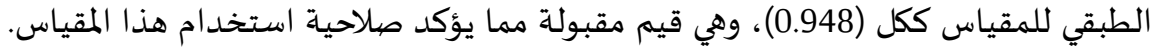

$$
\text { إجراءات تنفيذ البحث: }
$$

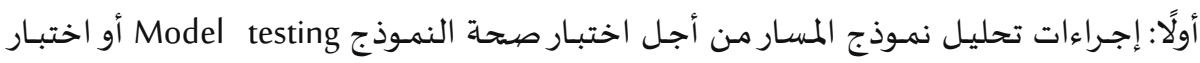

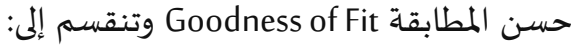

$$
\text { 1) إجراءات تتعلق باختبار النموذج ككل }
$$

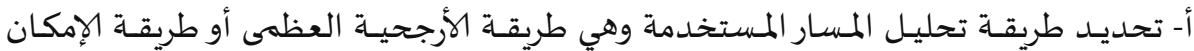

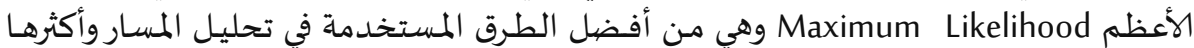
تكرارا بالدراسات السابقة ذات الصللة وأكثرها مناسبة لنوعية بيانات الدراسـة.

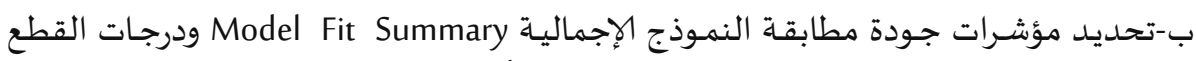
المثالية المستخدمة في الحكم على مدى قبول مطابة النموذج النموذج أم وجود حاجة لتعديله.

2- إجراءات اختبار الوساطة والتعديل الإحصائي للمتغير المُعدل 1* أي التدفق النفسي ومنها طريقة تقديرات بيزيان

* يمكن الرجوع إلى اختبارات الوساطة والتعديل الإحصائية المتنوعة بتنوع المداخل الإحصائية

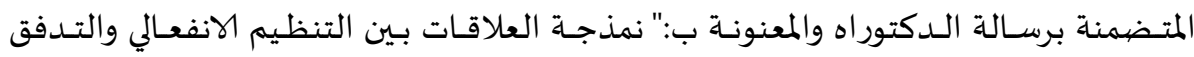

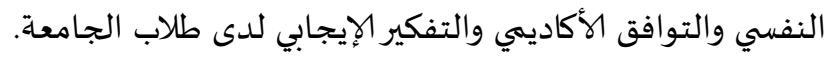




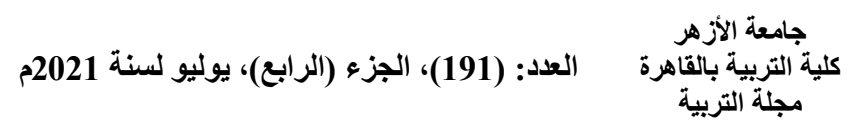

$$
\text { ثأ- الحكيًا: إجراءات ما بعد اختبار النموذج والتعديل الإحصائي وتتضمن ما يأتي: }
$$

ــ الحكم الهـائي على نمـوذج المسـار المعتمـد على التعـديل في ضهـوء مؤشـرات جـودة المطابقـة النهائية.

$$
\text { ب- الإجابة على تساؤلات البحث وفروضها. }
$$

ج-عـرض نتيجـة تحليل المسار المعتمـد على التعديل للنمـوذج في صـورته النهائية وتشتمل على

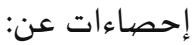
- التأثيرات الكلية غير المعيارية والمعيارية لبارامترات النموذج. - عرض موجز للمسارات الدالة بنموذج المسار بشكل نهائي.

د- تحليل نتـائج البحث؛ للوقـوف على إجابات لتساؤلاته والرد على فروضيه الإحصائية بهدف

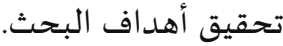

هـ-تقديم توصيات علمية في ضـوء النمـوذج النهائي للبحث لمن يهمـه الأمر من الطلاب وأولياء الأمور.

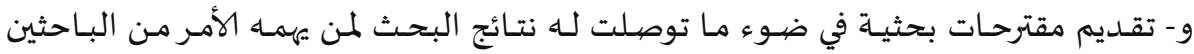
المتخصصين والجهات البحثية المعنية. ثالثًا: الأساليب الإحصائية المستخدمة يعتمد الباحث في تنفيذ البحث الحالي واختبار فروضه وتفسير نتائجها على الأساليب الإحصيائية

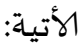
1-تحليـل المسـار المعتمـد على التعـديل باستخدام طريقـة الأرجحيـة العظهى(MLE) ؛ لتقـدير

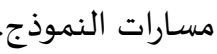
3-اختبـارات الدلالـة الإحصائية Confidence Interval Estimation بفترة وبنقطة لمسارات

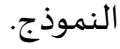
نتائج البحث: عرض وتفسير نتائج الفرض الأول:

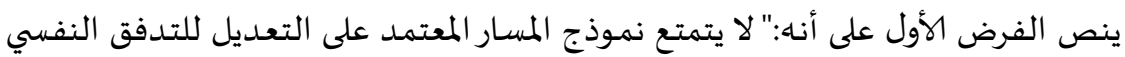

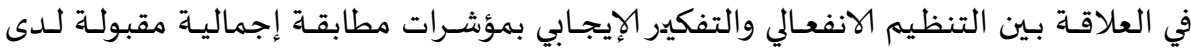
أفراد العينة من طلاب الجامعة". وللتحقق من صحة الفرض السابق قام الباحث باستخدام ماكرو (Process Macro) الذي

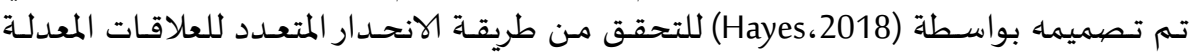
وكانت النتائج على النحو التالي: 


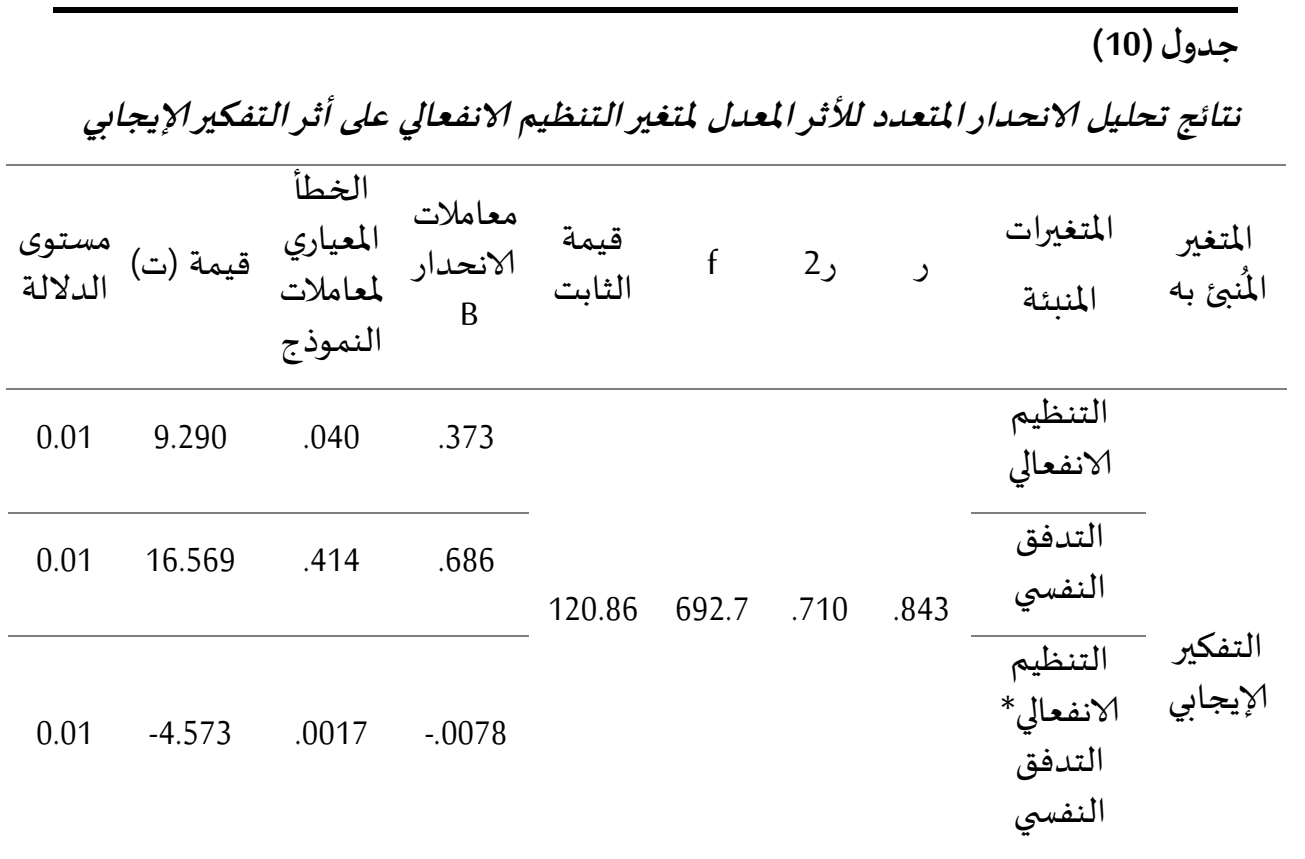

وتشير النتائج في جـدول (10) أن الـدور المعـدل المتغيير التـدفق النفسي دال احصيائيًا حيث

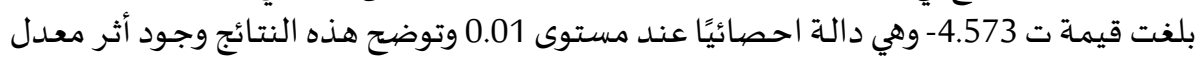
المتغير التدفق النفسي على أثر التنظيم الانفعالي على التفكير الإيجابي.

والشكل (1) يوضح التأثيرات المعدلة باستخدام المخطط البياني لجونسون نيمان باستخدام

شكل رقم (1) يوضسح العلاقة بين التنظيم الانفعالي والتفكير الإيجابي، من خلال المتغير

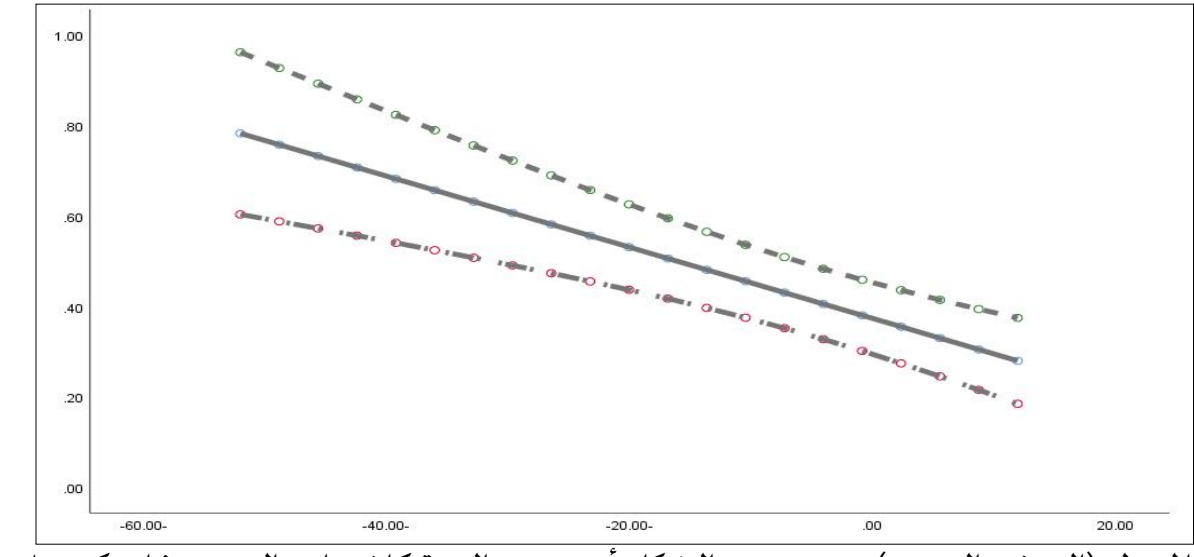

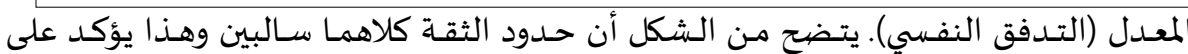

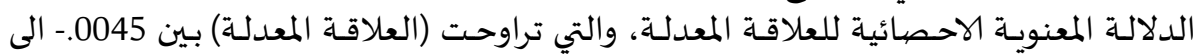

0112.- عند مستوى الثقة 95\%. 


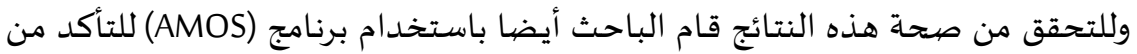

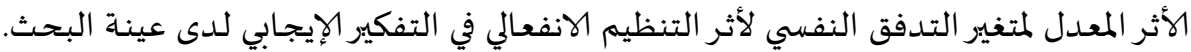

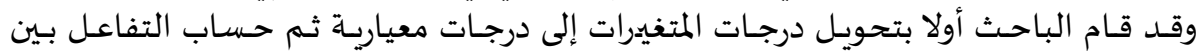

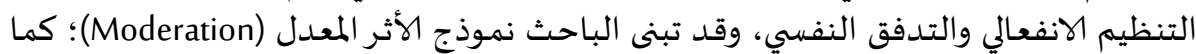

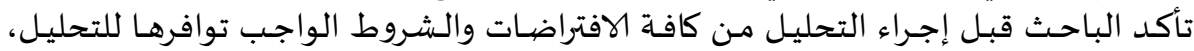

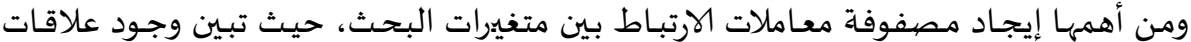

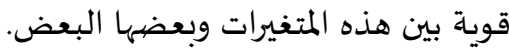
وبناءً على ما سبق تم إجراء تحليل المسار على عينة البحث الأساسية، وتم حساب معاملاملات

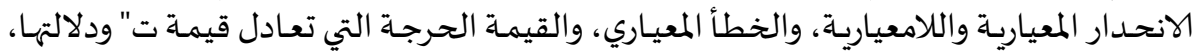
والشكل (2) يوضح النموذج المستخرج لمتغيرات الدراسية.

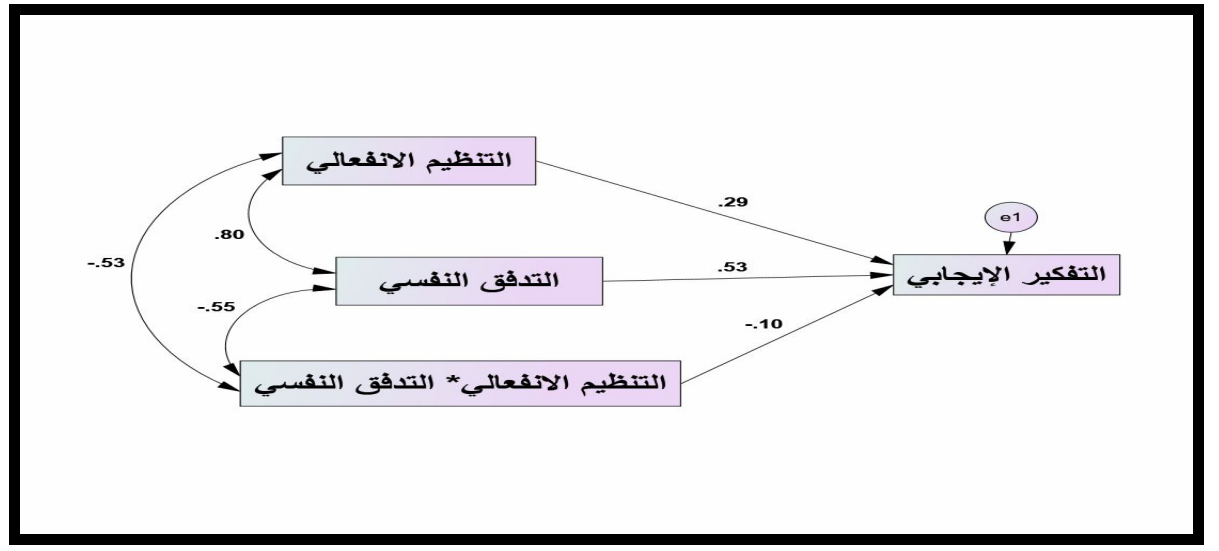

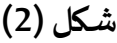

$$
\text { النموذج المُعدل المستخرج لمتغيرات الدراسـة. }
$$

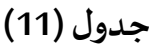

معاملات الانحدار اللامعيارية والمعيارية لنموذج تحليل المسار لمتغير المعدل لدى طلاب

\section{الجامعة}

\begin{tabular}{|c|c|c|c|c|c|c|}
\hline \multirow{2}{*}{ الدلالة } & \multirow{2}{*}{ الانحاملار } & \multirow{2}{*}{ الحرجة } & \multirow{2}{*}{ المعياري } & \multirow{2}{*}{ الانحددار } & \multicolumn{2}{|c|}{ المتغيرات واتجاه التأثير } \\
\hline & & & & & إلي - إ & من من \\
\hline$* * *$ & .291 & 9.307 & .040 & .374 & الإيجابي & التنظيم الانفعالي \\
\hline$* * *$ & .527 & 16.599 & .041 & .687 & الإيجابي & التدفق النفسي \\
\hline$* * *$ & -.103 & -4.581 & .002 & -.008 & الإيجابي & التنظيم النفسعي \\
\hline
\end{tabular}




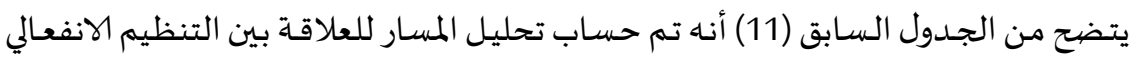

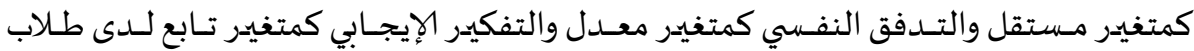

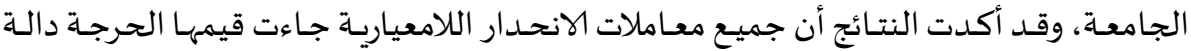

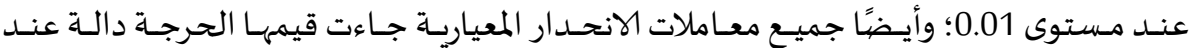

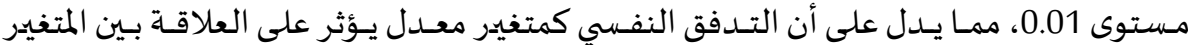
المستقل (التنظيم الانفعالي) والمتغير التابع (التفكير الإيجابي).

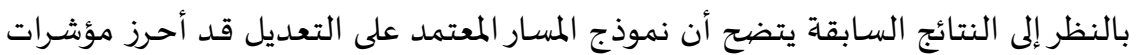

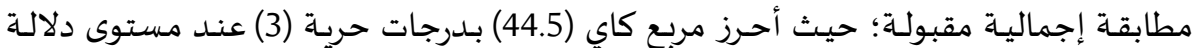

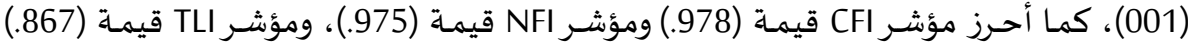

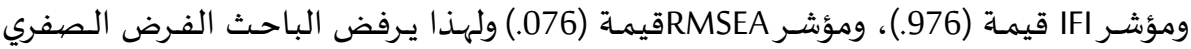
ويقبل الفرض البديل حيث تمتع نموذج البحث بمؤشرات مطابقة إجمالية مقبولة.

$$
\text { وقد أسفرت النتائج عن الآتي: }
$$

1) وجود تأثير سببي مباشر موجب دال إحصائيًا عند مستوى 0.01 للتنظيم الانفعالي في التفكير الإيجابي.

2) وجود تأثير سببي مباشر سالب دال إحصائيًا عند مستوى 0.01 لتفاعل التنظيم الانفعالي مع التدفق النفسي كمتغير معدل في التفكير الإيجابي.

3) وجود تأثير سببي مباشر موجب دال إحصيائيًا عند مستوى 0.01 للتدفق النفسي في التفكير إإيجابي.

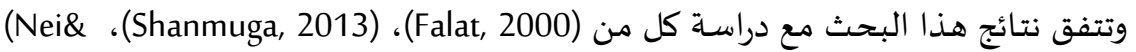

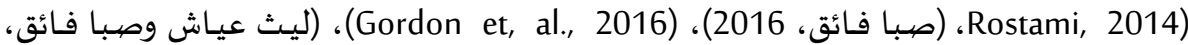

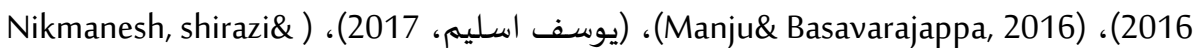
(Farazinezhad, 2017 (إسـلام الزحراوي، (2018)، (هالـة مصطفي، 2018)، (آمنـة خصاونة،

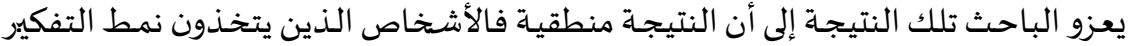

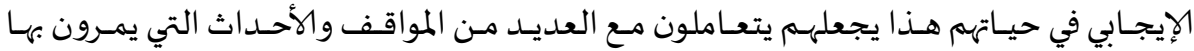

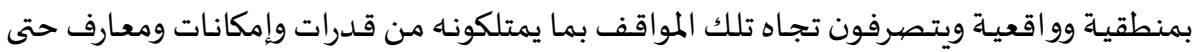

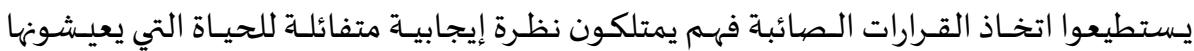

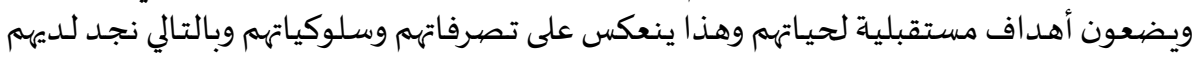

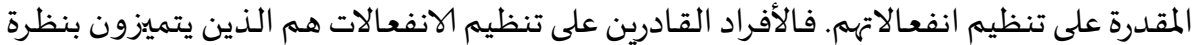

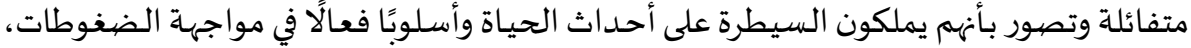

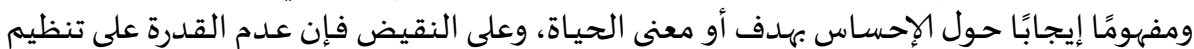

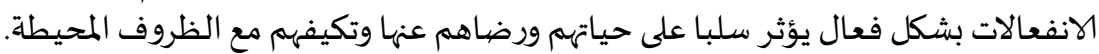

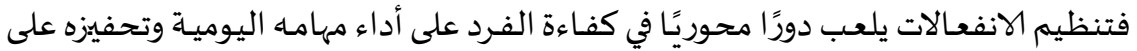

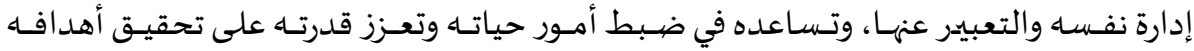


المرسـومة، وتشعره بالارتيـاح والرضيـا عنهـا والانطلاق لتحقيق آمالـه المرسـومة وفقًا للطموحاتـه

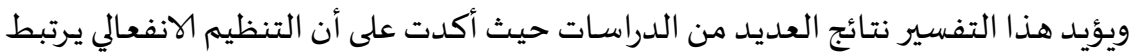

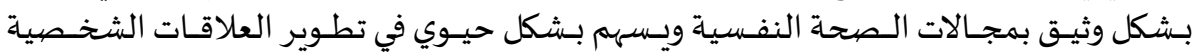

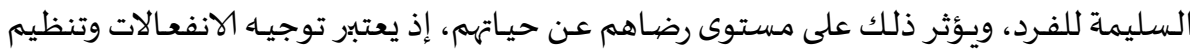

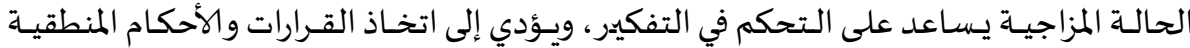
ويقدم حلول إبداعية للمشكلات تتميز بالجدة والتنوع.

ولكي يتمتع الفرد بالصحة النفسية، فلا بـد أن تتوفر لديها القدرة على التعامل مع أحسداث

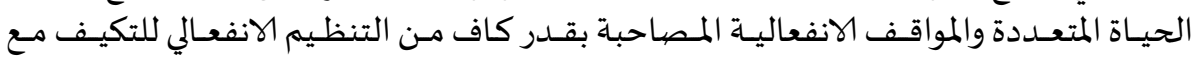

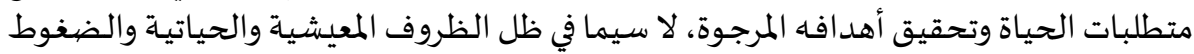
اليومية والزٔمات التي يعيشها الفرد.

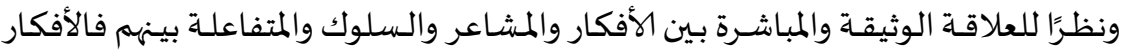

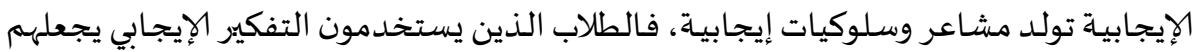

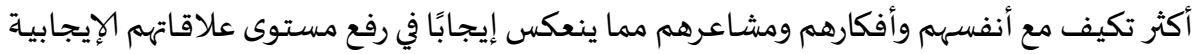

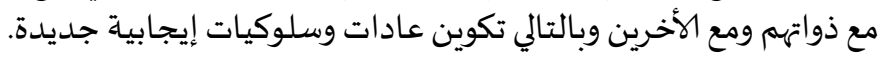

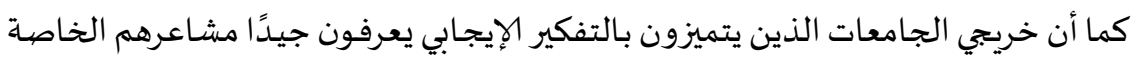

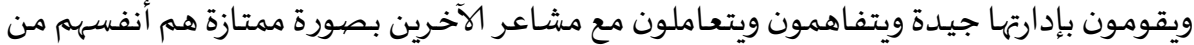

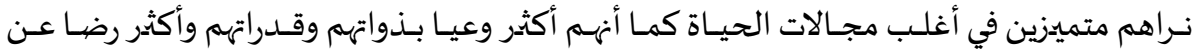

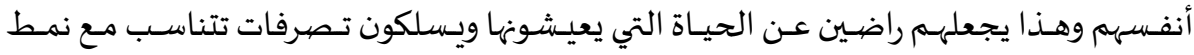
التفكير الإيجابي الذي يتحلون بها

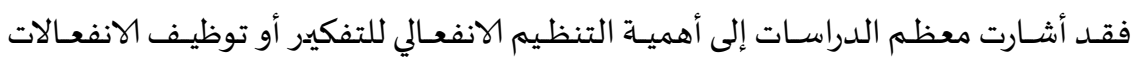

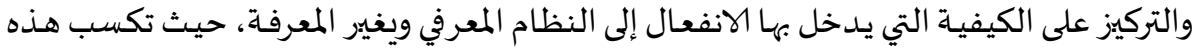

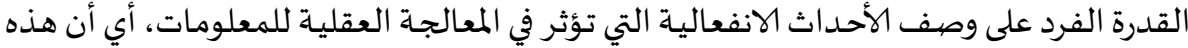

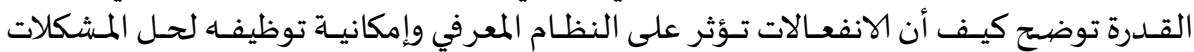
والاستنتاج وصنع القرار واتخاذ القرارات الصحيحة الاتئ.

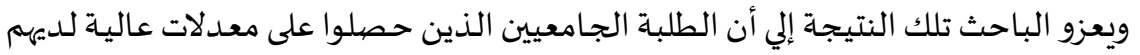

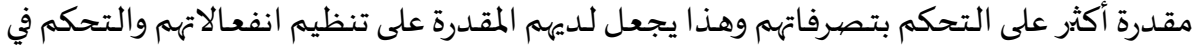

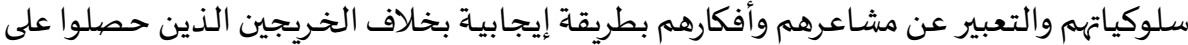

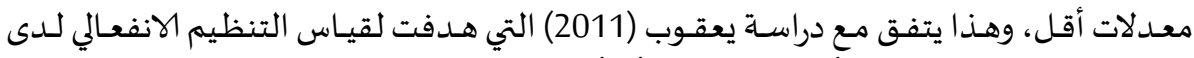

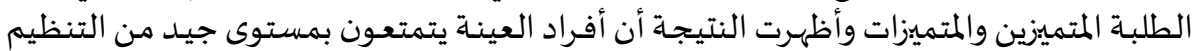

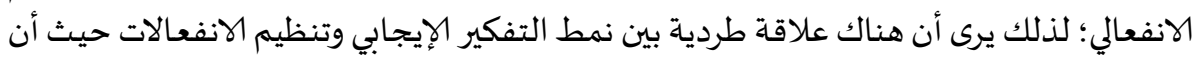

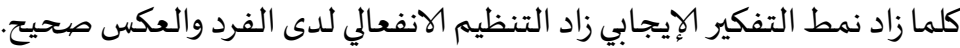




\section{عرض وتفسير نتائج الفرض الثاني}

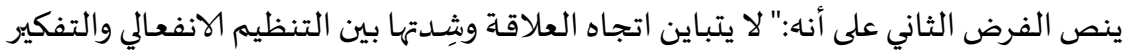

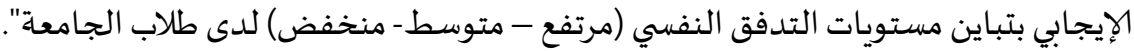

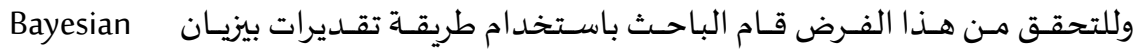

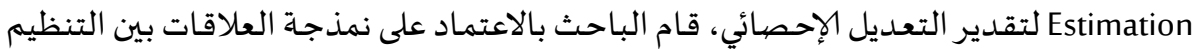

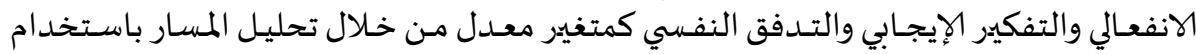
برنامج AMOS V 23 لعينة البحث الأساسية.

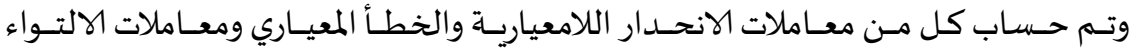

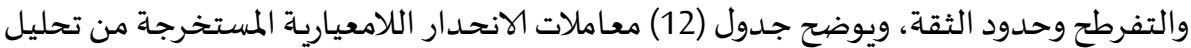

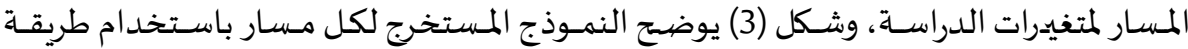
تقديرات بيزيان.

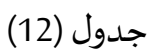

معاملات الانحدار اللامعيارية (Mean) ومعاملات الالتواء المستخرجة من تقديرات بيزيان للمعدل

50\% 50\% المتغيـرات واتجــاه

Upper Lower Kurtosis Skewness C.S. S.D. S.E. Mean التأثير bound bound

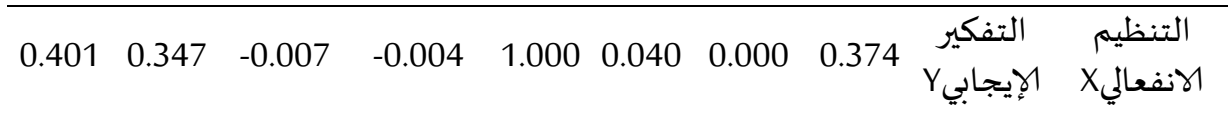

التدفق

النفسيخ الإيجابيY Y

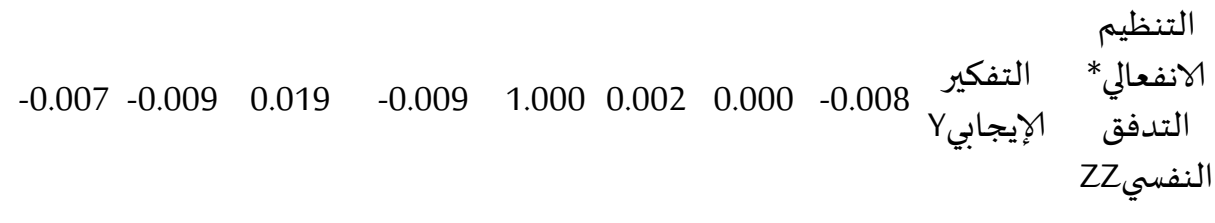

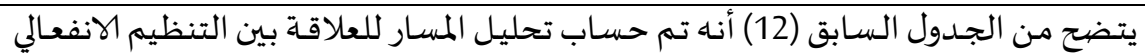

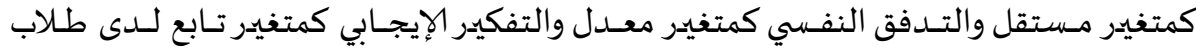

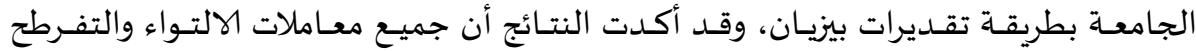

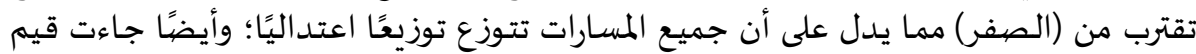

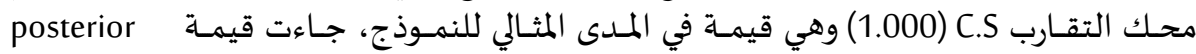
(0.49) predictive p (ppp) 


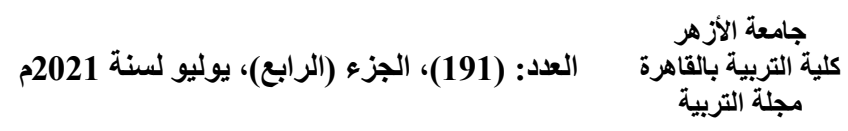

ويوضح شكل (3) تأثير المتغير المعدل التنظيم الانفعالي* التدفق النفسي ZZ على التفكير

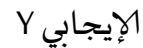

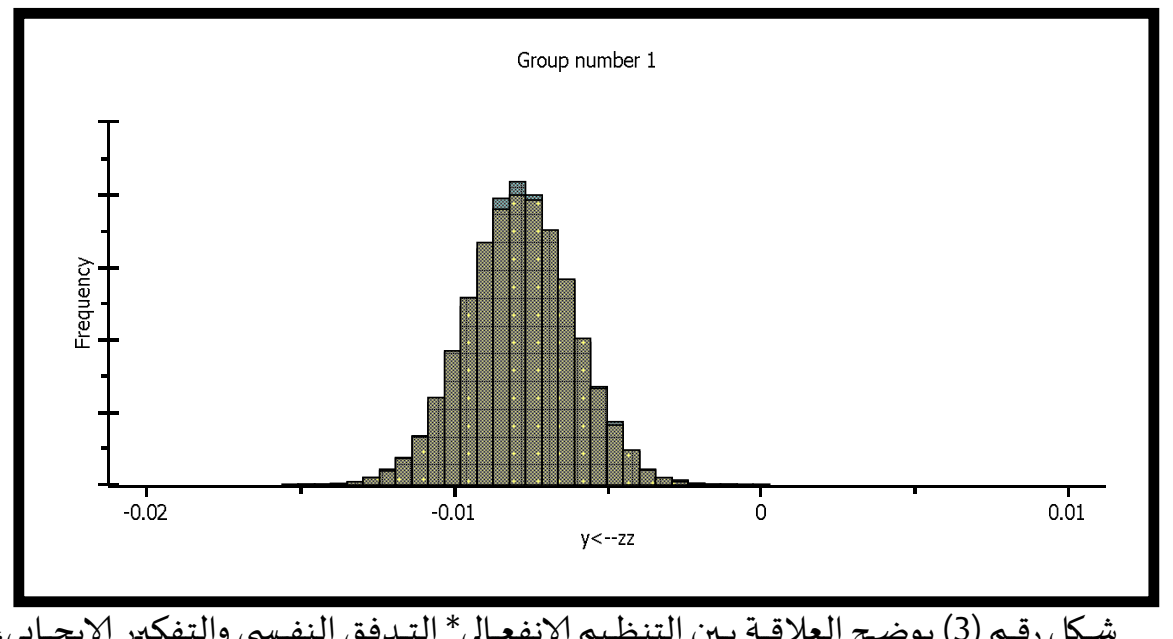

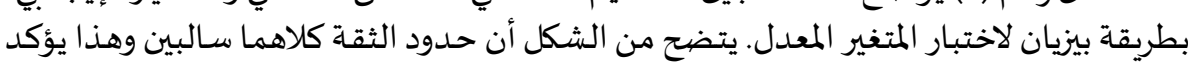

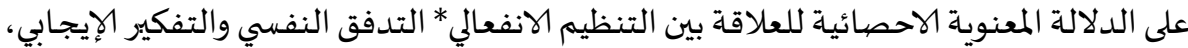
والتي تراوحت في المجتمع الكلي بين 009.- الى 007.- عند مستوى الثقة 95 \%

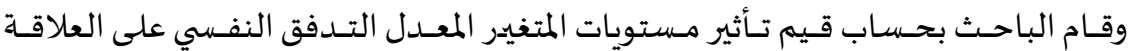

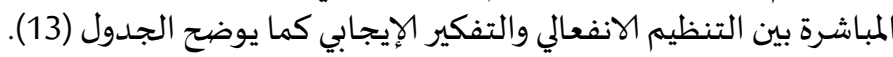

جدول (13)

قيم تأثير مستويات (مرتفع - متوسط - منخفض) المتغير المعدل

\begin{tabular}{|c|c|c|c|c|c|}
\hline \multirow{2}{*}{$* * *$} & \multirow{2}{*}{$\begin{array}{l}\text { Upper } \\
.502\end{array}$} & \multirow{2}{*}{$\begin{array}{l}\text { Lower } \\
.243\end{array}$} & \multicolumn{2}{|c|}{$\begin{array}{c}\text { معاملات الانحعيارية } \\
\text { اللامعيار }\end{array}$} & \multirow{2}{*}{ 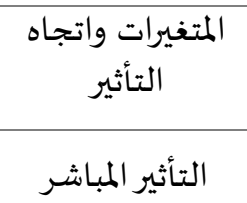 } \\
\hline & & & .361 & منخفض & \\
\hline$* * *$ & .391 & .116 & .239 & متوسط & لمستويات التدفق \\
\hline 102 & 295 & -.020 & 116 & مرتفع & \\
\hline
\end{tabular}

يتضح من الجدول السابق (13) أنها تم حساب تحليل المسار للعلاقة المباشـرة بين التنظيم

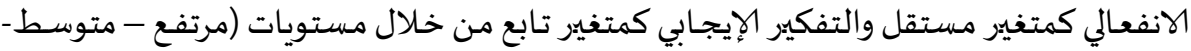

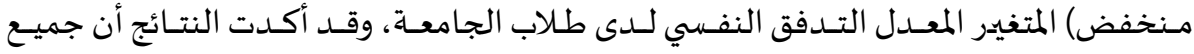

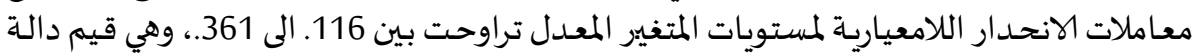

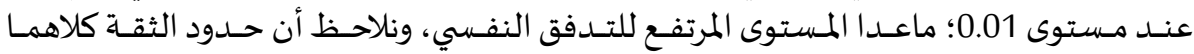




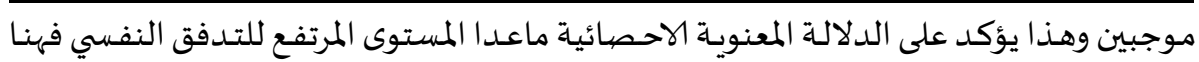

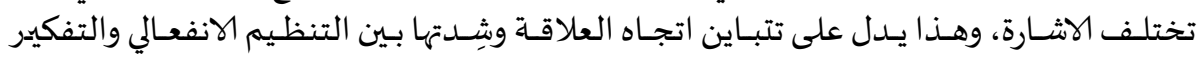

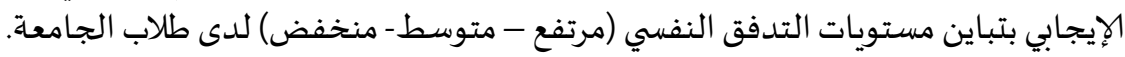

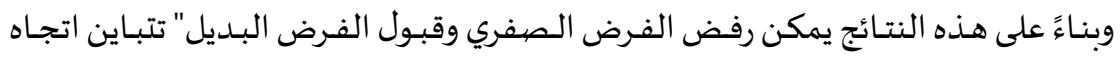

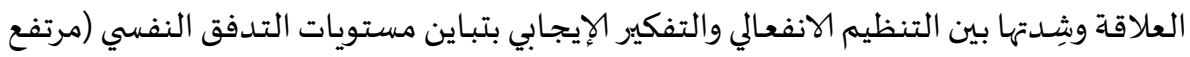

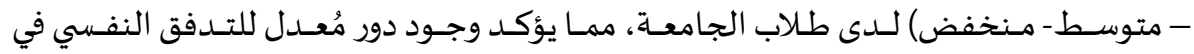
العلاقة بين التنظيم الانفعالي والتفكير الإيجابي.

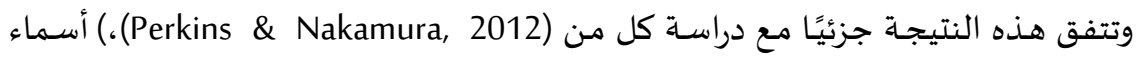

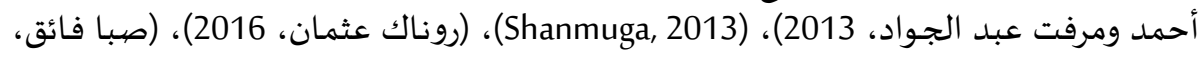

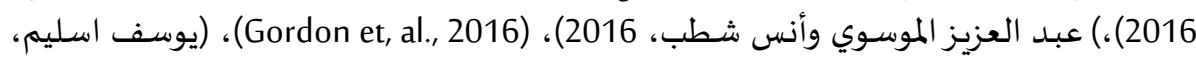

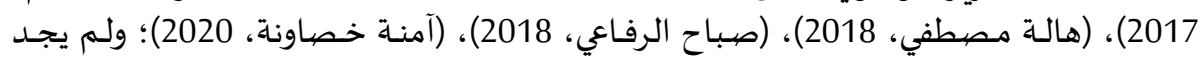

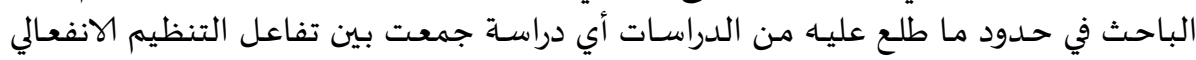
والتدفق النفسي في التفكير الإيجابي.

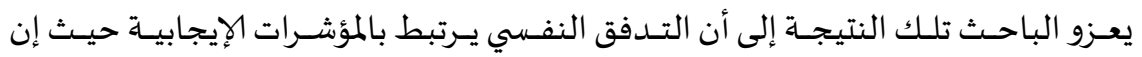

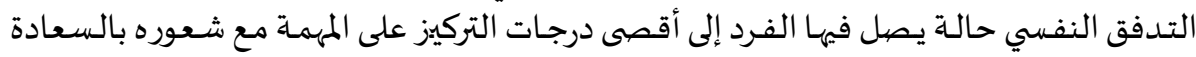

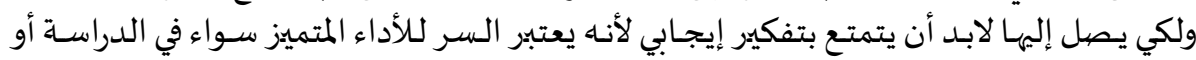

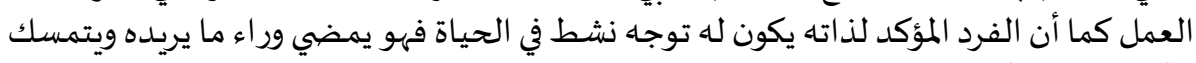

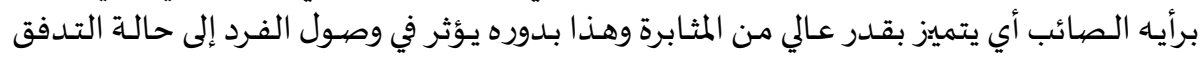
النفسي.

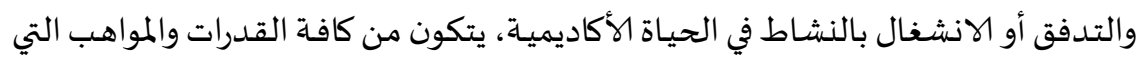

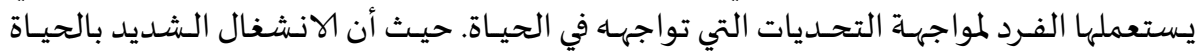

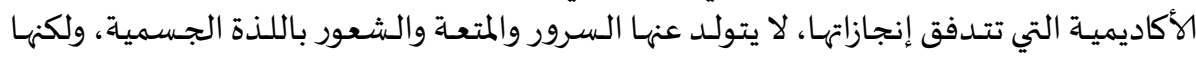

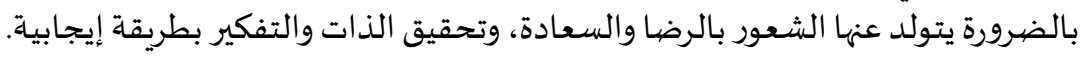

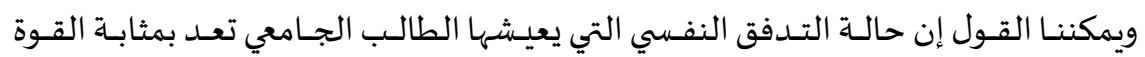

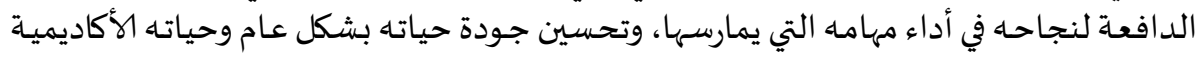

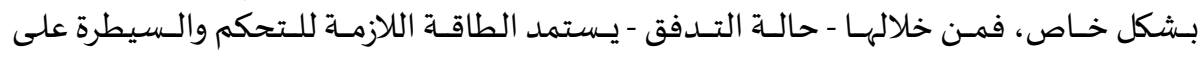

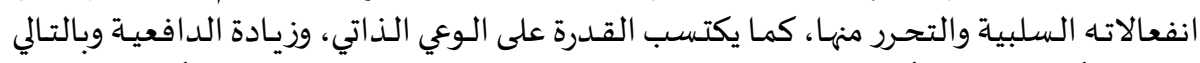

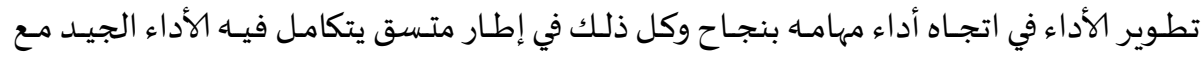
الصفاء الذهني.

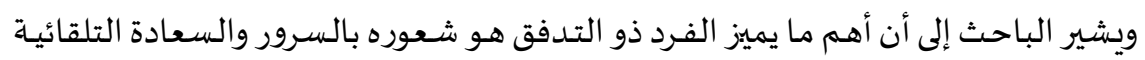

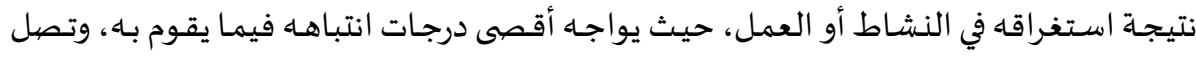

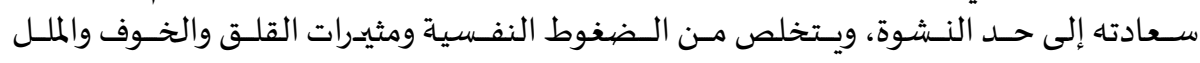

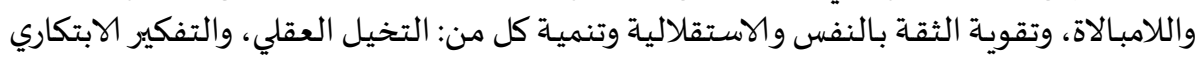

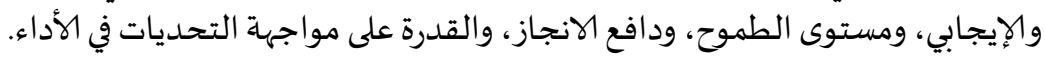


كما أنه يشعر بأن النشاط الذي يقوم بهاه هو هدف جوهري ومجزي في حد ذاته وهو النشو ما يجعله

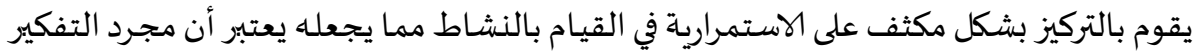

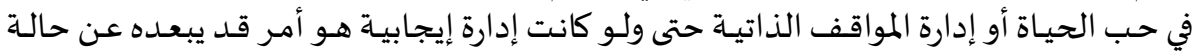
التدفق النفسي التي يعيش فيها ويستمتع بها.

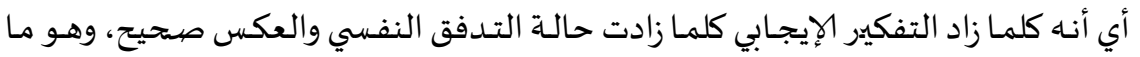

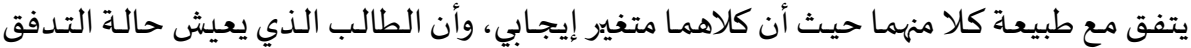

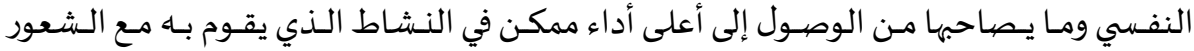

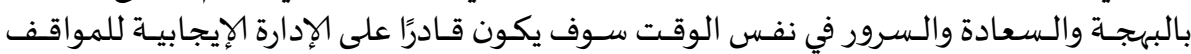

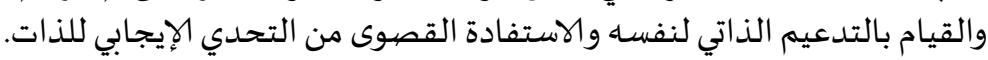

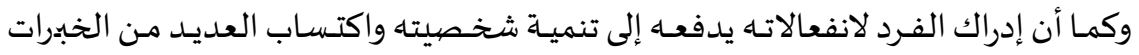

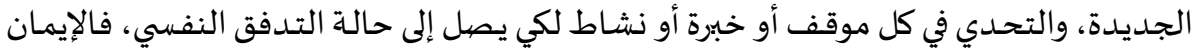

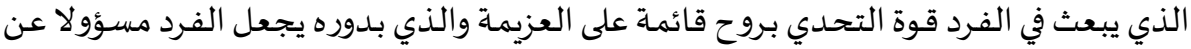

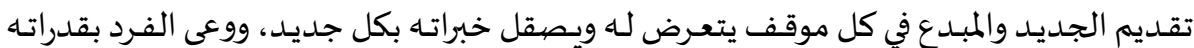

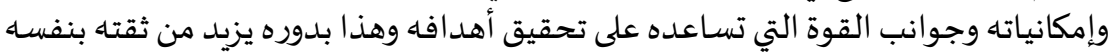
ويجعلـه شخص إيجـابي في تفكييره وفي تعاملاتهـ مـع الآخـرين وفي اتجاهاتـه نحـو الحاضـر و والمستقبل.

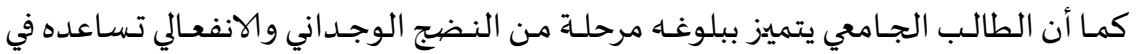

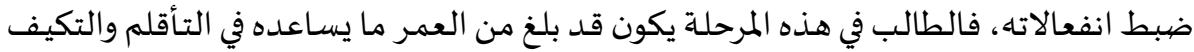

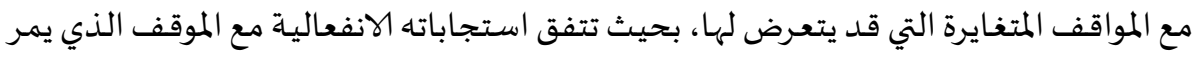

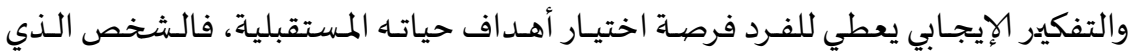

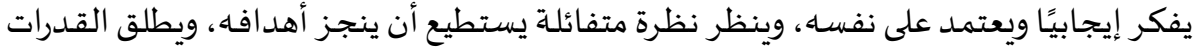

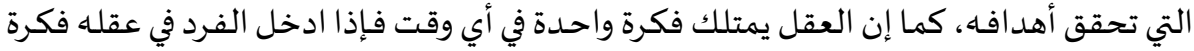

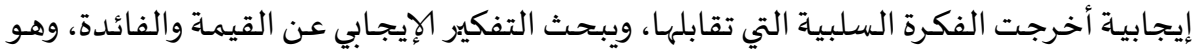

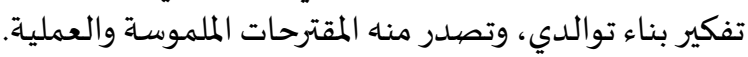

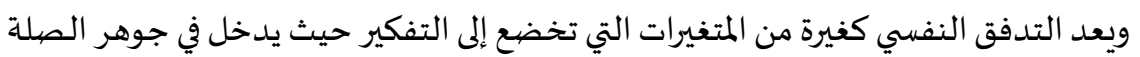

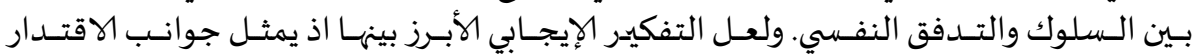

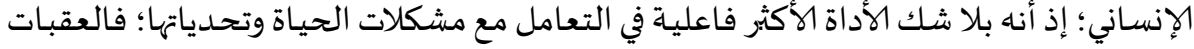

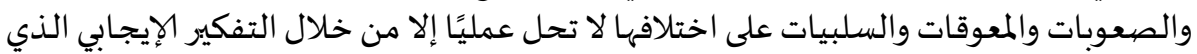

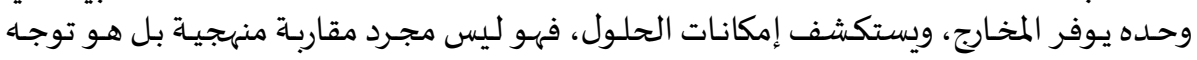

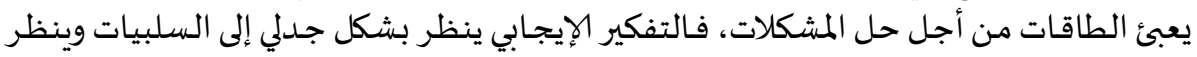

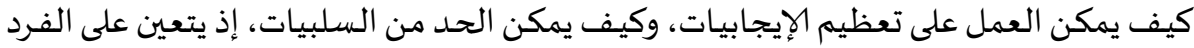

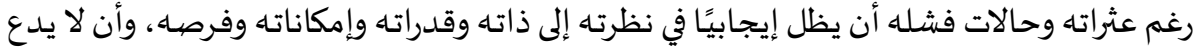

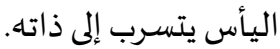




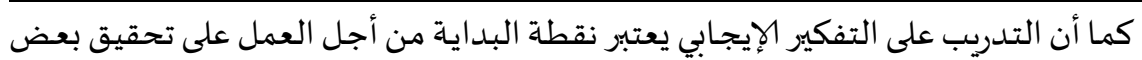

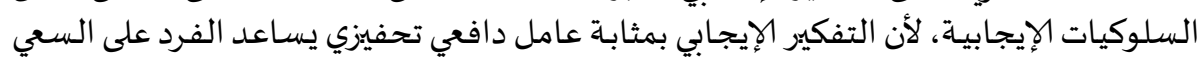

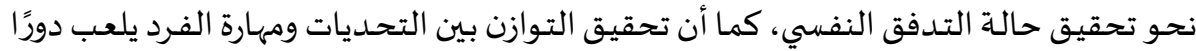

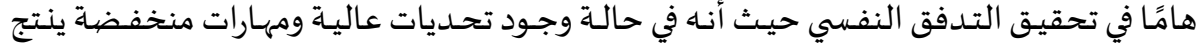

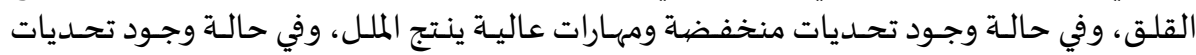

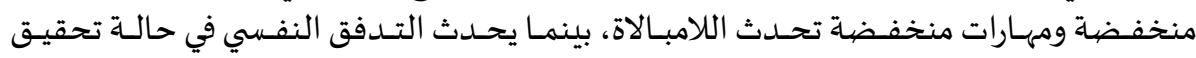

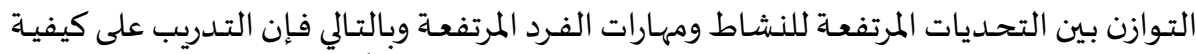

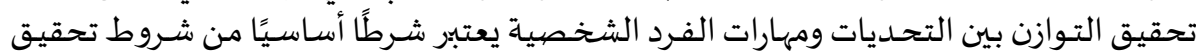
التدفق النفسي بل أن البعض يعتبره الشرط الوحيد لتحقيق التدفق النفسي.

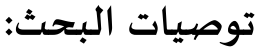

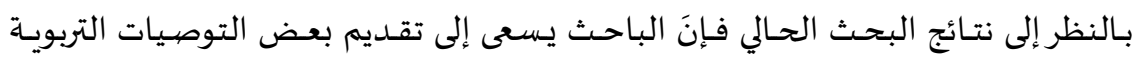

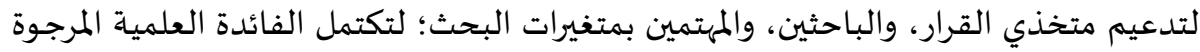
من إجراء البحث الحالي، ومن أهم هذه التوصيات والمتين ما يأتي:

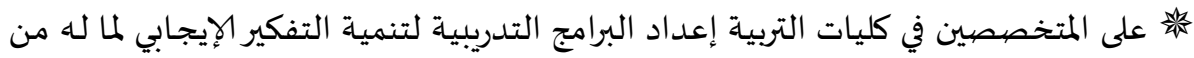
دور كبيروأثر إيجابي على سلوك الطلاب في بيئة التعله.

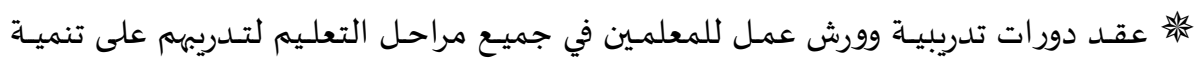
التنظيم الانفعالي والتفكير الإيجابي والتدفق النفسي لدئ في الطلاب.

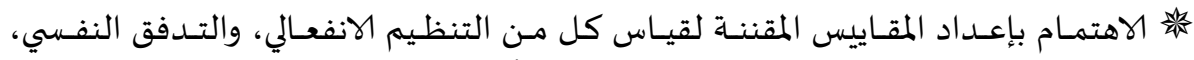
والتفكير الإيجابي، في جميع المراحل العمرية نظرًا لأهمية تلك المقائل المقايس.

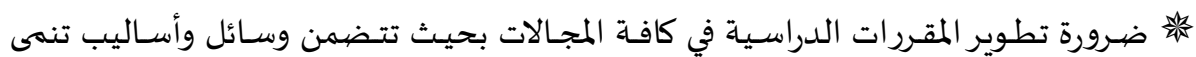

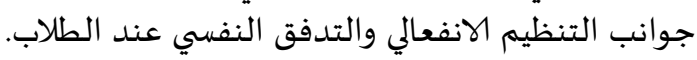

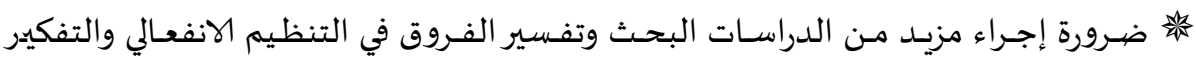
الإيجابي والتي ترجع للنوع، والتخصص، والمدات المستوى الدراسي في مراحل عمرية مختلفة.

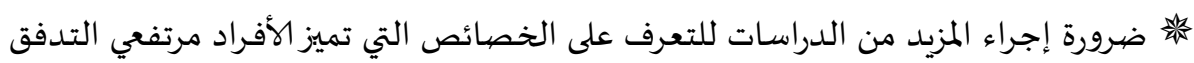
النفسي والتفكير الإيجابي عن الأفراد منخفضي الترفي التدفق النفسي والتفكير الإيجابي.

بحوث ودراسات مقترحة:

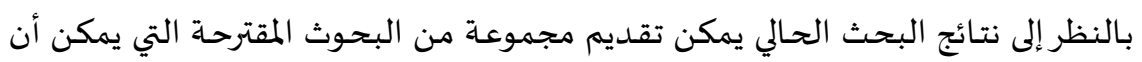

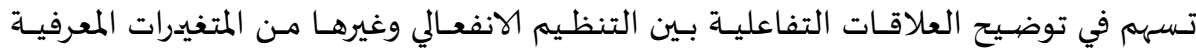
والوجدانية:ومن أهم البحوث المقترحة: دراسة الخط النمائي للتنظيم الانفعالي عبر مراحل عمرية مختلفة.

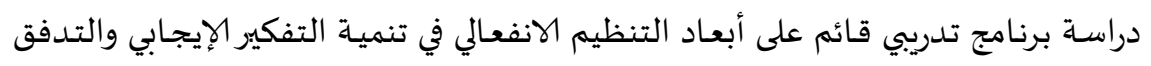

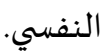




$$
\begin{aligned}
& \text { كلية أتربية بالقاهرةة العدد: (191)، الجزء (الرابع)، يوليو لسنة 2021م } \\
& \text { مجلة التربية } \\
& \text { والاجتماعي. }
\end{aligned}
$$




\section{المراجع}

أولًا: المراجع العربية

- أحلام على عبـد الستار جبر. (2011). فاعلية برنامج تـلديبي لمهارات التفكييز الإيجابي وأثره في

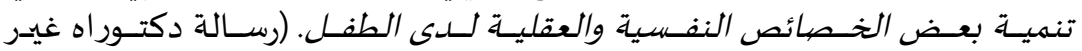
منشورة). جامعة القاهرة، معهد الدراسات والبحوث البهو التربوية.

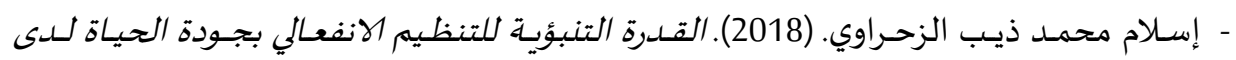

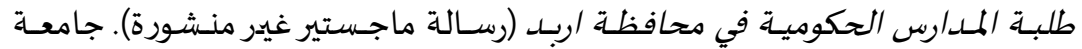

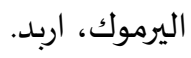

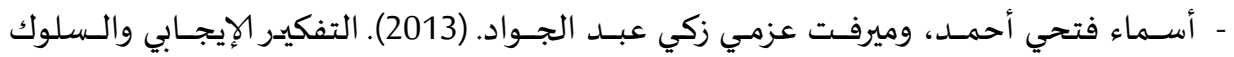

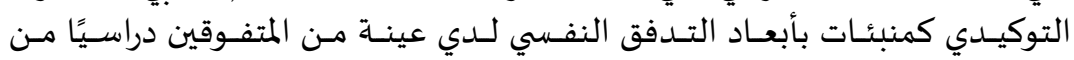

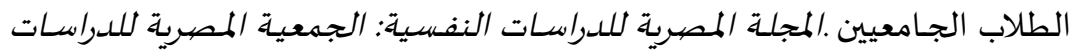

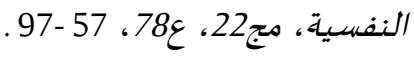

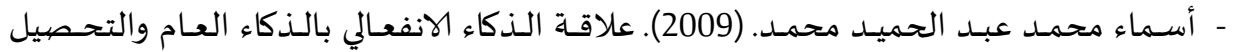

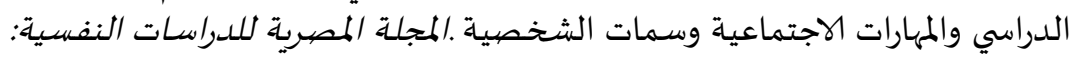

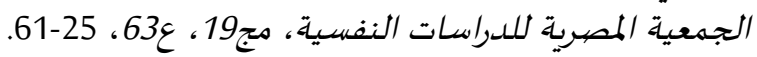

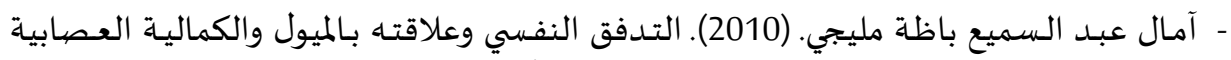

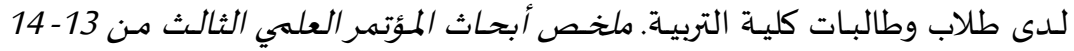

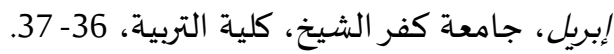

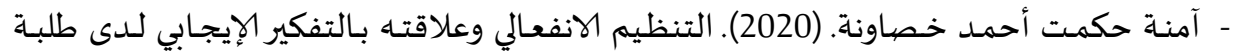

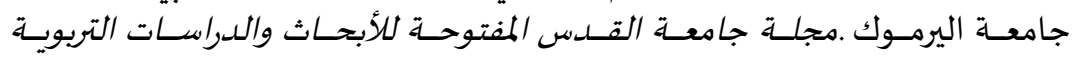
والنفسية: جامعة القدس المفتوحة، مج11، عامعة ع30، 30 -46.

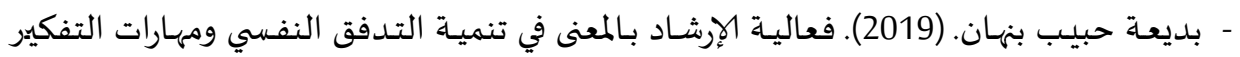

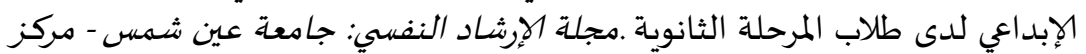

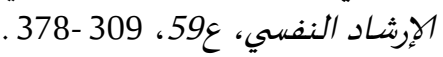

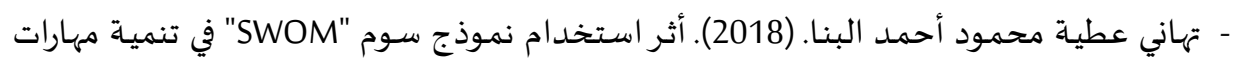

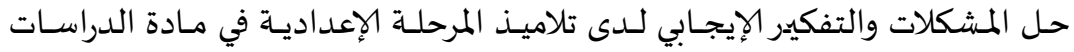

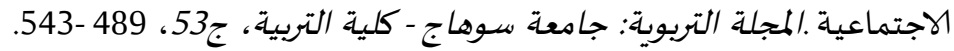

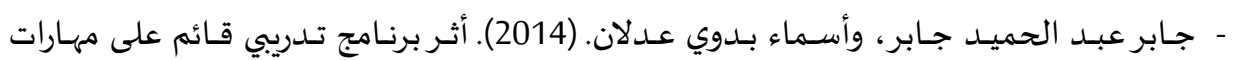

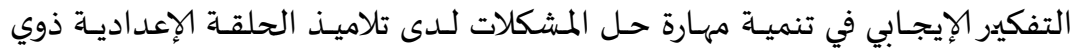

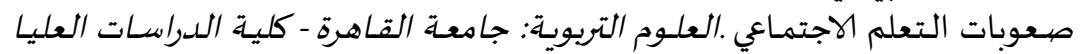
ل للتبية، مج22، ع3، 371 - 302. 


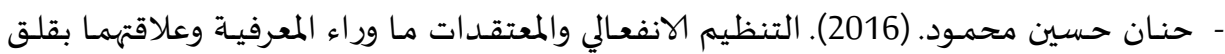

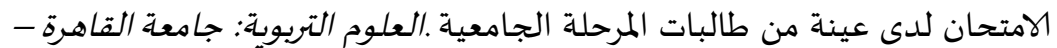

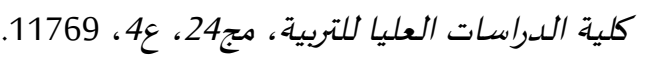

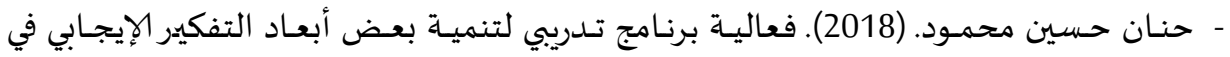

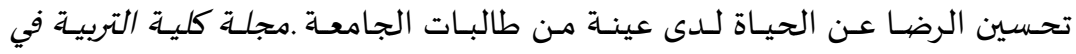
العلوم النفسية: جامعاة عين شمس - كلية التربية، مج42، ع1 ، 230 -298.

- ربيعة بن الشيخ .(2015) .علاقة الاتزان الانفعالي بالتدفق النفسي: دراسة ميدانية على عينة

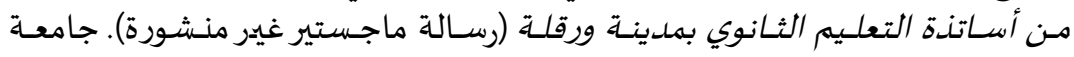
قاصدي مرباح، ورقلة. كلية العلوم الإنسانية والاجتماعية، الجزائر .

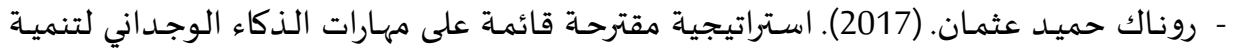

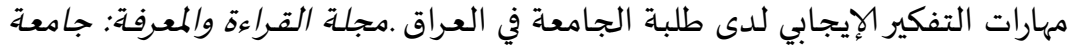
عين شمس - كلية التربية - الجمعية المصرية للقراءة والمعرفة، ع186، 21 - 50.

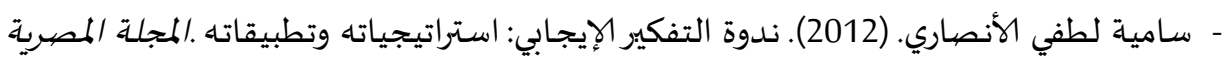

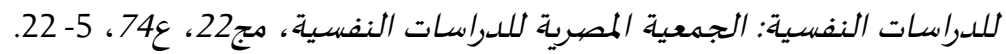

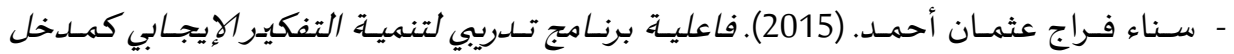

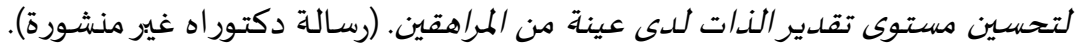
جامعة عين شمس، كلية البنات للآداب والعلوم والتربية.

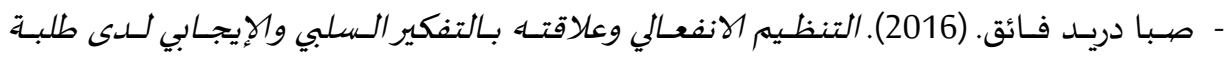

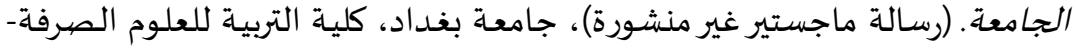

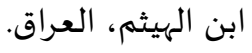

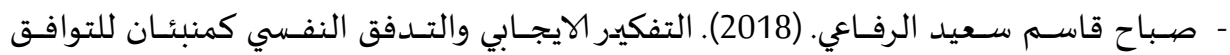

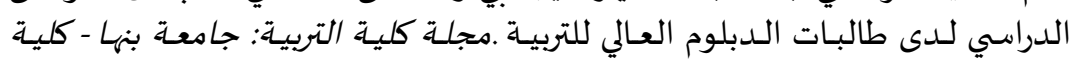

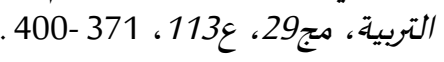

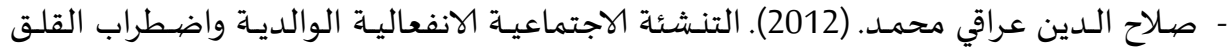
لدى الأطفال .مجلة كلية التربية: جامعة طنطا - كلية التربية، ع47، 243 -277.

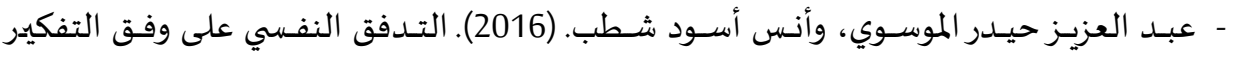

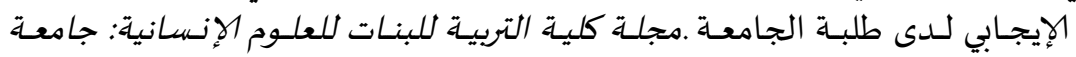

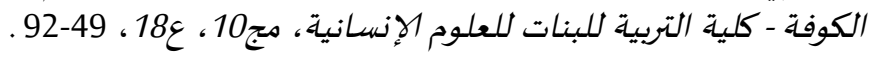

- عبد الناصر عبد الفتاح محمد محمود. (2013).أثر استراتيجية تعلم الأقران في تنمية التفكير التمبير

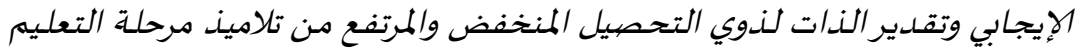

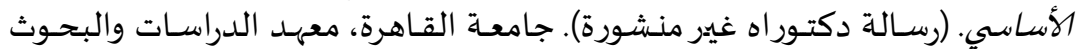
التربوية. 


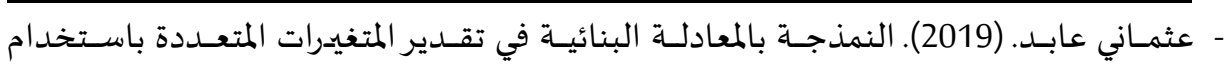

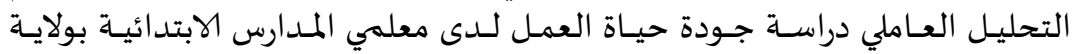
غليزان. رسالة دكتوراه

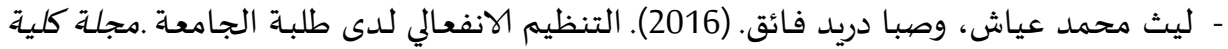

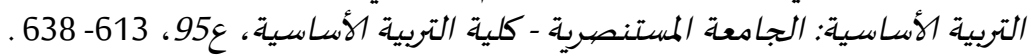

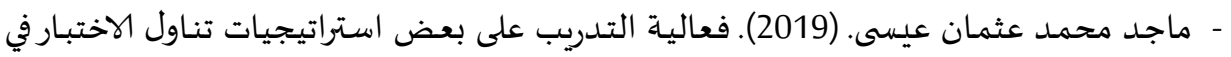

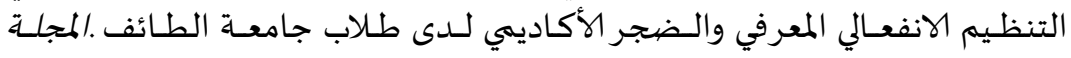

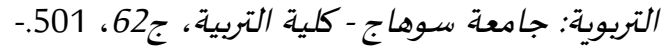

- ماجدة عبد السلام عبد المجيد، سلوى محمد عبد الباقي، وثريا يوسف لاشين. (2016). التدفق

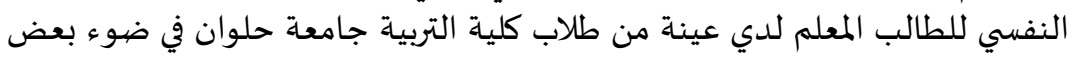

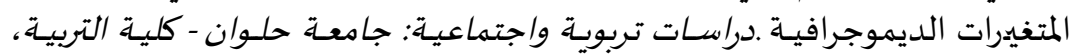

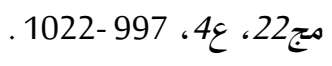

- محدب رزيقة. (2014). الذكاء الانفعالي وعلاقته بمستوى الطموح لدى الطالب الجامعي: دراسـة

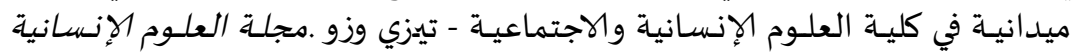

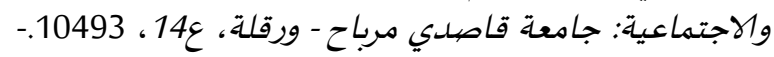

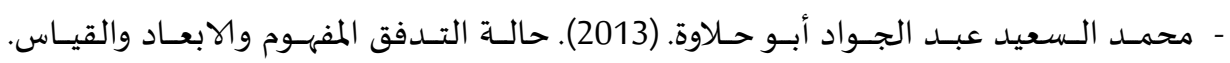
اصدارات شبكة العلوم النفسية العربية، ع عاد الوان. 29.

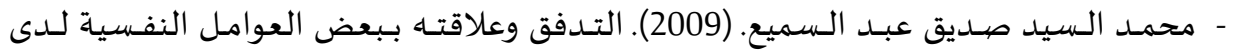

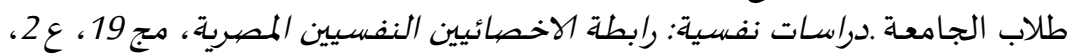

- محمد مصطفى عبد الرازق مصطفى. (2019). فعالية برنامج إرشادي معرفي قائم على اليقظة

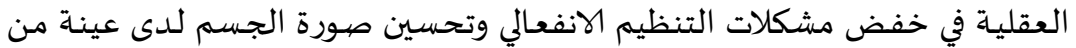
طلاب الجامعة المكفوفين .المجلة التربوية: جامعة سوهاج - كلية التربية، ج62، 363 .464 -

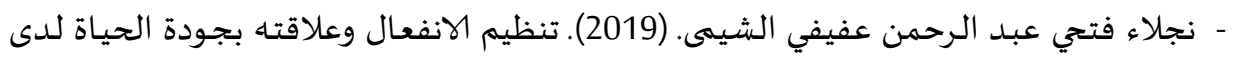

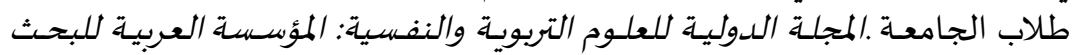

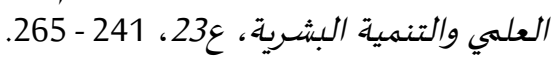

- هالة عبد الوهاب جـاد مصطفى، نبيل عيد رجب الزهـار، وزينب عبـد العليم بـدوي. (2018).

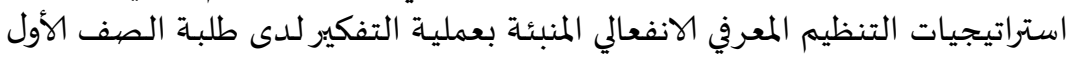

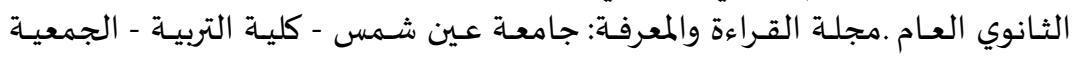
المصرية للقراءة والمعرفة، ع200، 191167.

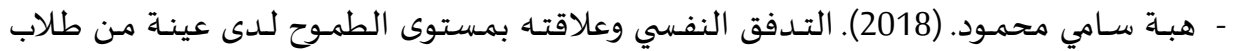
كلية التربية .مجلة كلية التربية في العلوم النفسية: جامعة عين شمس النفس - كلية التربية،

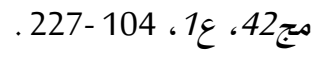




$$
\begin{aligned}
& \text { كلية الترعبة الأزقاهرة } \\
& \text { - ياسـر عبد الكـريم بكار. (2005). القـرارفي يديك، مركز الرايـة للتنميـة الفكريـة، دار البيروتي، } \\
& \text { دمشق، سوريا. }
\end{aligned}
$$

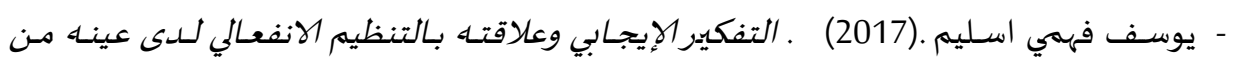

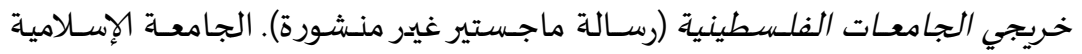

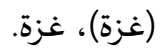

$$
\begin{aligned}
& \text { ثانيًا: المراجع العربية باللغة الأجنبية }
\end{aligned}
$$

- Abdel Nasser Abdel Fattah Mohamed Mahmoud (2013). The effect of peer learning strategy on developing positive thinking and selfesteem for those with low and high achievement levels of basic education stage students. (Unpublished $\mathrm{PhD}$ thesis). Cairo University, Institute of Educational Studies and Research.

- Abdul Aziz Haider Al-Mousawi, and Anas Aswad written off (2016). Psychological flow according to the positive thinking of university students. Journal of the College of Education for Girls for Human Sciences: University of Kufa - College of Education for Girls for Humanities, 10, (18), 49, 92.

- Ahlam Ali Abdul Sattar Jabr (2011). The effectiveness of a training program for positive thinking skills and its impact on the development of some psychological and mental characteristics of the child. (Unpublished $\mathrm{PhD}$ thesis). Cairo University, Institute of Educational Studies and Research.

- Amal Abdel Samea Baza Meliji. (2010). Psychological flow and its relationship to neurotic tendencies and perfectionism among male and female students of the College of Education. Research summary of the third scientific conference from April 13-14, Kafr El-Sheikh University, College of Education, 36-37.

- Amna Hikmat Ahmed Khasawneh. (2020). Emotional regulation and its relationship to positive thinking among Yarmouk University students. Journal of Al-Quds Open University for Research and Educational and Psychological Studies: Al-Quds Open University, 11, (30), 30. 46.

- Asma Muhammad Abdul Hamid Muhammad. (2009). The relationship of emotional intelligence to general intelligence, academic achievement, social skills, and personality traits. The Egyptian Journal of Psychological Studies: The Egyptian Society for Psychological Studies, 19, (63), 25-61.

- Asmaa Fathy Ahmed and Mervat Azmy Zaki Abdel-Gawad (2013). Positive thinking and affirmative behavior as predictors of psychological flow dimensions in a sample of high achieving students from undergraduates. The Egyptian Journal of Psychological Studies: The Egyptian Society for Psychological Studies, 22, (78), 57, 97. 
- Badiaa Habib Banhan. (2019). The effectiveness of coaching with meaning in developing psychological flow and creative thinking skills among high school students. Journal of Psychological Counseling: Ain Shams University - Center for Psychological Counseling, 59, 309, 378.

- Hala Abdel-Wahab Gad Mustafa, Nabil Eid Rajab Al-Zahhar, and Zainab Abdel-Alim Badawi (2018). Strategies for emotional cognitive organization that predict the thinking process for firstgrade general secondary students. Reading and Knowledge Journal: Ain Shams University - College of Education - Egyptian Society for Reading and Knowledge, 200, 167, 191.

- Hanan Hussein Mahmoud (2016). Emotional organization and metacognitive beliefs and their relationship to test anxiety among a sample of undergraduate students. Educational Sciences: Cairo University - Graduate School of Education, 24, (4), 69, 117.

- Hanan Hussein Mahmoud (2018). The effectiveness of a training program to develop some dimensions of positive thinking in improving life satisfaction among a sample of university students. Journal of the College of Education in Psychological Sciences: Ain Shams University - College of Education, 42, (1), 230, 298.

- Heba Sami Mahmoud (2018). Psychological flow and its relationship to the level of ambition among a sample of students of the College of Education. Journal of the College of Education in Psychological Sciences: Ain Shams University - College of Education, 42, (1), 104, 227.

- Ibn Al-Haytham, Iraq. Sabah Qasim Saeed Al-Rifai (2018). Positive thinking and psychological flow as predictors of academic compatibility among female students of the Higher Diploma in Education. Journal of the College of Education: Benha University - College of Education, 29, (113), 371, 400.

- Islam Muhammad Deeb Al-Zahrawi (2018). The predictive power of emotional regulation of the quality of life among students of government schools in Irbid Governorate (unpublished master's thesis). Yarmouk University, Irbid.

- Jaber Abdel Hamid Jaber, and Asma Badawi Adlan (2014). The effect of a training program based on positive thinking skills on developing problem-solving skills among middle school students with social learning difficulties. Educational Sciences: Cairo University - Graduate School of Education, 22, (3), 371, 402.

- Laith Muhammad Ayyash and Saba Duraid Faeq. (2016). Emotional regulation among university students. Journal of the College of Basic Education: Al-Mustansiriya University - College of Basic Education, 95, 613, 638. 
- Magda Abdel Salam Abdel Majid, Salwa Mohamed Abdel Baqi, and Thuraya Youssef Lashin (2016). Psychological flow of student teacher in a sample of students of the Faculty of Education, Helwan University in light of some demographic variables. Educational and social studies: Helwan University - Faculty of Education, 22, (4), 997, 1022.

- Majid Muhammad Othman Issa (2019). The effectiveness of training on some test-taking strategies in cognitive emotional regulation and academic boredom among Taif University students. The Educational Journal: Suhag University - College of Education, $62,1,50$.

- Muhammad Al-Saeed Abdul-Jawad Abu Halawa (2013). flow State; Concept, dimensions and measurement. Publications of the Arab Psychological Science Network.

- Muhammad al-Sayed Siddiq Abd al-Sami (2009). Flow and its relationship to some psychological factors among university students. Psychological studies: The Egyptian Psychologists Association, 19, (2), 313, 357.

- Muhammad Mustafa Abdel Razek Mustafa (2019). The effectiveness of a cognitive counseling program based on mental alertness in reducing the problems of emotional regulation and improving body image among a sample of blind university students. The Educational Journal: Suhag University - Faculty of Education, 62, 363, 464.

- Naglaa Fathy Abd Al-Rahman Afifi Al-Shimi (2019). Regulating emotion and its relationship to the quality of life of university students. International Journal of Educational and Psychological Sciences: The Arab Foundation for Scientific Research and Human Development, 23, 241, 265.

- Ottoman Abed (2019). Modeling by Structural Equation in Estimating Multiple Variables Using Factor Analysis A study of the quality of work life among primary school teachers in Relizane state. Ph.D.

- Rabia bin Sheikh (2015). The relationship of emotional balance to psychological flow: a field study on a sample of secondary education professors in the city of Ouargla (unpublished master's thesis). Qasidi Merbah University, and Ouargla. Faculty of Humanities and Social Sciences, Algeria.

- Rizeqa Mehdeb (2014). Emotional Intelligence and its Relation to the Level of Ambition of the University Student: A Field Study at the College of Humanities and Social Sciences - Tizi Ouzou. Journal of Human and Social Sciences: Qasidi Merbah University - Ouargla, 14, 93-104. 
- Ronak Hamid Othman (2017). A proposed strategy based on emotional intelligence skills to develop positive thinking skills among university students in Iraq. Journal of Reading and Knowledge: Ain Shams University - College of Education Egyptian Society for Reading and Knowledge, 186, 21, 50.

- Saba Duraid Faeq (2016). Emotional regulation and its relationship to negative and positive thinking among university students. (Unpublished Master Thesis), University of Baghdad, College of Education for Pure Sciences.

- Salahuddin Iraqi Muhammad (2012). Parental emotional socialization and childhood anxiety disorder. Journal of the Faculty of Education: Tanta University - Faculty of Education, 47, 243, 277.

- Samia Lotfi Al-Ansari. (2012). Positive Thinking Seminar: Strategies and Applications. The Egyptian Journal of Psychological Studies: The Egyptian Society for Psychological Studies, 22, (74), 5, 22.

- Sana Faraj Othman Ahmed (2015). The effectiveness of a training program to develop positive thinking as an input to improve the level of self-esteem of a sample of adolescents. (Unpublished $\mathrm{PhD}$ thesis). Ain Shams University, Girls' College of Arts, Sciences and Education.

- Tahani Attia Mahmoud Ahmed Al-Banna (2018). The effect of using the "SWOM" model in developing the skills of problem-solving and positive thinking among middle school students in the subject of social studies. The Educational Journal: Suhag University - Faculty of Education, 53, 489.543.

- Yasser Abdul Karim Bakkar (2005). The decision is in your hands, AlRaya Center for Intellectual Development, Dar Al-Beiruti, Damascus, Syria.

- Youssef Fahmy Aslim. (2017). Positive thinking and its relationship to emotional regulation of a sample of Palestinian university graduates (unpublished master's thesis). The Islamic University (Gaza), Gaza.

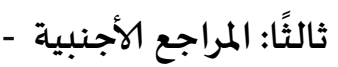

- Babkirk. S.. Rios. V.. \& Dennis. T. A. (2015). The late positive notential predicts emotion regulation strategv use in school $\square$ aged children concurrentlv and two years later. Developmental science, 18(5), 832-841.

- Brenning. K.. Soenens. B.. Van Petegem. S.. \& Vansteenkiste. M. (2015). Perceived maternal autonomv sunnort and earlv adolescent emotion regulation: A longitudinal study. Social Development, 24(3), 561-578. 
- Burnam. A.. Komarraiu. M.. Hamel. R.. \& Nadler. D. R. (2014). Do adaptive perfectionism and self-determined motivation reduce academic procrastination? Learning and Individual Differences, 36, 165-172.

- Carmeli. A.. Meitar. R.. \& Weisherg. J. (2006). Self-leadershin skills and innovative behavior at work. International journal of manpower, 27(1), 75-90.

- Cashwell. C. S.. Giordano. A. L.. King. K.. Lankford. C.. \& Henson. R. K. (2017). Emotion regulation and sex addiction among college students. International Journal of Mental Health and Addiction, 15(1), 16-27.

- Conolev. C. W.. \& Conolev. J. C. (2009). Positive nsvchologv and familv therapv: Creative techniaues and practical tools for guiding change and enhancing growth. John Wiley \& Sons.

- Csikszentmihalvi. M.. Abuhamdeh. S.. \& Nakamura. J. (2014). Flow. In Flow and the foundations of positive psychology (pp. 227238). Springer, Dordrecht.

- Dias, P. C.. \& Cadime. I. (2017). Protective factors and resilience in adolescents: The mediating role of self-regulation. Psicologia educativa, 23(1), 37-43.

- Edmeads. J. (2009). The power of negative thinking related with some factors. Journal Articles, (00178748).

- Falat, M. (2000). Creativitv as a nredictor of" good" coping? Studia Psychologica, 42(4), 317-324.

- Ghodsbin. F.. Safaei. M.. Jahanbin. I.. Ostovan. M. A.. \& Keshvarzi. S. (2015). The effect of nositive thinking training on the level of spiritual well-being among the patients with coronarv arterv diseases referred to Imam Reza specialtv and subspecialtv clinic in Shiraz. Iran: A randomized controlled clinical trial. ARYA atherosclerosis, 11(6), 341.

- Gordon. S. E.. Goatlev. C. H.. \& Bellwood. D. R. (2016). Combosition and temporal stabilitv of turf sediments on inner-shelf coral reefs. Marine pollution bulletin, 111(1-2), 178-183.

- Hong. Z. R.. \& Lin. H. S. (2012). Impacts of a book reading club intervention on enhancing parents' positive thinking. Journal of health psychology, 17(2), 273-284.

- Jackson. S. (2014). Flow scales. In A.C. Michalos (ed.). Encvclonedia of aualitv of life and well-being research. (vp. 2305-2308). New York: Springer Science, Business Media Dordrecht. 
- Kuo, J. R.. Fitzbatrick. S.. Metcalfe. R. K.. \& McMain. S. (2016). A multi-method laboratorv investigation of emotional reactivitv and emotion regulation abilities in borderline personalitv disorder. Journal of behavior therapy and experimental psychiatry, 50, 52-60.

- Kuzucu. Y. (2016). Do anger control and social problem-solving mediate relationshins between difficulties in emotion regulation and aggression in adolescents? Educational Sciences: Theory \& Practice, 16(3)، 849-866.

- Manju. H. K.. \& Basavaraianna. S. (2016). Role of emotion regulation in auality of life. The International Journal of Indian Psychology, 4(1), 18.

- Moran. A. (2012). Thinking in action: Some insights from cognitive sport psychology. Thinking Skills and Creativity, 7(2), 85-92.

- Mustafa. S. M. S.. Elias. H.. Noah. S. M.. \& Roslan. S. (2010). A nronosed model of motivational influences on academic achievement with flow as the mediator. Procedia-Social and Behavioral Sciences, 7, 2-9.

- Nikmanesh. Z.. Shirazi. M.. \& Farazinezhad. F. (2017). Examining the nredictive role of emotional self-regulation in aualitv of life and percention of suffering among patients with breast cancer. Middle East Journal of Cancer, 8(2), 93-101.

- Park, C. J.. \& Yoo. S. K. (2016). Meaning in life and its relationshins with intrinsic religiositv. deliberate rumination. and emotional regulation. Asian Journal of Social Psychology, 19(4), 325-335.

- Perkins. k.. \& Nakamura. J.. (2012). positive leisure sciences, springer science and business media dordect, 181-197.

- Rostami. M. (2014). Role of honestv-humilitv. emotionalitv. extraversion. agreeableness. conscientiousness and openness to exnerience nersonalitv dimensions. emotion regulation and stress coning strategies in predicting the aualitv of life in migraine peoples. Journal of Mazandaran University of Medical Sciences, 24(112), 67-76.

- Salovev. P.. Maver. J. D.. Caruso. D.. \& Yoo. S. H. (2009). The positive psychology of emotional intelligence.

- Scheier. M. F.. \& Carver. C. S. (2005). On the power of positive thinking: The benefits of being optimistic. Current directions in psychological science, 2(1), 26-30.

- Seligman. M. E. (2002). Positive psvchologv. positive prevention. and positive therapy. Handbook of positive psychology, 2(2002), 312.

- Shanmuga. K. p. (2013). cognitive emotion regulation of Teachers in Relation to their Gender and Experience. Journal of Research \& Method in Education, 1, (2),05-08. 

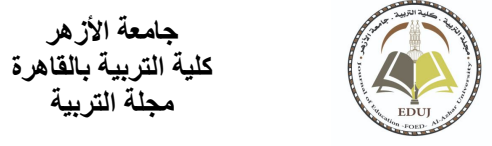

- Wilson. V. E.. \& Pener. E. (2004). The effects of unright and slumned postures on the recall of positive and negative thoughts. Applied psychophysiology and biofeedback, 29(3), 189-195.

- Wolters. C. A. (2011). Regulation of motivation: Contextual and social aspects. Teachers College Record, 113(2), 265-283.

- Wong. S. S. (2012). Negative thinking versus positive thinking in a Singaporean student sample: Relationships with psvchological well-being and nsvchological maladjustment. Learning and Individual Differences, 22(1), 76-82.

- Zapata. L. E. P. (2017). Personal self-regulation. learning approaches. resilience and test anxiety in psychology students. Estudios sobre educación, 32, 9-26. 